Portland State University

PDXScholar

\title{
Indoor Air Quality Impacts of a Woodstove Exchange Program in Washington County, Oregon
}

Matthew Forrest Survilo

Portland State University

Follow this and additional works at: https://pdxscholar.library.pdx.edu/open_access_etds

Part of the Environmental Sciences Commons, and the Mechanical Engineering Commons Let us know how access to this document benefits you.

\section{Recommended Citation}

Survilo, Matthew Forrest, "Indoor Air Quality Impacts of a Woodstove Exchange Program in Washington County, Oregon" (2020). Dissertations and Theses. Paper 5583.

https://doi.org/10.15760/etd.7455

This Thesis is brought to you for free and open access. It has been accepted for inclusion in Dissertations and Theses by an authorized administrator of PDXScholar. Please contact us if we can make this document more accessible: pdxscholar@pdx.edu. 
Indoor Air Quality Impacts of a Woodstove Exchange Program

in Washington County, Oregon

by

Matthew Forrest Survilo

A thesis submitted in partial fulfillment of the requirements for the degree of

\author{
Master of Science \\ in \\ Mechanical Engineering
}

Thesis Committee:

Elliott Gall, Chair

Alex Hunt

Mark Weislogel

Portland State University

2020 


\section{Abstract}

More than six million people in the United States use wood stoves as their primary heat source. Wood stoves emit air pollutants that may impact health, e.g., wood combustion products are associated with premature death and aggravation of pulmonary and cardiovascular conditions. There are few studies investigating the efficacy of wood stove exchange programs (WSEPs) as a method to improve indoor air quality (IAQ). In partnership with Washington County Department of Health and Human Services we conducted an air quality study to measure the impact of a WSEP on indoor and neighborhood levels of wood combustion products. Twenty households engaged in the air quality study, consisting of monitoring pre and post stove change-out where a newer, more efficient burning stove or gas insert was installed. Monitors deployed included lowcost particle counters to measure indoor and outdoor particle levels, a blower-door test to measure residence airtightness, and stove use monitoring. In five additional households we did more intensive monitoring which added deployment of a weather station and research grade monitors for carbon monoxide, black carbon, size resolved particles from $10 \mathrm{~nm}-10 \mu \mathrm{m}$, and in select homes, $\mathrm{NO}$ and $\mathrm{NO}_{2}$.

Median levels of $\mathrm{PM}_{2.5}$ measured by PurpleAir sensors, pre and post-exchange were similar in magnitude when comparing across all homes, increasing indoors by $0.6 \mathrm{ug} / \mathrm{m}^{3}$ and decreasing outdoors by $0.2 \mathrm{ug} / \mathrm{m}^{3}$. Comparing air quality levels only during periods of woodstove use led to more marked differences when comparing pre and post-exchange impacts, with 12 of 17 homes exhibiting a median indoor $\mathrm{PM}_{2.5}$ reduction of $0.8 \mathrm{ug} / \mathrm{m}^{3}$. 
Additionally, 13 of 17 houses with data available showed large transient peaks of $\mathrm{PM}_{2.5}$ when first operating the new woodstove. This data was analyzed to find a $\mathrm{PM}_{2.5}$ stove emission source strength for four homes. The four homes had an average stove source strength of $14,130 \mathrm{ug} / \mathrm{h}$. 


\section{Acknowledgements}

I would like to extend deep gratitude to my thesis advisor Dr. Elliott Gall. From the moment I stepped into his office to discuss working with him, he has been both a source of guidance and friendly face. In addition to his mentorship surrounding this body of work, he has supported me in numerous side projects. Dr. Gall believed in me when I told him I could figure things out, and that allotted me a great deal of freedom to learn and feel supported. He was a wonderful boss, both holding me to a high standard and by being my advocate.

Additionally, I would like to thank my colleagues in my lab, Pradeep Ramasubramanian, Aurelie Laguerre and Everett Stiley for both their direct support on this project and their good-natured guidance throughout my time at Portland State. I would also like to thank my two thesis advisors Mark Weislogel and Alex Hunt. They have both been excellent teachers and I am thankful to have them review this body of work.

Lastly, I am deeply grateful for my mom, Francine. Her belief in my abilities has been a source of great comfort and confidence, and I would not be as where I am today if she had not been so such a thoughtful and resilient mother. 
Table of Contents

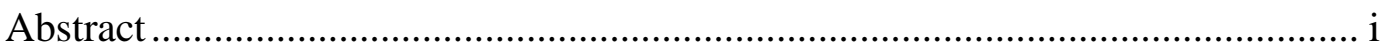

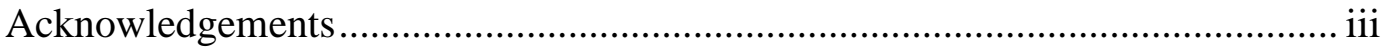

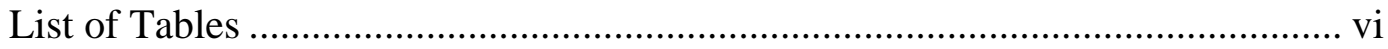

List of Figures ........................................................................................ vii

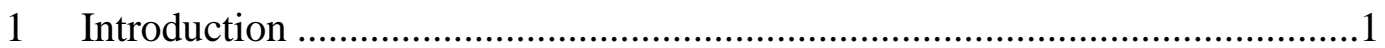

1.1 Review of Current Literature ..........................................................2

1.2 Washington County Wood Stove Exchange Program .............................5

1.3 WSE Program Indoor Air Quality Study ...........................................

1.4 Source Strength Identification..........................................................

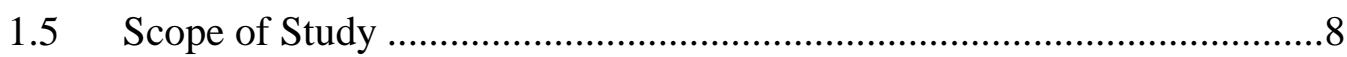

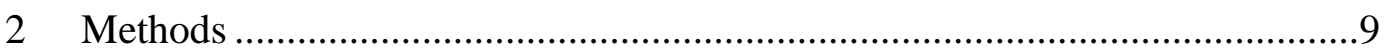

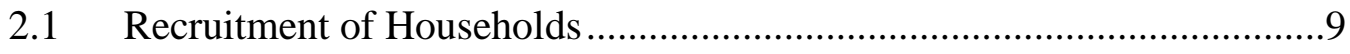

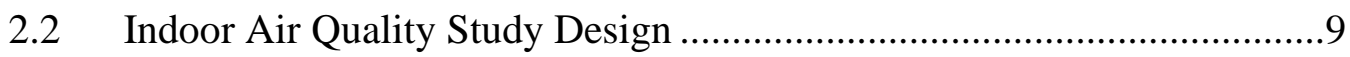

2.3 Description of Quality Assurance/Quality Control...............................13

2.3.1 PurpleAir Monitors ...................................................................13

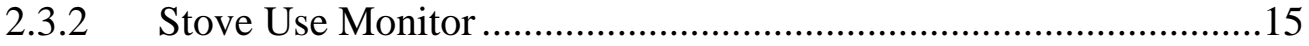

2.3.3 Carbon Monoxide Monitor ...............................................................15

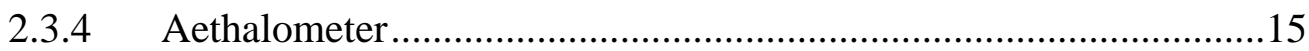

2.4 Data Analysis: Blower Door Test ....................................................16

2.5 Data Analysis: Estimation of WSE Impacts on Indoor and Outdoor Pollution 18

2.6 Source Strength Analysis ..............................................................20

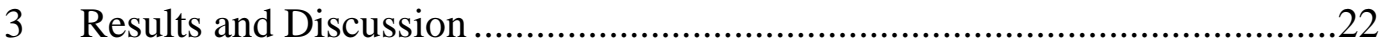

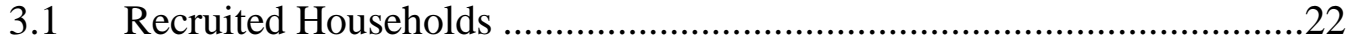

3.2 Results of PurpleAir Sensor Quality Assurance Efforts ......................25

3.3 Household airtightness monitoring .................................................29

3.4 Air Monitoring Results: Household Temperatures ...............................32

3.5 Air Monitoring Results: Example Time-series Data (Basic Monitoring)34

3.6 Air Monitoring Results: Comparison of $\mathrm{PM}_{2.5}$ Pre- and Post exchange .36

3.7 Air Monitoring Results: Influence of Stove Operation on Air Pollution Levels 43 


\subsection{Air Monitoring Results: Example Time-series Data (Enhanced Monitoring) 46}

3.9 Bulk Statistical Analysis ..................................................................50

3.10 Emission Event Source Strength Analysis …………………………......52

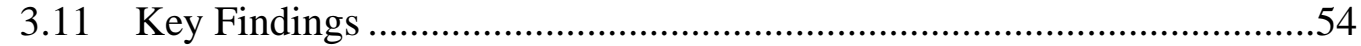

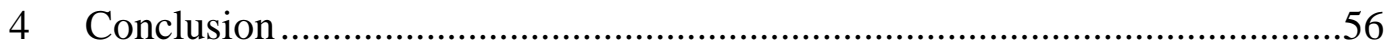

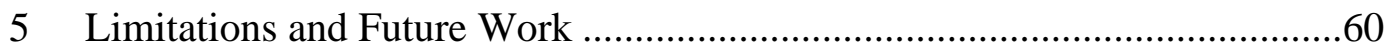

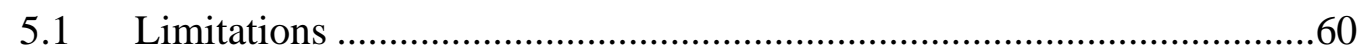

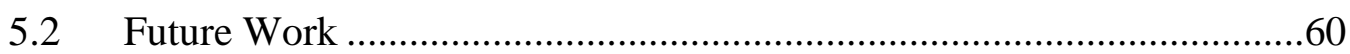

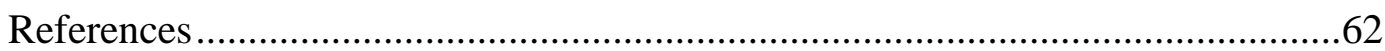

Appendix A: Quality assurance and quality control, supplemental information...66

Appendix B: Time series data for each household. .77 


\section{List of Tables}

Table 1. Summary of extant literature on indoor and neighborhood air quality impacts of wood stove exchange programs. ..............................................

Table 2. List of sensors used in "basic" monitoring. ............................................10

Table 3. List of sensors used in "enhanced" monitoring. ...................................12

Table 4. Characteristics of study homes and sampling periods............................24

Table 5. Summary of calibration results of co-located PurpleAirs with

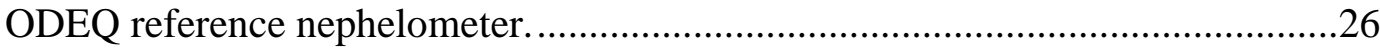

Table 6. Summary of indoor co-location of six PurpleAir sensors........................28

Table 7. Household airtightness metrics, flow coefficient, $\mathrm{C}$, and pressure exponent $n$.

Table 8. Magnitudes of measured indoor and outdoor temperatures pre and post exchange.

Table 9. Magnitudes of measured indoor and outdoor $\mathrm{PM}_{2.5}$ pre- and post-exchange.

Table 10.Magnitudes of indoor minus outdoor levels pre and post exchange.......41

Table 11.Median outdoor and indoor $\mathrm{PM}_{2.5}$ pre and post exchange

during periods of woodstove operation

Table 12.Magnitudes of measured indoor and outdoor carbon monoxide levels pre and post-exchange.

Table 13. Magnitudes of measured indoor and outdoor black carbon (BC)

levels pre and post-exchange.

Table 14. Magnitudes of measured indoor and outdoor brown carbon (BrC, given by UVPM as described in the methods) levels pre and post-exchange.

Table 15. Fit parameters derived from fitting equation 6 to experimental data. ...54 


\section{List of Figures}

Figure 1. Example of one PurpleAir PA-II co-location with Oregon DEQ calibrated.

Figure 2. Summary of ACH50 and Effective Leakage Area calculations across homes involved in the indoor air quality study of the Washington County Woodstove Exchange Program.

Figure 3. Example time-series data from wood stove exchange household

B-10.

Figure 4. Boxplots showing variability in measured indoor and outdoor

$\mathrm{PM}_{2.5}$ levels at each household.

Figure 5. Regional $\mathrm{PM}_{2.5}$ levels as measured ODEQ at the Hillsboro Hare

Field site for 10/19-6/19.

Figure 6. Regression of normalized leakage area vs. change in indoor-outdoor $\mathrm{PM}_{2.5}\left(\Delta \mathrm{PM}_{2.5}\right)$ level (post exchange minus pre exchange).

Figure 7. Example of time-series measurements for enhanced monitoring household, E-32.

Figure 8. Statistical analysis of $\mathrm{PM}_{2.5}$ medians before and after exchange ............51

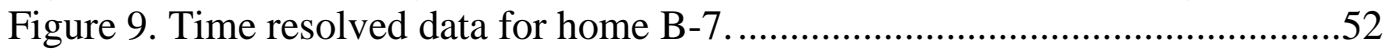

Figure 10. Non-linear curve fit for home B-7 .............................................53 


\section{Introduction}

A substantial fraction of homes in the U.S. use wood as a heating fuel source: 11.6 million homes used wood as either their primary or secondary fuel source as of $2015^{1}$.Wood stoves used to heat homes are often old and inefficient ${ }^{2}$, and generate particulate matter (PM) and other products of incomplete combustion that leads to degraded air quality and increases potential for noncompliance with outdoor air quality standards. Furthermore, there exists evidence that shows indoor levels of particulate matter emitted from inefficient cook stoves may also be elevated and can adversely affect human health ${ }^{3}$.

Human exposure to PM air pollution is associated with increased risk of various adverse health outcomes, including cardiovascular disease and overall mortality ${ }^{4-7}$.Timeactivity surveys reveal that we spend the vast majority of our time indoors ${ }^{8}$, and as a result, most human exposure to PM occurs indoors ${ }^{9}$. Emissions of air pollutants from woodstoves may contribute to elevated human exposure via two pathways. First, if the woodstove is improperly vented, an indoor woodstove may act as a source of PM directly to the indoor space. Second, regions with a high number of inefficient household woodstoves may experience elevated outdoor air pollution from combustion products exhausted from woodstoves. Since all buildings require ventilation of indoor air with outdoor air, degraded outdoor air quality from woodstoves may adversely impact outdoor air. In fact, the EPA estimates that wood stoves, hydronic heaters, and fireplaces emit approximately 350,000 tons of $\mathrm{PM}_{2.5}$ (that is, $\mathrm{PM}<2.5 \mu \mathrm{m}$ ) into U.S. airsheds each year ${ }^{10}$ 


\subsection{Review of Current Literature}

There exists a substantial body of literature concerning the impact of woodstoves on indoor air quality. From this literature and the associated health studies, and it is known that products of biomass combustion may impact human health ${ }^{11}$. However, much of this literature is focused on the developing world where indoor combustion of biomass is a primary fuel source for cooking and heating. The literature on indoor and neighborhood air quality impacts of woodstove use in the developed world is more limited. Prior studies that have investigated the impact of woodstove exchange programs on indoor particle levels generally come to mixed conclusions; these studies are summarized in Table 1. 
Table 1. Summary of extant literature on indoor and neighborhood air quality impacts of wood stove exchange programs.

\begin{tabular}{|c|c|c|c|c|}
\hline Study & $\begin{array}{l}\text { Loca } \\
\text { tion }\end{array}$ & Size & Constituents measured & Effect \\
\hline $\begin{array}{l}\text { T. Ward and } \\
\text { Noonan 2008) }\end{array}$ & Libby, MT & 16 homes & $\begin{array}{l}\text { Indoor/outdoor } \mathrm{PM}_{2.5} \text {, Levoglucosan, } \\
\text { Elemental carbon, DHA } \\
\text { (dehydroabietic acid) }\end{array}$ & $\begin{array}{l}71 \% \text { reduction in average } \mathrm{PM}_{2.5} \text { levels, } \\
45 \% \text { reduction in levoglucosan, } 6 \% \\
\text { reduction in } \mathrm{BC} .45 \% 133 \% \text { increase in } \\
\text { DHA }\end{array}$ \\
\hline $\begin{array}{l}\text { Tony Ward et } \\
\text { al. 2011) }\end{array}$ & $\begin{array}{l}\text { Nez Perce } \\
\text { Reservation, } \\
\text { ID }\end{array}$ & 16 homes & $\begin{array}{l}\text { Indoor } \mathrm{PM}_{2.5} \text {, Organic and Elemental } \\
\text { carbon, Levoglucosan, DHA, } \\
\text { additional chemical markers of wood } \\
\text { smoke. }\end{array}$ & $\begin{array}{l}36 \% \text { reduction in average } \mathrm{PM}_{2.5} \text { levels, } \\
21 \% \text { reduction in organic carbon, } 63 \% \\
\text { reduction in levoglucosan. }\end{array}$ \\
\hline $\begin{array}{l}\text { C. W. Noonan } \\
\text { et al. } 2012\end{array}$ & Libby, MT & 21 homes & $\begin{array}{l}\mathrm{PM}_{2.5} \text {, Organic and Elemental } \\
\text { carbon, levoglucosan, DHA, abietic } \\
\text { acid }\end{array}$ & $\begin{array}{l}41 \% \text { reduction in indoor } \mathrm{PM}_{2.5} .39 \% \text { and } \\
41 \% \text { reduction in organic and elemental } \\
\text { carbon, respectively. } 81 \% \text { DHA and } 219 \% \\
\text { abietic acid increase. }\end{array}$ \\
\hline $\begin{array}{l}\text { Curtis W. } \\
\text { Noonan et al. } \\
2012\end{array}$ & Libby, MT & 1200 stoves & $\begin{array}{l}\text { Ambient PM } 2.5 \text { and children's } \\
\text { respiratory outcomes via survey to } \\
\text { parents }\end{array}$ & $\begin{array}{l}27 \% \text { reduction in ambient winter } \mathrm{PM}_{2.5}, \\
27 \% \text { reduction in reported odds of } \\
\text { wheezing, reductions in chances of: } \\
\text { common cold: } 25.4 \% \text {, bronchitis: } 54.6 \% \text {, } \\
\text { influenza: } 52.3 \% \text {, throat infection: } 45 \% \text {. }\end{array}$ \\
\hline $\begin{array}{l}\text { T. J. Ward et } \\
\text { al. } 2009\end{array}$ & Libby, MT & 1200 stoves & $\begin{array}{l}\text { Outdoor sampling only of PAHs and } \\
\mathrm{PM}_{2.5}\end{array}$ & $\begin{array}{l}64 \% \text { reduction in phenolics and } \\
\text { polycyclic aromatic hydrocarbons, } 20 \% \\
\text { reduction in } \mathrm{PM}_{2.5} \text { mass. }\end{array}$ \\
\hline $\begin{array}{l}\text { T. J. Ward, } \\
\text { Palmer, and } \\
\text { Noonan } 2010 \\
\end{array}$ & Libby, MT & 1200 stoves & $\begin{array}{l}\text { Ambient } \mathrm{PM}_{2.5} \text {, Organic and } \\
\text { Elemental carbon }\end{array}$ & $\begin{array}{l}20 \% \text { reduction in average outdoor winter } \\
\mathrm{PM}_{2.5} \text { levels. } 28 \% \text { reduction in } \\
\text { woodsmoke-related } \mathrm{PM}_{2.5}\end{array}$ \\
\hline $\begin{array}{l}\text { Bergauff et al. } \\
2009\end{array}$ & Libby, MT & 1200 stoves & $\begin{array}{l}\text { Ambient } \mathrm{PM}_{2.5} \text { and } 7 \text { chemical } \\
\text { tracers of woodsmoke }\end{array}$ & $\begin{array}{l}20 \% \text { reduction in ambient } \mathrm{PM}_{2.5}, 50 \% \\
\text { reduction in levoglucosan. Increase in } \\
\text { resin acids. }\end{array}$ \\
\hline $\begin{array}{l}\text { T. J. Ward et } \\
\text { al. } 2011\end{array}$ & Libby, MT & 1200 stoves & $\begin{array}{l}\text { Ambient total, Organic, and } \\
\text { Elemental carbon }\end{array}$ & $\begin{array}{l}26 \% \text { reduction in total carbon, no effect } \\
\text { in elemental carbon, organic carbon } \\
\text { reduction consistent with } \mathrm{PM}_{2.5} .\end{array}$ \\
\hline
\end{tabular}


Table 1. Continued.

\begin{tabular}{|l|l|l|l|l|}
\hline $\begin{array}{l}\text { Allen et al. } \\
2009\end{array}$ & $\begin{array}{l}\text { Telkwa, } \\
\text { BC, } \\
\text { Canada }\end{array}$ & 15 homes & $\begin{array}{l}\text { 6-day sampling pre and post } \\
\text { exchange of stove; } \mathrm{PM}_{2.5}, \\
\text { Levoglucosan }\end{array}$ & $\begin{array}{l}\text { No effect observed for } \mathrm{PM}_{2.5} \text { or } \\
\text { levoglucosan }\end{array}$ \\
\hline $\begin{array}{l}\text { T. J. Ward } \\
\text { et al. } 2017\end{array}$ & $\begin{array}{l}\text { Missoula, } \\
\text { MT }\end{array}$ & 16 homes & $\begin{array}{l}\text { Indoor } \mathrm{PM}_{2.5} \text { and carbon } \\
\text { monoxide }\end{array}$ & $\begin{array}{l}\text { No effect PM } \\
\text { count basis }\end{array}$ \\
\hline $\begin{array}{l}\text { T. J. Ward } \\
\text { et al. } 2013\end{array}$ & Libby, & $\begin{array}{l}1200 \text { stoves } \\
\text { exchanged, }\end{array}$ & $\begin{array}{l}\mathrm{PM}_{2.5} \text { and levoglucosan within } \\
\text { school }\end{array}$ & $\begin{array}{l}\text { Overall reduction in ambient } \\
\text { PM } \\
\text { within but no significant change } \\
\text { sample period. }\end{array}$ \\
\hline
\end{tabular}


A major outcome of the existing literature on the subject of indoor air pollution and woodstove exchange programs is that controlled study of woodstoves in actual field environments is challenging, due to the presence of myriad confounders ranging from human behavior to fluctuations in outdoor levels of particles. There is general consensus, however, that outdoor air quality can be meaningfully improved by community-level interventions like woodstove exchange programs ${ }^{23}$. Wheeler et al., in a study ${ }^{24}$ of 31 homes in Canada using wood fuel as a heat source, report that both indoor and outdoor fine particles were elevated when woodstoves were in use. Similarly, Semmens et al. report indoor PM in 96 homes in the Northwestern US and Alaska, concluding that high indoor PM levels are attributed, in part, to biomass combustion. ${ }^{3}$ A study in the Northern Rocky Mountains showed $\mathrm{PM}_{2.5}$ reductions of $\sim 75 \%$ in 16 homes where old stoves were replaced with EPA certified stoves ${ }^{18}$. Conversely, several recent studies have shown that woodstove interventions have no or limited impact on indoor PM levels ${ }^{22,25}$. In general, prior studies acknowledge important limitations with field studies attempting indoor air monitoring that generally include small sample sizes and short sampling durations, in some cases only 24 -hour period were monitored. Human behavior and building type are also acknowledged as potential confounders.

\subsection{Washington County Wood Stove Exchange Program}

Washington County routinely ranks as one of the healthiest counties in Oregon, however, those rankings often mask concerning disparities. In particular, Washington County has some of the worst winter-time air quality in the state. A major source of 
winter-time air pollution in Washington County is older and uncertified wood stoves. Nearly a third of households throughout the county have older wood stoves that produce an excessive amount of residential wood smoke, which negatively affects air quality, the local environment and residents' health. In 2014, Oregon Department of Environmental Quality (DEQ) shared data from an air quality monitor within the city of Hillsboro that revealed levels of $\mathrm{PM}_{2.5}$ that exceeded the federal health-based standards for two years of a three-year period, putting Washington County at risk for violating the federal Clean Air Act.

To help address winter-time air pollution in the county and prevent the county from going into non-attainment with the Clean Air Act, Washington County Department of Health and Human Services and the Office of Community Development partnered to develop the Washington County Wood Stove Exchange program (WSE) that provides grants (full cost) and rebates (between $\$ 1,500-\$ 3,500$ ) to households that change to a cleaner heating source. Woodstoves are operated by homeowners themselves and are thus not subject to the same regulations as other sources of air pollution. Thus, it is critical that communities be engaged and are active participants to enable a successful woodstove exchange program ${ }^{2}$.

Since the launch of the WSE program on August 24, 2016, the program has received 649 applications and completed 390 stove exchanges. Of these 390 exchanges, 250 were grant-based and 140 were rebate-based. The average payout was nearly $\$ 4,000$ and the program leveraged more than $\$ 78,000$ in utilizing other incentives and tax credits. The WSE estimates that over 28.86 tons of particulate matter pollution were prevented and 
over 164 tons of other air pollutants (carbon monoxide, volatile organic compounds, and other hazardous air pollutants) were prevented. The WSE has a goal of replacing 700 old and uncertified woodstoves, and continuing to sustain the program through public and private partnerships.

\subsection{WSE Program Indoor Air Quality Study}

This study investigates the impact of a woodstove exchange program on indoor and outdoor air quality at homes in Washington County, Oregon. The study was designed with a tiered approach, where households were recruited to opt-in to engage in "basic" or "enhanced" air pollution monitoring. As will be discussed in detail subsequently, basic monitoring consisted of measurement of particulate matter with calibrated, low-cost light-scattering particle counters along with measurement of building airtightness and stove temperature. A subset of houses in the basic monitoring campaign included measurement of indoor-outdoor carbon dioxide levels. The enhanced monitoring program complemented these measurements with the deployment of additional air pollution monitoring equipment, specifically a reference-grade carbon monoxide monitor and seven-wavelength aethalometer. These advanced instruments enable measurement of additional indicators of biomass combustion, and will be used to inform understanding of the potential for a woodstove exchange program to impact a variety of metrics of indoor and neighborhood air quality.

\subsection{Source Strength Identification}

In 13 of 17 homes, with data available, we observed large transient $\mathrm{PM}_{2.5}$ peaks associated with the first burn of the new stove. This data provided an opportunity to 
investigate particle source and sink mechanisms by applying mass-balance principles to a substantial elevation and subsequent decay of indoor $\mathrm{PM}_{2.5}$.

\subsection{Scope of Study}

This study aimed to answer four main questions:

Does the exchange of a woodstove for a more efficient form of heating impact indoor levels of air pollution?

Does the exchange of a woodstove for a more efficient form of heating impact household outdoor levels of air pollution?

Are periods of woodstove operation associated with elevated indoor or household outdoor levels of air pollution?

Are building weatherization (i.e. airtightness) metrics associated with indoor or household outdoor air pollution levels? 


\section{Methods}

\subsection{Recruitment of Households}

Two requirements were necessary for inclusion of this study, firstly the household must have an existing woodstove or fireplace, and secondly it was required that the new heating source either be a new woodstove or a ductless heat pump. Households were offered the opportunity to engage with the indoor air quality study during their discussion with a representative of the Washington County Office of Community Development regarding the Woodstove Exchange Program. Participants engaging in the indoor air quality monitoring portion of the study were offered a financial incentive to compensate for their electricity usage, and time. The protocol was reviewed and approved by the Institutional Review Board of Portland State University under protocol \#184684.

\subsection{Indoor Air Quality Study Design}

Households agreeing to participate in the indoor air quality monitoring component of the WSE program were contacted 4 weeks prior to the stove exchange date to coordinate the installation of air and stove monitoring devices and to schedule the blower door test. During this installation, the homeowner was present and was asked to complete a questionnaire detailing their behaviors, perceptions, and household descriptors.

Homeowners signed up for either "basic" or "enhanced" air quality monitoring. The details of these two options are explained below. During the actual woodstove exchange, where a certified contractor removed the old woodstove and installed a more efficient system (generally, but not always an EPA-certified woodstove), the stove use monitor was removed and placed on to a surface of the new heating device that would 
provide a heat signature indicative of operation. Air monitoring continued with a goal of creating pre and post monitoring datasets of approximately equal duration.

A table of deployed monitoring devices into homes participating in "basic" monitoring is shown in Table 2. Basic monitoring employed unobtrusive, low-cost sensors to enable monitoring for months with minimal disruption to the homeowner.

Table 2. List of sensors used in "basic" monitoring.

\begin{tabular}{ccccc} 
Constituent & Method & Device & $\begin{array}{c}\text { Time- } \\
\text { resolution }\end{array}$ & Deployment \\
\hline PM 2.5, PM10 & $\begin{array}{c}\text { Low cost, } \\
\text { light- } \\
\text { scattering } \\
\text { sensor }\end{array}$ & $\begin{array}{c}\text { PurpleAir } \\
\text { PA-II SD }\end{array}$ & $\begin{array}{c}\text { Real-time, }<5 \\
\text { min }\end{array}$ & $\begin{array}{c}\text { Entire monitoring } \\
\text { period }\end{array}$ \\
\hline $\begin{array}{c}\text { Stove } \\
\text { operation }\end{array}$ & $\begin{array}{c}\text { Temperature } \\
\text { sensor/logger }\end{array}$ & $\begin{array}{c}\text { Geocene } \\
\text { Dot }\end{array}$ & $\begin{array}{c}\text { Real-time, }<5 \\
\text { min }\end{array}$ & $\begin{array}{c}\text { Entire monitoring } \\
\text { period }\end{array}$ \\
\hline $\begin{array}{c}\text { Building } \\
\text { airtightness }\end{array}$ & $\begin{array}{c}\text { Whole-house } \\
\text { blower door } \\
\text { test }\end{array}$ & $\begin{array}{c}\text { Minneapolis } \\
\text { Blower } \\
\text { Door }\end{array}$ & $\begin{array}{c}\text { Once per } \\
\text { home }\end{array}$ & Once per home \\
\hline $\begin{array}{c}\text { Carbon } \\
\text { dioxide }\end{array}$ & $\begin{array}{c}\text { Non- } \\
\text { dispersive } \\
\text { infrared sensor }\end{array}$ & $\begin{array}{c}\text { Onset } \\
\text { MX1102 }\end{array}$ & 5 min & $\begin{array}{c}\text { Entire monitoring } \\
\text { period }\end{array}$ \\
\hline
\end{tabular}

All instruments selected for basic monitoring are routinely used in building assessment and building science measurements. The PurpleAir PA-II is a widely used low-cost monitoring tool that has been shown to perform robustly in tracking changes in particle counts in the $0.3-10$ micrometer range. The PurpleAir PA-II has been shown to be responsive to particle counts from a range of sources and generally within a factor of two compared to reference or research grade instrumentation ${ }^{26,27}$. As will be discussed, we calibrated the PurpleAir PA-IIs prior to deployment by co-locating the devices with nephelometers maintained and calibrated to a gravimetric standard by the Oregon 
Department of Environment Quality. We also co-located the PurpleAir PA-IIs with an indoor gravimetric sample to assess the general sensor response and appropriateness of an outdoor calibration factor for the measurement of indoor aerosol.

The Geocene Dot is an evolution of the Berkeley Air Monitoring Group Stove Use Monitoring System ${ }^{28}$, and includes a temperature sensor and logger that enables high time resolution and long-term surface temperature monitoring. Data from the temperature sensor provides an indication of the use of the heating device. Data was filtered to only include data when the stoves were active. Filtering was accomplished by analyzing stove temperature signatures and choosing threshold temperatures above which stove use was apparent.

The Minneapolis Blower Door Test was used to conduct a multi-point blower door test that enabled estimation of pressure-flow relationships for each household at elevated indoor-outdoor pressure difference as well as back-calculation of estimate leakage area following established protocols ${ }^{29}$.

A table of monitoring devices deployed into homes participating in "enhanced" monitoring is shown in Table 3. Note that the monitors described in Table 3 were deployed in addition to the monitoring conducted in the basic monitoring described above and listed in Table 2. 
Table 3. List of sensors used in "enhanced" monitoring.

\begin{tabular}{lllll} 
Constituent & \multicolumn{1}{c}{ Method } & \multicolumn{1}{c}{ Device } & \multicolumn{1}{c}{ Time-resolution } & \multicolumn{1}{c}{ Deployment } \\
\hline Black carbon & $\begin{array}{l}\text { 5-wavelength } \\
\text { aethalometer }\end{array}$ & $\begin{array}{l}\text { Magee } \\
\text { Aethalometer }\end{array}$ & $\begin{array}{l}\text { Real-time, 5 } \\
\text { minute resolution } \\
\text { due to switching } \\
\text { valve }\end{array}$ & $\begin{array}{l}\text { 3 days pre } \\
\text { exchange, 3 days } \\
\text { post }\end{array}$ \\
\hline $\begin{array}{l}\text { Brown carbon } \\
\text { (UVPM) }\end{array}$ & $\begin{array}{l}\text { 5-wavelength } \\
\text { aethalometer }\end{array}$ & $\begin{array}{l}\text { Magee } \\
\text { Aethalometer }\end{array}$ & $\begin{array}{l}\text { Real-time, } 5 \\
\text { minute resolution } \\
\text { due to switching } \\
\text { valve }\end{array}$ & $\begin{array}{l}\text { 3 days pre } \\
\text { exchange, 3 days } \\
\text { post }\end{array}$ \\
\hline $\begin{array}{l}\text { Carbon } \\
\text { monoxide }\end{array}$ & $\begin{array}{l}\text { Non-dispersive } \\
\text { infrared with } \\
\text { filter correlation }\end{array}$ & $\begin{array}{l}\text { Ecotech } \\
\text { Serinus 30 } \\
\text { CO monitor }\end{array}$ & $\begin{array}{l}\text { Real-time, 5 } \\
\text { minute resolution } \\
\text { due to switching } \\
\text { valve }\end{array}$ & $\begin{array}{l}\text { 3 days pre } \\
\text { post }\end{array}$ \\
\hline
\end{tabular}

The monitors listed in Table 3 provide additional measurements of air pollutants that inform our understanding of the potential for various byproducts of wood combustion to enter the indoor and surrounding outdoor environment as a result of woodstove operation. The measurement devices deployed for enhanced monitoring are substantially more expensive than those listed in Table 3, and thus could not be purchased with sufficient replication to enable months-long monitoring or simultaneous monitoring across multiple sites. Thus, we opted to target a four-day period prior to woodstove exchange and a three-day period post woodstove exchange where "enhanced" instrumentation could be deployed. These instruments were "active", meaning they required sampling pumps to introduce air into the instrument; the instruments created noise due to their operation that may not have been acceptable to all homeowners. Homeowners were fully briefed on the instrumentation in accordance with the approved IRB protocol. Further, because only one set of instruments was available, we installed a switching valve system that alternated sampling between the indoor and outdoor environment to enable measurement in two locations using one set of instrumentation. 
The Magee Aethelometer is a seven-wavelength light attenuation monitor that enables measurement of the light attenuation of a collected mass of aerosol which deposits on a movable filter tape inside the instrument at a flowrate of 5 liters per minute. Analysis of the aerosol particles is conducting by measuring the transmission of light through the portion of the filter tape containing the sample versus the transmission through the portion acting as a reference area. The Magee Aethalometer has been widely used in studies assessing fossil and biomass combustion, and includes on-board algorithms for estimating black carbon levels as well as the contribution biomass combustion to aerosol mass ${ }^{30-32}$. We report black carbon from the light attenuation at 880 $\mathrm{nm}$ and a proxy for brown carbon by the attenuation at $370 \mathrm{~nm}^{33}$.

The Ecotech Serinus 30 is a non-dispersive infrared carbon monoxide monitor with gas filter correction that provides reference-grade measurement of carbon monoxide to a lower detection limit of $40 \mathrm{ppb}$ across a range of $0-200 \mathrm{ppm}$. It is thus suitable for measurement of carbon monoxide as a tracer; note that we do not expect levels of indoor carbon monoxide due to the presence of a vented woodstove that would constitute an acute health threat.

\subsection{Description of Quality Assurance/Quality Control}

\subsubsection{PurpleAir Monitors}

Low-cost particle monitors (PurpleAir PA-II) were co-located with Oregon Department of Environment Quality (ODEQ) Hillsboro Hare Field monitoring site for a period of two weeks from 9/27/2918 to 10/8/2018 where a light-scattering nephelometer operated by ODEQ recorded time-series $\mathrm{PM}_{2.5}$. The nephelometer was previously 
calibrated using the Federal Reference Method combined with gravimetric measurements of $\mathrm{PM}_{2.5}$ collected over a period of greater than two years by the Oregon Department of Environmental Quality. Data from the PurpleAir was time-averaged to match the time resolution of the nephelometer and linear regression was performed to obtain a slope and intercept that allows the time-series PurpleAir data to be corrected to the nephelometer data.

A site specific colocation between six purple air sensors and two low-volume gravimetric particle samplers (ARA N-FRM) was conducted over a period of three days in one participating household, E-31. Three gravimetric samples were collected over the three-day period, with the low volume gravimetric sampler collecting particles onto a filter over a $12 \mathrm{~h}, 27 \mathrm{~h}$, and $24 \mathrm{~h}$ period. Note that non- 24 hour periods were in two instances used due to the need to coordinate access to the indoor low-volume sampler with the homeowner. Appropriate corrections to the total sample volume were made by noting start and end times of the low volume gravimetric sampler. Woodstove operation occurred throughout the duration of the sampling. The two ARA N-FRM samplers were installed with $\mathrm{PM}_{10}$ and $\mathrm{PM}_{2.5}$ impactors to enable a site specific indoor calibration for both $\mathrm{PM}_{10}$ and $\mathrm{PM}_{2.5}$. We report on only $\mathrm{PM}_{2.5}$ for the purposes of this study. The polytetrafluoroethylene (PTFE) filters from the ARA samplers were stored in a refrigerator when not in use, and were transported in a cooler to the ODEQ laboratory. ODEQ conducted pre- and post- gravimetric measurements to enable three indoor particle mass correction factors to be calculated Additionally, stove use was monitored 
with a Geocene Dot stove use monitor during the period of co-location. Results of PurpleAir co-locations and calibrations are provided in Section 4.2.

\subsubsection{Stove Use Monitor}

The Geocene Dot is a K-type thermocouple and temperature logger, appropriate for measuring temperatures from $-100 \mathrm{C}$ to $400 \mathrm{C}$. The thermocouples were purchased new from Geocene, Inc., and were factory calibrated with a reported accuracy of $0.5^{\circ} \mathrm{C}$ across this range with a reported temperature resolution of $0.0625^{\circ} \mathrm{C}$.

\subsubsection{Carbon Monoxide Monitor}

We employed the Ecotech Serinus 30 (Automated Reference Method: RFCA0509-174) analyzer. The analyzer was factory calibrated prior to field deployment and the calibration was verified with span gas using a Dasibi Model 5008 dilution system and span gas on two occasions during the study. A calibration for the Ecotech Serinus 30 carbon monoxide analyzer was conducted on $8 / 2 / 18$. The calibration curve for the CO analyzer is attached in Appendix A.

\subsubsection{Aethalometer}

The aethalometer was maintained by performing a flow check prior to the initiation of the sampling campaign to confirm the instrument flowrate was 5.0 LPM, determined with a primary flow calibrator (Sensidyne, Gilibrator 2). This flow check was conducted and confirmed monthly for the duration of the campaign. The response of the optical detectors of the Aethalometer can be verified by a Neutral Density (ND) optical filter, recommended to occur yearly by the manufacturer. The instrument used in this 
study was within the one-year period of factory calibration of the optical detectors for the duration of this study (the instrument was received in April, 2018 and first operated in July, 2018). However, to confirm the response of the optical detector, the instrument was co-located with a second Aethalometer that had undergone the ND optical filter calibration. The two instruments were co-located from $8 / 21 / 2018-8 / 22 / 2018$ in a location where filtered laboratory air and a sample of urban air near a freeway were accessible to the instruments. This arrangement enabled the response of the two instruments to be compared for a range of black carbon levels. Results of this comparison are shown in Appendix 2, and show the instrument to have a strong correlation $\left(\mathrm{r}^{2}>0.99\right)$ with the ND optical filter corrected aethalometer. Thus, we did not conduct an early NDF optical filter calibration on the instrument used during this study. Further details of calibration, data quality, personnel training, and instrument siting can be found in Appendix A.

\subsection{Data Analysis: Blower Door Test}

A depressurization blower door test was conducted using the Minneapolis blower door and multipoint pressure and flow data was acquired and analyzed in accordance with a modified version of ASTM E779-03, Standard Test Method for Determining Air Leakage Rate by Fan Pressurization. (ASTM 2003) Note that data presented here have not been corrected for pressure differences incurred by temperature differences across the building envelope because blower door tests were conducted during an initial assessment prior to the deployment of indoor-outdoor monitoring devices. We note that this error is acceptable as it is approximated as $10 \%$ under extreme temperature differences ${ }^{34}$. 
Pressure-flow relationships were log transformed and plotted to determine the air leakage coefficient, $\mathrm{C}\left(\mathrm{m}^{3} / \mathrm{s} / \mathrm{Pa}^{\mathrm{n}}\right)$, and the pressure exponent, $\mathrm{n}(-)$, of each house from a least squares regression fit of the linearized equation, shown below in equation 1 .

$$
\log \mathrm{Q}=\log \mathrm{C}+\mathrm{n} \log \Delta \mathrm{P} \quad \text { Equation 1. Pressure flow relationship }
$$

where $\mathrm{Q}$ is the flowrate measured by the blower door system $\left(\mathrm{m}^{3} / \mathrm{s}\right)$ and $\Delta \mathrm{P}$ is the pressure drop across the fan measured by the blower door system $(\mathrm{Pa})$.

The multi-point blower door test was conducted with the intent of encompassing a range of envelope pressure differences that spanned 10-60 Pa. However, one typically reported metric of airtightness is the air changes per hour at $50 \mathrm{~Pa}$. Our study design prioritized the measurement of multiple pressure drop-flow rate points, and were not always able to obtain a direct measurement at exactly $50 \mathrm{~Pa}$ in a timeframe acceptable to the study subjects. Therefore, we used the calculated best fit parameters for $\mathrm{C}$ and $\mathrm{n}$ to solve for the flowrate through the house at elevated pressure of $50 \mathrm{~Pa}$, or $\mathrm{Q}_{50} \mathrm{~Pa}\left(\mathrm{~m}^{3} / \mathrm{s}\right)$. This flowrate was normalized by the estimated volume of each home to calculate the air changes per hour at $50 \mathrm{~Pa}$, or $\mathrm{ACH}_{50}\left(\mathrm{~h}^{-1}\right)$.

The effective leakage area, ELA $\left(\mathrm{m}^{2}\right)$ is the cross-sectional area of an orifice that would yield the same leakage flow rate as the building if subjected to a 4 Pa pressure difference. This value can be used in the Lawrence Berkeley National Laboratory infiltration model to estimate infiltration from the indoor-outdoor pressure difference or from environmental conditions like local wind speeds and indoor-outdoor temperature 
differences. The ELA value was calculated from the previously defined $\mathrm{C}$ and $\mathrm{n}$ values by using the equation below.

$$
\text { ELA }=\sqrt{\frac{\rho}{2}} C \Delta P_{r}^{n-0.5} \quad \text { Equation 2. Estimated Leakage Area }
$$

Note that we report the effective leakage area from data acquired from a depressurization blower door test only.

Normalized leakage (NL, -) was calculated from the effective leakage area determined from the equation 3, developed by the Lawrence Berkeley National Laboratory ${ }^{35}$ and as described in ASHRAE Standard 119.

$$
\mathrm{NL}=1000 \times\left(\frac{\mathrm{ELA}}{\mathrm{A}_{\mathrm{floor}}}\right)\left(\frac{\mathrm{H}}{\text { Href }}\right)^{0.3 \quad \text { Equation 3. Normalized leakage area. }}
$$

\subsection{Data Analysis: Estimation of WSE Impacts on Indoor and Outdoor Pollution} A primary motivation of this study is to ascertain the impact of the woodstove on exposure to indoor air pollutants that may be generated by wood burning heating devices. Presumably, more efficient woodstoves emit fewer air pollutants into the outdoor or indoor space, reducing exposures to air pollution. However, in a field study, many variables cannot be controlled. The households involved in this study are engaging in behaviors and activities that are variant in time and variant across households. In addition, regional ambient background levels of air pollution are changing on diurnal, weekly, and seasonal time-scales. Thus, a variety of empirical approaches were taken 
here as a first-step in developing an understanding of a woodstove exchange's impact on local and indoor air quality.

First, we assess the impact of the woodstove exchange on "local outdoor" air quality; for this analysis, unless otherwise noted, we refer to outdoor air quality as the measurements made outside a particular home, typically in proximity to the building itself from a sensor installed on an exterior façade of the building not near the exhaust of the woodstove. We investigate the potential for the woodstove exchange to impact local outdoor air quality by comparing local outdoor levels of air pollution pre- and postwoodstove exchange. This comparison should be interpreted cautiously, as background levels of air pollution changed over the course of the study for some deployments.

Similarly, we compare absolute levels of indoor air pollution measured pre and post exchange to inform understanding of how the woodstove exchange impacts true exposures to air pollution. From the perspective of exposure to the measured air pollutants, this metric is a direct representation of whether the woodstove exchange program reduced exposures to air pollution.

In this report, we report summarize $\mathrm{PM}_{2.5}$ data with the median value. We do so as the measured distributions for temperatures and air pollutants were generally nonnormal in their distribution. We compare medians of distributions (e.g., the median value of $\mathrm{PM}_{2.5}$ level prior to woodstove exchange to the median $\mathrm{PM}_{2.5}$ level post woodstove exchange) using the nonparametric statistic test, the Wilcoxon rank sum test. The PI has used this test to make comparisons of similar environmental air pollution data in the previous studies ${ }^{36}$. Differences between indoor and outdoor $\mathrm{PM}_{2.5}$ levels are compared 
before and after the exchange to do a bulk normalization. This is an attempt to compensate for fluctuations in outdoor $\mathrm{PM}_{2.5}$ throughout the duration of sampling.

\subsection{Source Strength Analysis}

Data from the intense first burn emission event was used to investigate stove source strength. A commonly used ${ }^{37}$ macroscopic model of particle decay was applied to our data with the aim of quantifying a woodstove emission rate. Subsequent work could investigate the chemical and physical processes governing the emission event observed. Emission mechanisms are complex and outside the scope of this study.

This emission data has two distinct regions, the first half is an intense injection event and the second half is a decay period. Each section can be independently modeled according to equation 4 , where $\lambda\left(\mathrm{hr}^{-1}\right)$ is the air exchange rate under "natural" (i.e., indoor-outdoor pressure driven flow due to buoyancy and meteorology per normal occupancy conditions), $\mathrm{S}$ is the source strength $(\mathrm{ug} / \mathrm{h})$ and $\mathrm{V}\left(\mathrm{m}^{3}\right)$ is the volume of the building.

$$
\frac{\mathrm{dC}}{\mathrm{dt}}=-\lambda \mathrm{C}+\lambda \mathrm{C}_{\text {out }}+\mathrm{S} / \mathrm{V}
$$

Equation 4. General differential equation for change in concentration

Integrating equation $4, \mathrm{PM}_{2.5}$ concentration can be isolated as a function of the initial concentration, $\mathrm{C}_{\mathrm{t}=0}\left(\mathrm{ug} / \mathrm{m}^{3}\right)$, the loss rate coefficient, $\mathrm{k}\left(\mathrm{hr}^{-1}\right)$, the particle penetration factor, $\mathrm{P}$, and $\mathrm{S}(\mathrm{ug} / \mathrm{h})$ the source strength, the air exchange rate and time, as shown in equation 5: 


$$
\begin{aligned}
C_{t}=C_{t=0} e^{-t(k+\lambda)} & \\
& +\left(\frac{\lambda P C_{o u t}}{(k+\lambda)}+\frac{S}{(k+\lambda)}\right)\left(1-e^{-t(k+\lambda)}\right)
\end{aligned}
$$

Equation 5. Non-linear curve fit for an injection period.

Using equation 5 and MATLAB's non-linear curve fitting tools, the injection period data is used to find $P, k, \lambda$ and a first source strength $S_{1}$. $S_{1}$ is a combination of two sources, the off gassing particulate emission unique to the first burn, and the emission due to the actual wood burning. To ensure realistic values were determined, $\mathrm{P}$ was limited to the interval $[0,1]$, lambda was set on the interval $\left[\lambda_{\text {natural }}, 100\right]$ where $\lambda_{\text {natural }}$ is the natural ventilation rate given by equation 6 below. The air exchange rate at $50 \mathrm{psi}, \mathrm{ACH}_{50}$ was calculated from blower door data.

$$
\lambda=\frac{\mathrm{ACH}_{50}}{18}-0.08
$$

Equation 6. Estimation of natural ventilation rate.

Next equation 5 was fit to the decay period data to find $S_{2}$, the emission due to only wood stove burning. During this data fit, the only fit variable was $S_{2}$ as $k, \lambda$, and $\mathrm{P}$ were identified in the injection period fit. 


\section{Results and Discussion}

\subsection{Recruited Households}

In total, twenty households were enrolled into the woodstove exchange program indoor air quality monitoring study. No homes included in the study were located near major roadways or other visually identifiable sources of air pollution. Note that all homes were stand-alone dwellings and were generally not in close proximity to other houses. A summary of the characteristics of the included households is shown below in Table 4, including characteristics of the household as well milestones relevant to the indoor air quality study. Fifteen households were engaged in the basic air monitoring effort while five of these households were engaged in the enhanced air monitoring effort.

Homes involved in the study were built between 1925 and 2001, with an average household building age of 50 years. Home sizes ranged between $1100-3200 \mathrm{ft}^{2}$ with an average size of $1830 \mathrm{ft}^{2}$. Household income ranged from $\$ 6700-110,000$, averaging $\$ 46150$. In general, homes participating in the indoor air quality study received an upgraded wood burning device, as was the case for 18 out of 20 participating homes. Two of the twenty homes received non-wood burning stoves, with homes E-32 and E-34 receiving a ductless heat pump and gas insert, respectively.

Households involved in the study were assured anonymity as per the institutional review board agreement. Each household is thus referred to by an anonymized code B-X or $\mathrm{E}-\mathrm{X}$ where $\mathrm{X}$ is the number of the household engaged in the study and the " $\mathrm{B}$ " or " $\mathrm{E}$ " indicator preceding the number indicates the household engaged in the basic (B) or enhanced (E) monitoring study. 
Due to a relatively mild winter in late 2018 and early 2019, wood stove exchanges began later than in past years of the woodstove exchange program. Table 4 indicates that the first stove exchange began in November, with the majority of stove exchanges not beginning until the end of January 2019. This contributed to a slightly lower than expected participation in the indoor air quality monitoring study of the woodstove exchange program. Nevertheless, as can be observed in the literature review summary (Table 1), this study, with nineteen participants with data available, constitutes one of the largest studies of pre- and post-woodstove exchange indoor air quality conducted to date. 
Table 4. Characteristics of study homes and sampling periods.

\begin{tabular}{|c|c|c|c|c|c|c|c|}
\hline Home & $\begin{array}{l}\text { Year } \\
\text { built }\end{array}$ & $\begin{array}{c}\text { Square } \\
\text { footage } \\
\left(\mathbf{f t}^{2}\right)\end{array}$ & $\begin{array}{c}\text { Pre- } \\
\text { exchange } \\
\text { sampling } \\
\text { start date }\end{array}$ & $\begin{array}{c}\text { Stove } \\
\text { exchange } \\
\text { date }\end{array}$ & $\begin{array}{l}\text { Heating source, } \\
\text { post-exchange }\end{array}$ & $\begin{array}{l}\text { Household } \\
\text { income }\end{array}$ & $\begin{array}{l}\text { Primary or } \\
\text { secondary } \\
\text { heat source }\end{array}$ \\
\hline B-1 & 1984 & 3000 & $10 / 18 / 2018$ & $11 / 8 / 2018$ & Wood stove insert & 21000 & $S$ \\
\hline B-2 & 1950 & 1820 & $11 / 8 / 2018$ & $11 / 28 / 2018$ & Wood stove insert & 46000 & $\mathrm{P}$ \\
\hline B-3 & 2001 & 3200 & $11 / 29 / 2018$ & $12 / 14 / 2018$ & Wood stove & 36000 & $\mathrm{P}$ \\
\hline B-4 & 1978 & 1800 & $12 / 6 / 2018$ & $12 / 21 / 2018$ & Pellet stove insert & 42000 & $\mathrm{P}$ \\
\hline B-5 & 1962 & 1100 & $12 / 6 / 2018$ & $12 / 20 / 2018$ & Wood stove & 107000 & $\mathrm{P}$ \\
\hline B-6 & 1974 & 1100 & $1 / 18 / 2019$ & $2 / 14 / 2019$ & Wood stove insert & 6700 & $\mathrm{P}$ \\
\hline B-7 & 1978 & 1600 & $1 / 21 / 2019$ & $1 / 24 / 2019$ & Wood stove & 37000 & $\mathrm{P}$ \\
\hline B-8 & 1930 & 1800 & $2 / 15 / 2019$ & $2 / 20 / 2019$ & Wood stove & 43000 & $\mathrm{P}$ \\
\hline B-10 & 1983 & 1700 & $2 / 22 / 2019$ & $2 / 25 / 2019$ & Pellet Stove & 69300 & $\mathrm{P}$ \\
\hline B-11 & 1976 & 1900 & $3 / 1 / 2019$ & $3 / 21 / 2019$ & Wood stove insert & 110000 & S \\
\hline B-12 & 1981 & 2700 & $3 / 26 / 2019$ & $4 / 12 / 2019$ & Wood stove & 68000 & $\mathrm{P}$ \\
\hline B-13 & 1925 & 1300 & $4 / 11 / 2019$ & $4 / 15 / 2019$ & Wood stove & 48000 & $\mathrm{P}$ \\
\hline B-14 & 1925 & 1800 & $3 / 28 / 2019$ & $4 / 18 / 2019$ & Wood Stove & 7700 & $\mathrm{P}$ \\
\hline B-15 & 1967 & 1200 & $4 / 3 / 2019$ & $5 / 14 / 2019$ & Wood Stove & 42000 & $\mathrm{P}$ \\
\hline B-16 & 1960 & 2100 & $4 / 18 / 2019$ & planned & Gas insert & 52000 & S \\
\hline E-31 & 1971 & 1300 & $1 / 21 / 2019$ & $1 / 23 / 2019$ & Wood stove & 28000 & $\mathrm{P}$ \\
\hline E-32 & 1991 & 1500 & $1 / 28 / 2019$ & 2/7/2019 & Ductless heat pump & 38000 & $\mathrm{P}$ \\
\hline E-33 & 1981 & 1800 & $2 / 15 / 2019$ & $2 / 21 / 2019$ & Wood stove & 22000 & $\mathrm{P}$ \\
\hline E-34 & 1968 & 1100 & $3 / 1 / 2019$ & $3 / 13 / 19$ & Gas Insert & 59000 & S \\
\hline E-35 & 1982 & 2800 & $3 / 25 / 2019$ & $3 / 29 / 2019$ & Pellet stove & $\mathrm{n} / \mathrm{d}$ & $\mathrm{S}$ \\
\hline
\end{tabular}




\subsection{Results of PurpleAir Sensor Quality Assurance Efforts}

PurpleAir sensors were employed in this investigation for "basic" monitoring efforts due to their low-cost which enabled multiple monitoring sites to be operated in parallel and for sensors to be simultaneously deployed to the indoor and outdoor environments at each house. Also, as noted previously, evidence for reliable reporting of particulate matter levels exists in the research literature when PA-IIs are calibrated. We conducted a group co-location to calibrate sixteen PA-IIs at the Hillsboro Hare Field ODEQ site. PurpleAir PA-IIs were co-located for a period of several weeks at the Hillsboro Hare Field site where nephelometers were recording time series data; the nephelometers were calibrated to a gravimetric standard by the Oregon Dept. of Environmental Quality and proven robust over a 2-year period. An example of a calibration curve resulting from the co-location is shown below in Figure 1, where the nephelometer is plotted as the independent variable vs. the PurpleAir data of a single sensor.

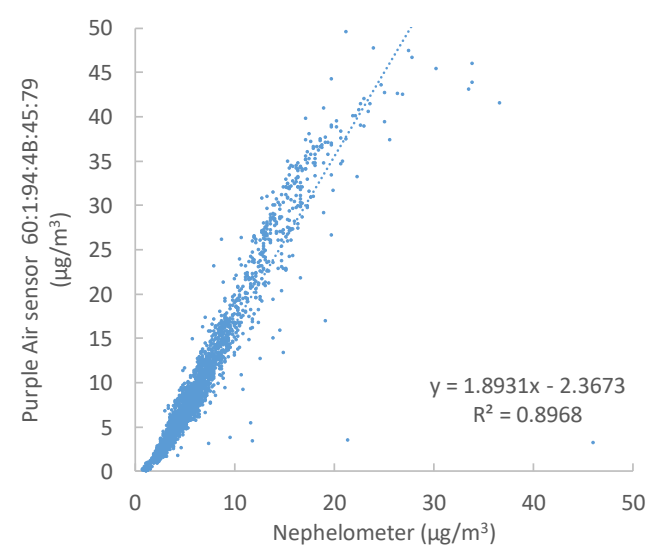

Figure 1. Example of one PurpleAir PA-II co-location with Oregon DEQ calibrated nephelometer. 
Results of the calibration of the sixteen PurpleAir sensors are shown below in Table 5. As can be observed, PurpleAir sensors behaved similarly, with slopes and intercepts that were consistent across sensors. The average slope correction necessary to the Purpleair was 1.88 with a standard deviation of 0.08 , implying that the PurpleAirs have a tendency to consistently over-estimate outdoor $\mathrm{PM}_{2.5}$ levels at this site by approximately a factor of 2 . The offset shows that there is a tendency to over-estimate the zero by approximately $2 \mu \mathrm{g} / \mathrm{m}^{3}$.

Table 5. Summary of calibration results of co-located PurpleAirs with ODEQ reference nephelometer.

\begin{tabular}{cccc} 
Purple Air ID & Slope & Y-intercept & $\mathbf{R}^{\mathbf{2}}$ \\
\hline 60 1 94 4B 45 79 & 1.89 & -2.37 & 0.90 \\
60 194 4B 45 85 & 1.89 & -2.37 & 0.90 \\
60 1 94 58 A0 9D & 1.98 & -2.12 & 0.89 \\
68 C6 3A 89 1D 78 & 1.86 & -1.68 & 0.90 \\
68 C6 3A 8E 59 42 & n/d & $\mathrm{n} / \mathrm{d}$ & $\mathrm{n} / \mathrm{d}$ \\
68 C6 3A 8E 8D 7 & 1.89 & -2.05 & 0.89 \\
68 C6 3A 8E 8E FA & 1.86 & -1.72 & 0.84 \\
84 F3 EB 45 31 65 & 1.76 & -0.99 & 0.87 \\
84 F3 EB 45 60 5C & 1.90 & -2.51 & 0.90 \\
84 F3 EB 91 44 3D & 1.91 & -1.92 & 0.89 \\
84 F3 EB 91 44 5A & 1.73 & -2.02 & 0.89 \\
84 F3 EB 91 44 5F & 1.89 & -2.37 & 0.90 \\
84 F3 EB 91 44 79 & 1.71 & -1.35 & 0.83 \\
84 F3 EB 91 AC 75 & 1.93 & -1.98 & 0.90 \\
84 F3 EB 91 AE 9 & 1.93 & -2.01 & 0.90 \\
EC FA BC B B1 6F & 2.01 & -2.34 & 0.90 \\
\hline average & $\mathbf{1 . 8 8}$ & $\mathbf{- 1 . 9 9}$ & $\mathbf{0 . 8 9}$ \\
standard deviation & $\mathbf{0 . 0 8}$ & $\mathbf{0 . 4 2}$ & $\mathbf{0 . 0 2}$ \\
\hline
\end{tabular}

We also explored the comparison of PurpleAir reported and nephelometer corrected $\mathrm{PM}_{2.5}$ values to a co-located indoor gravimetric sample. We conducted this indoor intercomparison to evaluate the differences between both "raw" PurpleAir data 
and nephelometer corrections of PurpleAir sensors with a sample of indoor aerosol. We deployed six PurpleAir sensors to an indoor environment (household B-31) and requested that the homeowners engage in extended duration woodstove operation. The homeowners reported that their woodstove was operating nearly continuously during the three-day period in which we conduct this intercomparison. Note that because this period was one of intensive indoor woodstove operation, we treat this comparison as exploratory; the appropriateness of density and shape factor corrections to convert light scattering particle count measurements to mass concentrations units for indoor vs. outdoor aerosol is a subject of intensive study and would require further investigation to fully assess. For example, there exist many potential confounders in determining a broadly applicable indoor aerosol correction factor/calibration including variation in indoor particle resuspension, human activity, and woodstove combustion.

Our preliminary data indicates that indoor aerosol during periods of woodstove operation may be different than that of outdoor aerosol, for which the PurpleAir sensors were calibrated as a group at the Hillsboro Hare Field site. Note that because the sampling occurred indoors, access to the low-volume sampler required coordination with the homeowner; thus, gravimetric samples taken with the low-volume gravimetric sampler occurred over 12, 27, and 24 hour periods. Appropriate corrections to sample volumes were made in calculated mass concentrations from gravimetric measurements. Detailed results of the gravimetric analysis and low-volume sampler are provided in Appendix 2 in Table A-4 and Table A-5. 
Table 6 below shows the results of a co-location between six PurpleAir sensors and a low-volume gravimetric sampler with a $\mathrm{PM}_{2.5}$ size selective inlet installed. The sensors were all co-located in the center of the living room of household B-31 with the sensors or inlets placed at approximately breathing height. Note that the "raw" PurpleAir data is the sensors reported value of mass concentration for $\mathrm{PM}_{2.5}$ time-averaged for the same period of the operation of the gravimetric sampler; the PurpleAir sensors include on-board algorithms that estimate this value from the size-resolved particle counts across six size bins. The results show that PurpleAir sensors, on average, reported mass concentrations of indoor $\mathrm{PM}_{2.5}$ during this $24-\mathrm{h}$ period that were within $41-86 \%$ of the gravimetric value. This contrasts with the nephelometer-corrected PurpleAir ouput which reports $51-70 \%$ of the gravimetric value. This divergence indicates that the correlations developed at Hillsboro Hare Field result in an under-reporting of indoor aerosol for $>2$ $\mu \mathrm{g} \mathrm{m}^{-3}$ where the calibration intercept has a smaller effect on the correction. This finding indicates the possibility of environmental and/or aerosol shape, density and optical characteristics that are different between the indoor and outdoor aerosols during colocation activities.

Table 6. Summary of indoor co-location of six PurpleAir sensors.

\begin{tabular}{|c|c|c|c|c|c|c|c|c|c|}
\hline \multirow[b]{2}{*}{ Sampler } & \multicolumn{3}{|c|}{ A1 } & \multicolumn{3}{|c|}{$\mathrm{A} 2$} & \multicolumn{3}{|c|}{$\mathrm{A} 3$} \\
\hline & $\begin{array}{c}\text { PA } \\
\text { Raw* }^{*}\end{array}$ & $\begin{array}{c}\text { Neph- } \\
\text { corr PA\% }\end{array}$ & $\mathrm{Grav}^{\#}$ & $\begin{array}{l}\text { PA } \\
\text { Raw }\end{array}$ & $\begin{array}{l}\text { Neph- } \\
\text { corr PA }\end{array}$ & Grav & $\begin{array}{l}\text { PA } \\
\text { Raw }\end{array}$ & $\begin{array}{l}\text { Neph- } \\
\text { corr PA }\end{array}$ & Grav \\
\hline PA 4585 & 0.65 & 1.60 & & 9.25 & 6.13 & & 22.82 & 13.30 & \\
\hline PA 5942 & 0.75 & $\mathrm{n} / \mathrm{d}$ & & 9.04 & $\mathrm{n} / \mathrm{d}$ & & 22.80 & $\mathrm{n} / \mathrm{d}$ & \\
\hline PA 1 AE9 & 1.12 & 1.62 & 123 & 11.69 & 7.10 & & 24.66 & 13.81 & \\
\hline PA E8D7 & 1.03 & 1.63 & 2.35 & 11.14 & 6.99 & 13.24 & 32.13 & 18.13 & 28.54 \\
\hline PA $605 C$ & 0.84 & 1.76 & & 9.26 & 6.18 & & 20.04 & 11.84 & \\
\hline PA 4479 & 1.36 & 1.58 & & 11.26 & 7.36 & & 21.89 & 13.56 & \\
\hline
\end{tabular}

*PurpleAir reported $\mathrm{PM}_{2.5}$ value from time duration of gravimetric measurement $\%$ Corrected to ODEQ calibration nephelometer \#Gravimetric measurement 
Additional a likely contributor to the divergence between the indoor and outdoor co-locations is the humidity differences between the two co-location events. During the co-location at Hillsboro Hare Field, the average relative humidity was $\sim 50 \%$. During the indoor co-location, the average relative humidity was lower, $\sim 30 \%$, in part due to nearcontinuous woodstove operation that resulted in warm indoor temperatures. The Plantower sensor, two of which are used in the PurpleAir sensor, are known to have relationships with relative humidity. A prior study of the response of the Plantower sensor indicates that these sensors may under-estimate mass concentrations measurements at lower relative humidities and over-estimate at higher relative humidities ${ }^{38}$, consistent with the findings of our two co-location efforts. Again, it should be noted that for all comparisons in this report, we apply nephelometer corrections to all PurpleAir data, due to the preliminary nature of this indoor co-location and the indoor conditions of near-continuous woodstove operation that were not necessarily representative of actual indoor houses. Because our study focuses on relative metrics (i.e., comparisons of air quality impacts pre- and post-exchange), the implications of differing indoor and outdoor calibration factors are mitigated.

\subsection{Household airtightness monitoring}

Infiltration is airflow across a building envelope that results of indoor-outdoor pressure differences created by wind and/or indoor-outdoor temperature differences. A blower door test provides quantitative data from a short-term test that enables determination of the relationship between airflow across a building's envelope at a range of artificially elevated pressure differences. This data can be normalized to typical 
indoor-outdoor pressure differences to enable modeling of infiltration airflows across the building and enables calculation of normalized metrics that enable comparison across buildings (e.g., the leakage area and normalized leakage). The results of the blower door results from each home are tabulated in Table 7. The $\mathrm{ACH}_{50}$ and the effective leakage area calculations are graphed in Figure 2.

The estimated $\mathrm{ACH}_{50}$ and leakage areas calculated inform our understanding of the potential for building leakage to contribute to indoor air pollution. These variables will be used subsequently to explore their ability to explain variation in observations of indooroutdoor air pollution differences. They also may be used to inform homeowners of opportunities for increasing the heating effectiveness of their new woodstoves, in turn reducing biomass needed to achieve a given indoor temperature setpoint. For example, two homes, B-13 and B-14, had very high leakage areas and $\mathrm{ACH}_{50}$. This implies that substantial improvements in household energy efficiency could be realized by weatherizing and air-sealing, while still maintaining an infiltration rate conducive to dilution of indoor generated air pollution. However, weatherization to reduce air exchange may create unintended consequences for indoor air quality, as it reduces the dilution of indoor sources of air pollution with outdoor air that may be cleaner than indoor air ${ }^{39}$.

In general, this subset of Washington County homes appeared subject to air leakage generally consistent with recommendations of the 2009 International Energy Conservation Code (IECC). The 2009 IECC recommends $<7 \mathrm{ACH}_{50}$ for the Oregon climate zone ${ }^{40}$; the median of the homes in this dataset was $11.1 \mathrm{ACH}_{50}$. Although, as 
shown in Figure 2, the dataset is subject to high variability with eleven homes having $\mathrm{ACH}_{50}$ greater than $10 \mathrm{~h}^{-1}$. Two homes have $\mathrm{ACH}_{50}$ of $29 \mathrm{~h}^{-1}$ or greater and should be advised to consider weatherization and air sealing to reduce biomass usage for heating to reduce cost to the homeowner and to reduce air pollution emissions from biomass burning for heating.

Table 7. Household airtightness metrics, flow coefficient, $C$, and pressure exponent $n$.

\begin{tabular}{|c|c|c|c|c|c|}
\hline Home & $\begin{array}{c}\mathrm{C} \\
\left(\mathbf{m}^{3} / \mathrm{s} / \mathbf{P a}^{\mathrm{n}}\right)\end{array}$ & $\begin{array}{l}\mathbf{n} \\
(-) \\
\end{array}$ & $\begin{array}{c}\operatorname{ACH}_{50} * \\
\left(h^{-1}\right)\end{array}$ & $\begin{array}{c}\text { Leakage area } \\
\left(\mathbf{m}^{2}\right)\end{array}$ & $\begin{array}{c}\text { Normalized } \\
\text { leakage } \\
(-) \\
\end{array}$ \\
\hline B-1 & 0.06 & 0.83 & 7.68 & 0.07 & 0.37 \\
\hline B-2 & 0.13 & 0.60 & 11.70 & 0.11 & 0.81 \\
\hline B-3 & 0.12 & 0.55 & 5.02 & 0.10 & 0.48 \\
\hline B-4 & 0.09 & 0.62 & 8.74 & 0.08 & 0.57 \\
\hline B-5 & 0.21 & 0.59 & 30.57 & 0.19 & 2.14 \\
\hline B-6 & 0.03 & 0.83 & 11.07 & 0.04 & 0.42 \\
\hline B-7 & $\mathrm{n} / \mathrm{d}$ & $\mathrm{n} / \mathrm{d}$ & $\mathrm{n} / \mathrm{d}$ & $\mathrm{n} / \mathrm{d}$ & $\mathrm{n} / \mathrm{d}$ \\
\hline B-8 & 0.00 & 0.99 & 1.77 & 0.01 & 0.06 \\
\hline B-10 & 0.15 & 0.58 & 13.36 & 0.13 & 0.96 \\
\hline B-11 & 0.11 & 0.69 & 13.35 & 0.11 & 0.91 \\
\hline B-12 & 0.09 & 0.72 & 9.07 & 0.10 & 0.57 \\
\hline B-13 & 0.35 & 0.49 & 29.29 & 0.27 & 2.64 \\
\hline B-14 & 1.19 & 0.33 & 38.31 & 0.73 & 5.27 \\
\hline B-15 & 0.03 & 0.74 & 6.16 & 0.03 & 0.30 \\
\hline B-16 & 0.21 & 0.48 & 10.20 & 0.16 & 0.95 \\
\hline E-31 & 0.07 & 0.64 & 11.06 & 0.07 & 0.69 \\
\hline E-32 & 0.10 & 0.65 & 12.80 & 0.10 & 0.78 \\
\hline E-33 & 0.06 & 0.68 & 7.53 & 0.06 & 0.42 \\
\hline E-34 & 0.04 & 0.76 & 9.09 & 0.04 & 0.45 \\
\hline E-35 & 0.20 & 0.60 & 12.22 & 0.18 & 1.03 \\
\hline Median & 0.10 & 0.64 & 11.06 & 0.10 & 0.69 \\
\hline
\end{tabular}

$* \mathrm{ACH}=$ Air changes per hour 


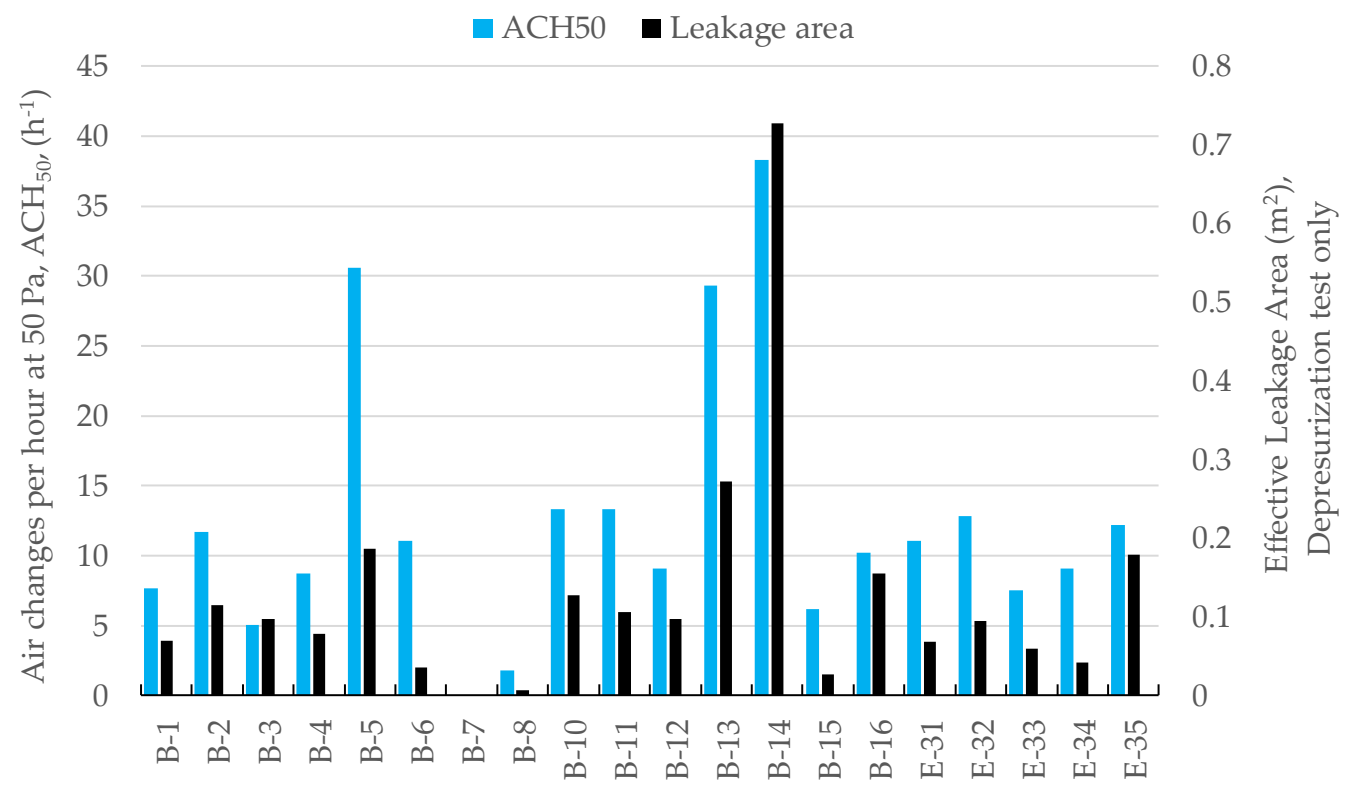

Figure 2. Summary of ACH50 and Effective Leakage Area calculations across homes involved in the indoor air quality study of the Washington County Woodstove Exchange Program.

The normalized leakage reported in Table 7 is a widely reported metric of airtightness, with leakage measurements being available for thousands of homes across the United States ${ }^{35}$. A study of 79 homes in Oregon resulted in a value of normalized leakage of $0.40^{35}$, slightly lower than the value of 0.69 reported here. As is the case with the calculated $\mathrm{ACH}_{50}$ values, these data are subject to variability in the WSE indoor air quality study dataset, with some homes experiencing substantial normalized leakage. Nevertheless, the comparison to a prior study of homes in Oregon yielding a similar result lends confidence in the method used to report various metrics of airtightness in this sample of homes.

\subsection{Air Monitoring Results: Household Temperatures}

Table 8 shows the summary of indoor and outdoor temperatures across the monitoring campaign. As can be observed in the columns reporting indoor median temperatures, the 
indoor environments were maintained at typical, comfortable indoor temperatures in all houses for which measurements are available. Note that instrument failures (due to sensor error or the household unplugging the sensor) resulted in loss of data for households B-4, B-6, B-13, B-15, and B-16. While the monitoring of indoor thermal comfort was not the primary goal of this study, it is nevertheless promising to see that indoor temperatures post-exchange were maintained at typically comfortable indoor levels after the new heating device was installed.

Table 8. Magnitudes of measured indoor and outdoor temperatures pre and post exchange.

\begin{tabular}{ccccc} 
Household & \multicolumn{2}{c}{ Pre-exchange } & \multicolumn{2}{c}{ Post-exchange } \\
\cline { 2 - 5 } & $\begin{array}{c}\text { Median } \\
\text { Outdoor Temp } \\
\left({ }^{\circ} \mathbf{C}\right)\end{array}$ & $\begin{array}{c}\text { Median Indoor } \\
\text { Temp }\left({ }^{\circ} \mathbf{C}\right)\end{array}$ & $\begin{array}{c}\text { Median } \\
\text { Outdoor Temp } \\
\left({ }^{\circ}\right)\end{array}$ & $\begin{array}{c}\text { Median Indoor } \\
\text { Temp }\left({ }^{\circ} \mathbf{C}\right)\end{array}$ \\
\hline B-1 & 16.7 & 25.0 & 11.7 & 23.3 \\
B-2 & 11.7 & 23.3 & 10.0 & 22.8 \\
B-3 & 9.1 & 25.6 & 10.6 & 26.3 \\
B-4 & & & & \\
B-5 & 11.2 & 31.7 & 10.6 & 31.7 \\
B-6 & 11.7 & 11.7 & 26.11 & \\
B-7 & 12.2 & 27.8 & 9.4 & 30.0 \\
B-8 & 8.9 & 26.7 & 7.2 & 26.1 \\
B-10 & 10.3 & 26.7 & 7.4 & 22.2 \\
B-11 & 10.6 & 26.7 & 12.8 & 23.1 \\
B-12 & 15.6 & 22.8 & 16.7 & 22.2 \\
B-13 & & & & \\
B-14 & 14.1 & 21.7 & 16.3 & \\
B-15 & & & & 22.2 \\
B-16 & 11.7 & 22.8 & 12.2 & 26.1 \\
E-31 & 8.9 & 25.6 & 5.0 & 24.2 \\
E-32 & 10.0 & 27.2 & 10.0 & 24.6 \\
E-33 & 7.8 & 23.9 & 14.4 & \\
E-34 & 12.7 & 23.9 & 16.1 & \\
E-35 & & & & \\
\hline
\end{tabular}




\subsection{Air Monitoring Results: Example Time-series Data (Basic Monitoring)}

As discussed in Section 3.2, households involved in "basic" air monitoring focused on measurement of indoor and outdoor temperatures, size-resolved particulate matter levels (with analysis focusing on $\mathrm{PM}_{2.5}$ ), woodstove temperatures, and for some homes, indoor carbon dioxide levels (as a proxy for occupancy). Time-series data for one household, B-10, is shown below in Figure 3. Time-series measurements for temperature, $\mathrm{PM}_{2.5}, \Delta \mathrm{PM}_{2.5}$ and stove temperature are provided in Appendix 3 for all households.

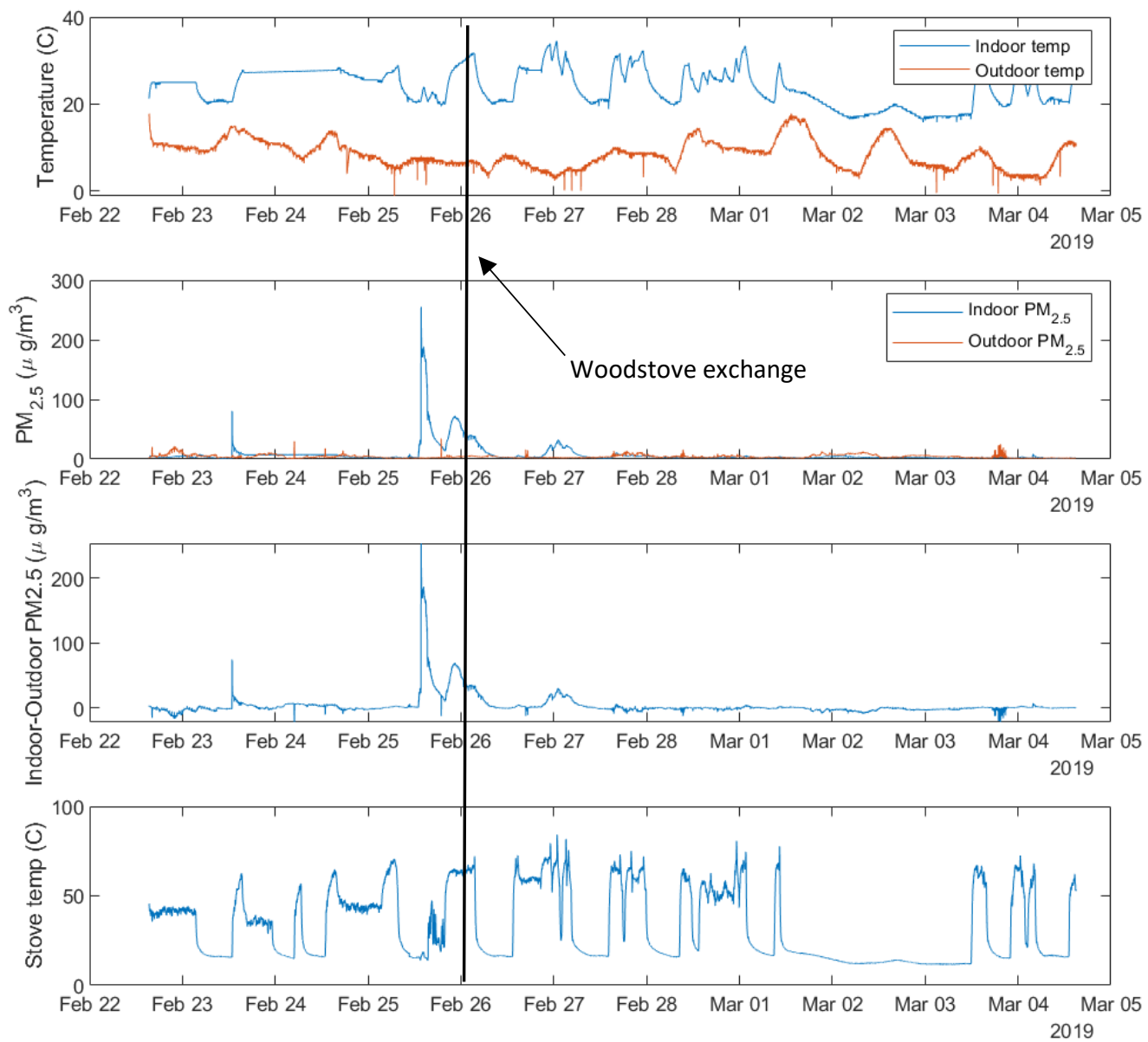

Figure 3. Example time-series data from wood stove exchange household B-10.

As can be observed in Figure 3, indoor temperatures were routinely higher than outdoor levels in household B-10, explained by the presence of indoor heat sources. This 
household experienced a woodstove exchange on February $25^{\text {th }}$, as reported in Table 4 . A recurrent observation in most (13 of 17 households with data available), was an associated extreme peak in indoor $\mathrm{PM}_{2.5}$ on the first usage of the new stove. This phenomenon can be observed in the elevated peak on Feb $25^{\text {th }}$ (blue line) for indoor $\mathrm{PM}_{2.5}$; indoor levels exceeded $200 \mu \mathrm{g} / \mathrm{m}^{3}$ during the first operation of the new woodstove. It can be observed that this is associated with the first use of the stove by observed the temperature profile of the stove on the day of Feb $25^{\text {th }}$. We observed similar behavior in indoor $\mathrm{PM}_{2.5}$ levels associated with the stove's first use in 12 out of 16 households for which data is available. This leads us to recommend consideration for a "first burn" to be conducted when the home is not occupied by the homeowner.

Prior to the exchange, the indoor $\mathrm{PM}_{2.5}$ level in house B-10 had a median value of $4.9 \mu \mathrm{g} / \mathrm{m}^{3}$, subsequent to the exchange, the median indoor $\mathrm{PM}_{2.5}$ level was $2.8 \mu \mathrm{g} / \mathrm{m}^{3}$. Therefore, in absolute terms, $\mathrm{PM}_{2.5}$ levels were reduced in this household post woodstove exchange. However, there are many drivers of indoor levels of $\mathrm{PM}_{2.5}$, including nonwoodstove indoor sources and outdoor levels of $\mathrm{PM}_{2.5}$. To ascertain if changing outdoor levels explained the differences in indoor $\mathrm{PM}_{2.5}$ pre and post-exchange we calculated the indoor-outdoor $\mathrm{PM}_{2.5}$ difference, also reported in Figure 5. The figure shows that indooroutdoor levels were similar (i.e. indoor levels were near outdoor levels for the duration of the monitoring campaign), with the exception of several indoor particle emissions events. On a median basis, the indoor-outdoor $\mathrm{PM}_{2.5}$ difference in household B-10 decreased from $0.33 \mu \mathrm{g} / \mathrm{m}^{3}$ to $-0.45 \mu \mathrm{g} / \mathrm{m}^{3}$. This implies that after accounting for the potential impact of changing outdoor levels on indoor levels, indoor $\mathrm{PM}_{2.5}$ levels were lower post- 
exchange relative to outdoor levels. Further analysis will be necessary to ascertain the impact of air exchange as a function of indoor-outdoor pressure difference to calculate indoor source strengths pre and post-woodstove exchange.

\subsection{Air Monitoring Results: Comparison of $\mathrm{PM}_{2.5}$ Pre- and Post exchange}

Summarized in Table 9 are the magnitudes of $\mathrm{PM}_{2.5}$ measured via PurpleAir sensors placed inside and outside each of the twenty homes participating in the study.

Table 9. Magnitudes of measured indoor and outdoor $\mathrm{PM}_{2.5}$ pre- and post-exchange.

\begin{tabular}{|c|c|c|c|c|c|c|}
\hline \multirow[b]{2}{*}{ Home } & \multicolumn{3}{|c|}{ Median outdoor $\mathbf{P M}_{2.5}\left(\mu \mathrm{g} / \mathrm{m}^{3}\right)$} & \multicolumn{3}{|c|}{ Median indoor $\mathrm{PM}_{2.5}\left(\mu \mathrm{g} / \mathrm{m}^{3}\right)$} \\
\hline & $\begin{array}{c}\text { Pre- } \\
\text { exchange }\end{array}$ & $\begin{array}{c}\text { Post- } \\
\text { exchange }\end{array}$ & Change & $\begin{array}{c}\text { Pre- } \\
\text { exchange }\end{array}$ & $\begin{array}{c}\text { Post- } \\
\text { exchange }^{\#}\end{array}$ & Change \\
\hline B-1 & 10.6 & 8.96 & -1.67 & 5.4 & $6.0 / 5.9$ & 0.57 \\
\hline B-2 & 10.8 & 7.79 & -2.97 & 7.9 & $5.2 / 4.0$ & -2.69 \\
\hline B-3 & 8.0 & 3.73 & -4.29 & 7.6 & $5.0 / 5.0$ & -2.53 \\
\hline B-4 & & & & 11.2 & $12.4 / 11.8$ & 1.23 \\
\hline B-5 & 10.9 & 5.07 & -5.88 & 6.0 & $3.7 / 3.6$ & -2.30 \\
\hline B-6 & 10.2 & 6.9 & -1.06 & 7.1 & $6.1 / 6.0$ & -1.1 \\
\hline B-7** & 3.1 & 9.43 & 6.31 & 31 & $42 / 41$ & 10.8 \\
\hline B-8 & 3.5 & 3.90 & 0.41 & 2.3 & $6.2 / 6.2$ & 3.86 \\
\hline B-10 & 4.6 & 3.28 & -1.27 & 4.9 & $2.8 / 2.7$ & -2.05 \\
\hline B-11 & 4.7 & 6.72 & 2.06 & 3.9 & $4.7 / 3.0$ & 0.83 \\
\hline B-12 & 3.3 & 3.01 & -0.25 & 1.6 & $2.1 / 2.0$ & 0.52 \\
\hline B-13 & & & & 1.9 & $2.6 / 2.6$ & \\
\hline B-14 & 2.3 & 3.41 & 1.10 & 1.6 & $2.5 / 2.6$ & 0.92 \\
\hline B-15 & 3.4 & 3.2 & -0.21 & & & \\
\hline B-16 & & & & & & \\
\hline E-31 & 2.7 & 2.63 & -0.10 & 2.1 & $3.0 / 4.7$ & 0.97 \\
\hline E-32 & 9.1 & 4.67 & -4.42 & 7.7 & $3.8 / 3.8$ & -3.97 \\
\hline E-33 & 4.6 & 6.05 & 1.48 & 4.3 & $6.8 / 6.8$ & 2.45 \\
\hline E-34 & 5.7 & 7.53 & 1.86 & 0.98 & $4.8 / 4.7$ & 3.85 \\
\hline E-35 & 2.0 & 3.53 & 1.58 & 1.1 & $2.1 / 2.0$ & 1.02 \\
\hline Median & 4.6 & 4.9 & -0.18 & 4.6 & 4.8 & 0.76 \\
\hline Median-NP \#\# & & & & 4.6 & 4.3 & 0.63 \\
\hline
\end{tabular}

**indoor smoking occurred

\# The indoor peak observed following installation and first operation of the stove is excluded from this data. The second value shown is the indoor median with the peak excluded. All calculations are made with data including the peak unless indicated.

Note that some homes do not have data available due to sensor error or the homeowner deactivating power to the instrument for a period of time that resulting in 
insufficient monitoring data. Ultimately, 16 households had adequate data to report on outdoor $\mathrm{PM}_{2.5}$ levels pre and post-exchange while 17 households had adequate data to report on indoor $\mathrm{PM}_{2.5}$ levels pre- and post-exchange. Nine of sixteen homes with available data experienced a reduction in absolute levels of local outdoor $\mathrm{PM}_{2.5}$ while seven of seventeen homes experienced a reduction in absolute levels of indoor $\mathrm{PM}_{2.5}$ post woodstove exchange. The median change in local outdoor $\mathrm{PM}_{2.5}$ was a reduction of 0.18 $\mu \mathrm{g} / \mathrm{m}^{3}$ while the median change indoors was an increase of $0.57 \mu \mathrm{g} / \mathrm{m}^{3}$.

As can be observed in boxplots shown in Figure 4, there existed variability in preand post- magnitudes of indoor and outdoor levels of $\mathrm{PM}_{2.5}$ before and after the woodstove exchange. In general, distributions of $\mathrm{PM}_{2.5}$ were observed to be non-normal; subsequent analysis include non-parametric tests and report median values that are less impacted by outliers and transient events. From a standpoint of human exposure, the median in this case will be more representative of a long-term exposure concentrations. Transient events which result in elevated, acute exposures are also of concern, and future exposure modeling using this data could consider employing a time-concentration model of exposure that employs empirical data measured with $\sim 1$ min time resolution to capture dynamics of indoor and outdoor exposures. 


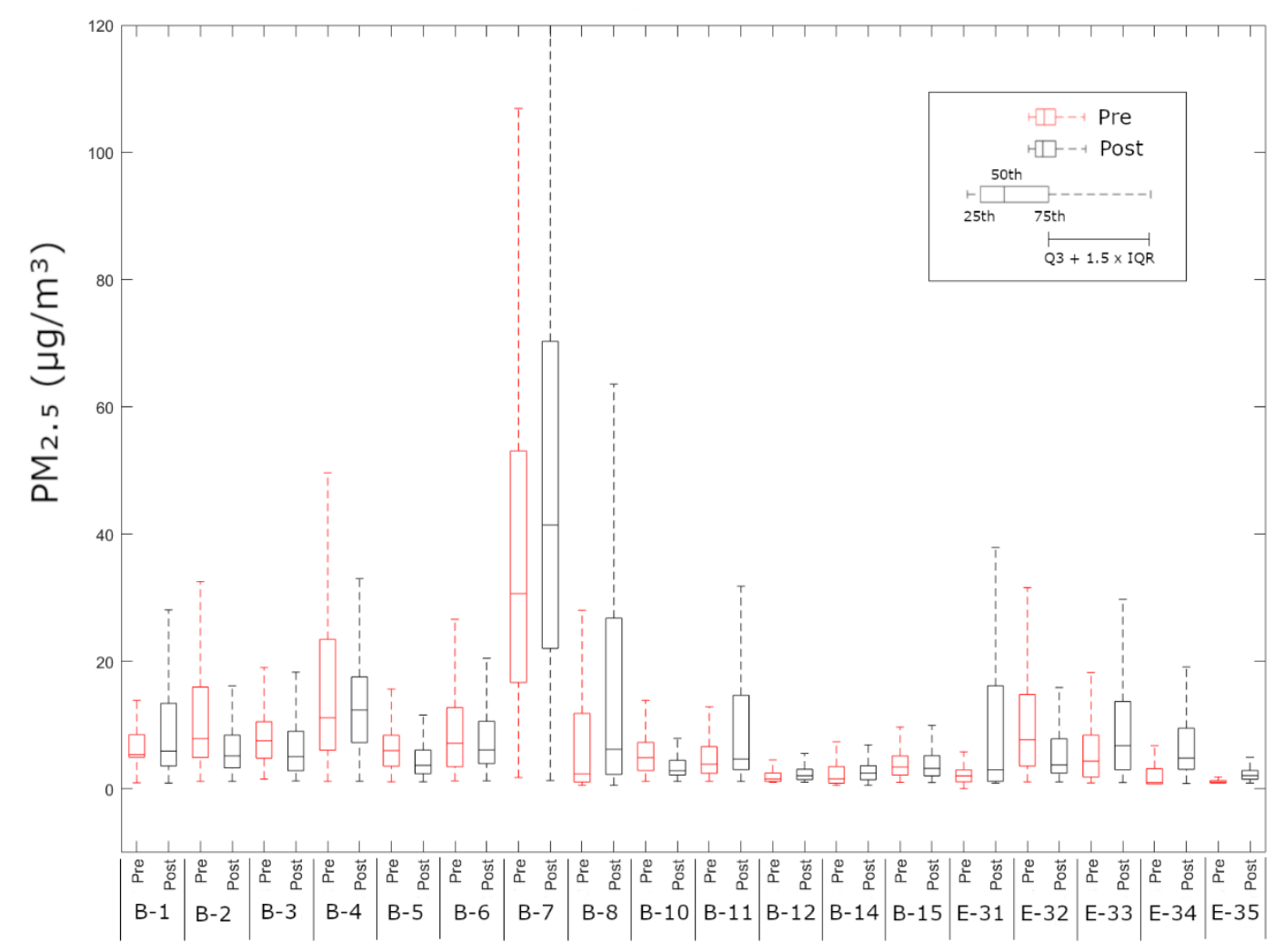

Figure 4. Boxplots showing variability in measured indoor and outdoor $\mathrm{PM}_{2.5}$ levels at each household.

It should be noted that observed changes in indoor and outdoor $\mathrm{PM}_{2.5}$ levels may not be due solely to the presence of a more efficient heating device. Depending on the timing on the installation, changes in regional ambient $\mathrm{PM}_{2.5}$ may have contributed to a reduction in indoor $\mathrm{PM}_{2.5}$, particularly for woodstove exchanges occurring towards the Spring, when meteorology associated with greater atmospheric mixing and higher atmospheric mixing height contribute to higher regional ventilation and lower levels of air pollution. Further, changes in occupant behavior and activity, and changes in neighborhood scale local sources are also possible. Figure 5 shows the regional $\mathrm{PM}_{2.5}$ as measured by Oregon DEQ at the Hillsboro Hare Field monitoring for the period in which 
woodstove exchange events occurred. During the winter periods of November through February, regional $\mathrm{PM}_{2.5}$ is elevated and variable compared to a general trend of lower levels beginning in March 2019. Further effort to parse local outdoor (i.e. at the household) vs. regional effects of $\mathrm{PM}_{2.5}$ levels on the measured indoor and outdoor $\mathrm{PM}_{2.5}$ relationships will improve understanding of the impact of regional $\mathrm{PM}_{2.5}$ as a possible confounder in this study.

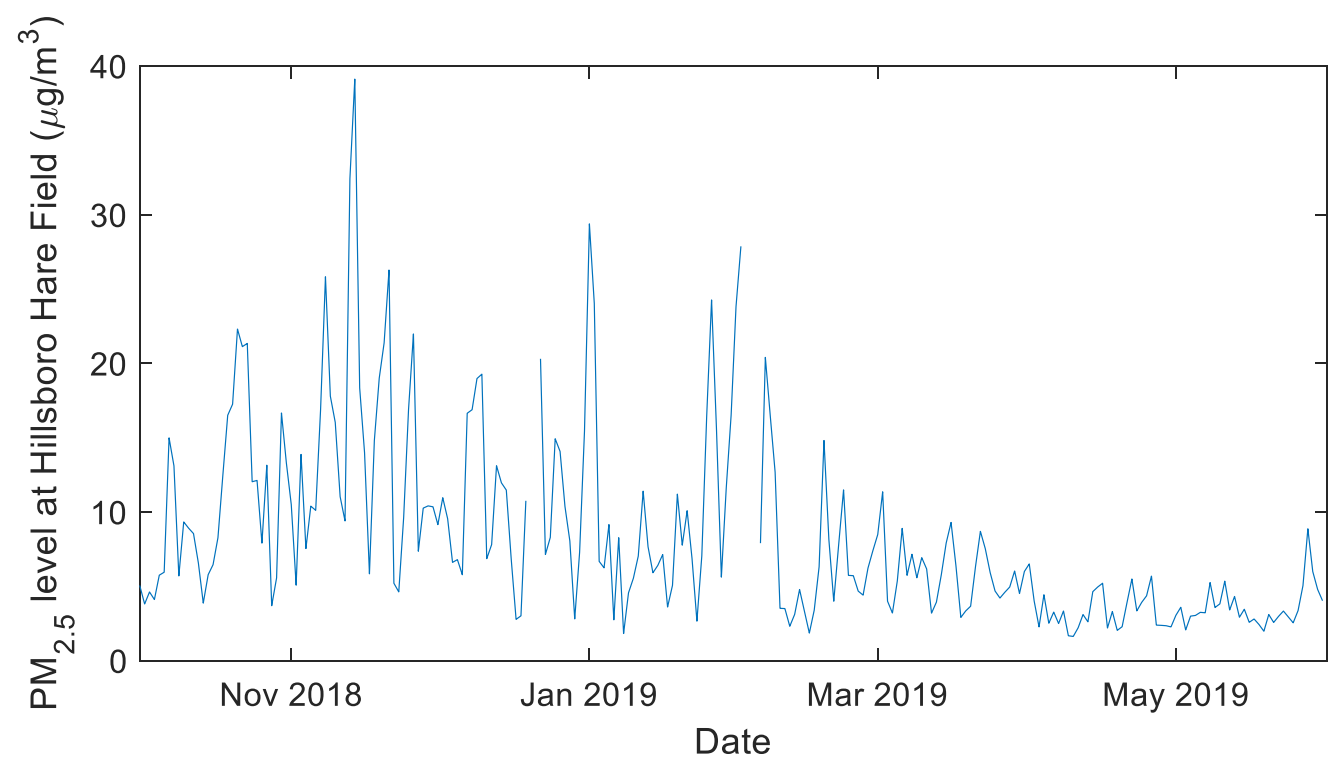

Figure 5. Regional $\mathrm{PM}_{2.5}$ levels as measured ODEQ at the Hillsboro Hare Field site for $10 / 19-6 / 19$

Indoor levels of $\mathrm{PM}_{2.5}$ pre and post-exchange were also variable across homes; seven homes experienced a reduction of absolute levels of $\mathrm{PM}_{2.5}$ while eight experience an increase. Across all households, median levels of $\mathrm{PM}_{2.5}$ were similar pre- and postexchange, with an increase of $0.57 \mu \mathrm{g} / \mathrm{m}^{3}$ measured when considering all homes in the dataset. 
As discussed previously, there exist many sources of indoor $\mathrm{PM}_{2.5}$, including outdoor $\mathrm{PM}_{2.5}$. Thus, normalizing the measured indoor $\mathrm{PM}_{2.5}$ levels for the monitored $\mathrm{PM}_{2.5}$ enables a rough proxy for the contribution of indoor sources to $\mathrm{PM}_{2.5}$ to be made. The $\Delta \mathrm{PM}_{2.5}$, or the indoor $\mathrm{PM}_{2.5}$ minus the outdoor $\mathrm{PM}_{2.5}$ is reported for all households with sufficient data to enable the calculation in Table 10. In contrast to the comparison shown in Table 9, where only absolute magnitudes are considered, fewer households experience a reduction in $\Delta \mathrm{PM}_{2.5}$, with only 5 of 16 households experience a reduction in $\Delta \mathrm{PM}_{2.5}$ when comparing pre- and post-exchange data.

We speculate that this reduction is due to some households engaging in the study during a period of improving regional outdoor air quality (Figure 5). For example, household B-6 experienced a reduction in absolute levels of indoor $\mathrm{PM}_{2.5}$, but experienced an increase of $\Delta \mathrm{PM}_{2.5}$ (indicating that relative to outdoor levels, indoor levels were higher post exchange). Household B-6 had a woodstove exchange relatively late in the season, with the new stove being installed Feb. $14^{\text {th }}, 2019$. The divergence in indoor air quality metrics $\left(\mathrm{PM}_{2.5}\right.$ levels vs. $\left.\Delta \mathrm{PM}_{2.5}\right)$ for $\mathrm{B}-6$ from Table 9 to 10 indicate that outdoor air quality improved with a greater magnitude than the observed improvement in indoor air quality pre- and post- stove for this household. This high-level analysis demonstrates the complexity of source apportionment; attributing the effect of the woodstove exchange to a quantitative improvement in indoor or local outdoor air pollution is challenging given the dynamic and uncontrolled nature of both the indoor and outdoor environments in which the study was occurring. Nevertheless, the parameterizations developed here imply that the woodstove exchange, when considering 
the central tendency across all homes, did not have an outsize effect on $\Delta \mathrm{PM}_{2.5}$; the median across all homes showed an increase of $1 \mu \mathrm{g} / \mathrm{m}^{3}$ albeit with large variability across individual households.

Table 10.Magnitudes of indoor minus outdoor levels pre and post exchange.

\begin{tabular}{cccc} 
& \multicolumn{2}{c}{ Median $\Delta \mathbf{P M}_{2.5}$ (indoors - outdoors) $\left(\boldsymbol{\mu g} / \mathbf{m}^{\mathbf{3}}\right)$} \\
\cline { 2 - 4 } Home & Pre-exchange & $\begin{array}{c}\text { Post- } \\
\text { exchange }\end{array}$ & $\begin{array}{c}\text { Change in } \\
\boldsymbol{\Delta P M} \mathbf{2 . 5}\end{array}$ \\
\hline B-1 & -5.28 & -3.03 & 2.24 \\
B-2 & -2.86 & -2.59 & 0.27 \\
B-3 & -0.45 & 1.31 & 1.76 \\
B-4 & & & \\
B-5 & -4.94 & -1.37 & 3.58 \\
B-6 & -3.13 & -0.86 & 2.26 \\
B-7 & 27.55 & 32.04 & 4.50 \\
B-8 & -1.15 & 2.31 & 3.46 \\
B-10 & 0.33 & -0.45 & -0.78 \\
B-11 & -0.80 & -2.03 & -1.23 \\
B-12 & -1.72 & -0.95 & 0.77 \\
B-13 & & & \\
B-14 & -0.74 & -0.92 & -0.18 \\
B-15 & & & \\
B-16 & & & \\
E-31 & -0.68 & 0.39 & 1.07 \\
E-32 & -1.38 & -0.92 & 0.45 \\
E-33 & -0.23 & 0.74 & 0.96 \\
E-34 & -4.69 & -2.70 & 1.99 \\
E-35 & -0.90 & -1.45 & -0.55 \\
\hline Median & -1.02 & -0.92 & 0.96 \\
\hline
\end{tabular}

The parameterization of $\Delta \mathrm{PM}_{2.5}$ provides the relative difference between indoor and outdoor $\mathrm{PM}_{2.5}$ levels. The controlling driver linking indoor and outdoor air pollution for an indoor environment is ventilation. We conducted blower door tests to enable calculation of metrics representative of household airtightness (a proxy for ventilation rate), including the normalized leakage area. In Figure 8, we plot the normalized leakage area vs. the $\Delta \mathrm{PM}_{2.5}$. As can be observed in the plot, $89 \%$ of the variance in post minus pre $\Delta \mathrm{PM}_{2.5}$ can be explained by the airtightness metric normalized leakage area. This finding 
indicates that woodstoves act as a source to the indoor environment, including during the observed "first burn" that created a large peak of indoor particulate matter indoors.

Household specific impacts may be better explained if site-specific ventilation conditions are considered. As shown in Figure 8, homes with higher normalized leakage areas, and thus higher ventilation rates for a given indoor-outdoor pressure difference, would ventilate particle of indoor origin out of the space more rapidly than homes with lower normalized leakage areas

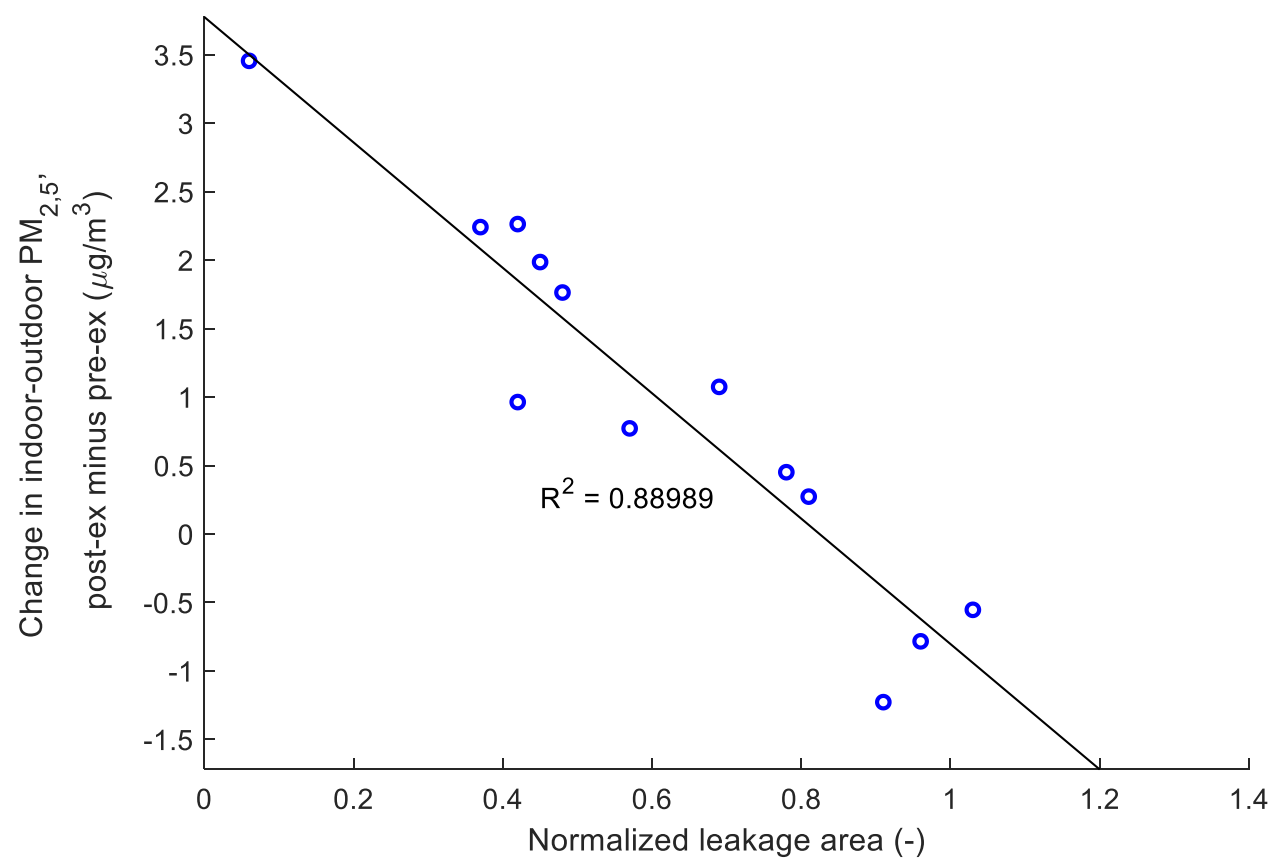

Figure 6. Regression of normalized leakage area vs. change in indoor-outdoor $\mathrm{PM}_{2.5}$ $\left(\triangle \mathrm{PM}_{2.5}\right)$ level (post exchange minus pre exchange).

Given that this was a field study the strength of this correlation was not expected. One observation that can be made from Figure 6 is that "tight" homes exhibit an increase in the indoor-outdoor $\mathrm{PM}_{2.5}$ after the exchange and "leaky" homes exhibit a decrease after the exchange. The assumption that during woodstove operation, indoor levels of $\mathrm{PM}_{2.5}$ 
are higher than outside can help to explain the observed phenomena. An initial hypothesis for this observed correlation is that upon receiving a new woodstove, homes with large NLA are more likely to have increased stack effects study using the database created in this project will continue to investigate household ventilation as an explanatory variable for woodstove-indoor air quality relationships.

The conclusions made around this set of data imply that it is better for your health to live in a home with high ventilation. While there are distinct benefits of having high ventilation rates within homes, it is important to note that thermal comfort and heating costs are often negatively impacted with increased air exchange rates. With increased air exchange rates, it becomes harder to heat the home efficiently, and thermal comfort may be diminished. Additionally, while the energy required to increase air exchange rate is often negligible (for example increased exhaust fan duty cycle) the energy to heat the home increases dramatically as heated air is released to the outdoor environment. In order to build a functional ventilation design for a home, factors including thermal comfort, energy costs and pollution build up must all be carefully considered. Recently "smart" ventilation systems have proven to be effective at balancing air flow, energy usage and indoor air quality ${ }^{41}$.

\subsection{Air Monitoring Results: Influence of Stove Operation on Air Pollution Levels} Data populating Table 12 was analyzed in a similar manner as the data reported in Table 9, however, in Table 12 data was filtered to only include periods when the stoves were active. Filtering was accomplished by analyzing stove temperature signatures and choosing threshold temperatures above which stove use was apparent. Data in which the 
stove was off was removed. Participants were not required to use their stove a specific amount of time and as the season progressed warmer weather was more common, and stove use tended to decrease. Table 12 shows larger overall decreases in $\mathrm{PM}_{2.5}$ levels both indoors and outside compared to Table 9. This is to be expected as the magnitude of $\mathrm{PM}_{2.5}$ levels is greater during active stove use. 
Table 11.Median outdoor and indoor $\mathrm{PM}_{2.5}$ pre and post exchange during periods of woodstove operation.

\begin{tabular}{|c|c|c|c|c|c|c|}
\hline \multirow[b]{2}{*}{ Home } & \multicolumn{3}{|c|}{ Median outdoor $\mathrm{PM}_{2.5}\left(\boldsymbol{\mu g} / \mathrm{m}^{3}\right)$} & \multicolumn{3}{|c|}{ Median indoor $\mathrm{PM}_{2.5}\left(\mu \mathrm{g} / \mathrm{m}^{3}\right)$} \\
\hline & $\begin{array}{c}\text { Pre- } \\
\text { exchange }\end{array}$ & $\begin{array}{c}\text { Post- } \\
\text { exchange }\end{array}$ & Change & $\begin{array}{c}\text { Pre- } \\
\text { exchange }\end{array}$ & $\begin{array}{c}\text { Post- } \\
\text { exchange }^{\#}\end{array}$ & Change \\
\hline B-1 & 11.4 & 9.7 & -1.7 & 5.4 & $4.5 / 4.5$ & -0.88 \\
\hline B-2 & 21.6 & 8.3 & -13.3 & 14.1 & $7.7 / 7.0$ & -8.0 \\
\hline B-3 & 7.8 & 3.7 & -4.1 & 8.0 & $5.2 / 5.1$ & -2.8 \\
\hline B-4 & & & & 13.7 & $17.2 / 16.9$ & 3.5 \\
\hline B-5 & 10.5 & 5.2 & -5.4 & 6.4 & $3.7 / 3.6$ & -2.7 \\
\hline B-6 & 14.6 & 9.1 & -5.5 & 7.9 & $7.3 / 7.0$ & -0.62 \\
\hline B-7 & 3.6 & 9.7 & 5.7 & 45.0 & $44.2 / 43.4$ & -0.75 \\
\hline \multicolumn{7}{|l|}{ B-8 } \\
\hline B-10 & 4.7 & 2.9 & -1.7 & 4.5 & $3.8 / 3.3$ & -0.69 \\
\hline B-11 & 5.8 & 6.3 & 0.56 & 4.9 & $3.3 / 2.7$ & -1.6 \\
\hline B-12 & 5.2 & 2.4 & -2.8 & 2.6 & $2.1 / 1.7$ & -0.43 \\
\hline \multicolumn{7}{|l|}{ B-13 } \\
\hline B-14 & 4.1 & 2.4 & -1.8 & 5.3 & $2.7 / 2.7$ & -2.6 \\
\hline B-15 & 3.7 & 2.6 & -1.1 & & & \\
\hline \multicolumn{7}{|l|}{ B-16 } \\
\hline E-31 & 4.3 & 3.1 & -1.1 & 2.8 & $12.5 / 7.6$ & 9.6 \\
\hline E-32 & 25.4 & 4.7 & -21 & 17.9 & $3.6 / 3.7$ & -14.2 \\
\hline E-33 & 4.6 & 6.1 & 1.5 & 4.3 & $6.8 / 6.8$ & 2.5 \\
\hline E-34 & 5.4 & 8.8 & 3.4 & 4.3 & $5.2 / 4.9$ & 0.8 \\
\hline E-35 & 1.9 & 5.1 & 3.2 & 1.1 & $2.3 / 2.3$ & 1.2 \\
\hline $\begin{array}{c}\text { Median } \\
\text { (stove on) }\end{array}$ & 5.41 & 5.18 & -1.74 & 5.34 & $4.83 / 4.7^{\#}$ & $-0.72 /-1.02^{\#}$ \\
\hline Median (all data)* & 4.62 & 4.87 & -0.18 & 4.6 & 4.8 & 0.76 \\
\hline
\end{tabular}

*median of all data is taken from Table 9

\#Second data value excludes the indoor peak observed following installation and first operation of the new stove.

The data reported in Table 12 show that reductions in outdoor $\mathrm{PM}_{2.5}$ occurred for 10 out of 15 households (67\%) when only considering periods of stove use, compared to 9 of 16 households (56\%) when all outdoor data is considered, as in Table 9. For indoor levels of $\mathrm{PM}_{2.5}$, the change is more marked. Twelve of 17 households (71\%) experienced a reduction in absolute levels of indoor $\mathrm{PM}_{2.5}$ post woodstove exchange when considering 
only periods of stove use, compared to only 7 of 17 (41\%) households experiencing a reduction of indoor $\mathrm{PM}_{2.5}$ when all data is considered.

\subsection{Air Monitoring Results: Example Time-series Data (Enhanced Monitoring)}

As discussed in Section 3, five homes opted for "enhanced" monitoring, where additional air monitoring devices were deployed into the homes. Shown below in Figure 7 are results of enhanced monitoring from household E-31. Note the presence of additional metrics of air pollution, including UVPM (an indicator of biomass burning), black carbon, and carbon monoxide.

The enhanced monitoring of E-31 started on 1/21/19 at approximately 12:00pm and continued until 1/25/19 at 2:00pm. The exchange took place on 1/23/19 at 12:00pm. There were two distinct woodstove signatures that occurred before the and after wood stove exchange. Concentrations of exterior particulate matter were much more intense before the wood stove exchange. Very large spikes of black carbon, and UVPM can be seen during the two burn periods before the swap. These particulate signatures decreased drastically during the two burn periods after the swap. This is a good indication that complete and efficient combustion was occurring in the new stove, with possible impact on near-household outdoor air quality conditions.

As noted earlier the first burn of a new wood stove appears to cause a very large indoor particle emission event. This is clearly present in all the particulate measurements. Interestingly this appears to be isolated to the indoor environment as outdoor levels do not rise uncharacteristically. One possible explanation is that this particle emission process is not directly related to combustion, which would be able to exit the chimney, 
but that the emission is related to a process occurring on the exterior surface of the stove as it is heated during the first use.

Additionally, it can be seen that the occurrence of intense carbon monoxide emission events is more likely during pre-exchange sampling. While the data does not give a clear indicator of why this may be it could be theorized that stove door use could be a cause. The residents noted that the new stove burned for a much longer period without having to add wood and tend to the fire. This would result in less stove door opening and exposure to wood smoke.

In contrast to the household E-31, household E-32 received a ductless heat pump. As can be observed in Figure 9, it appears that during the first operation of the heat pump (determined by the temperature sensor which was placed near the outlet of the indoor terminal of the heat pump), there was no indoor peak of particles during first operation, likely due to the lower operating temperature of the air circulating through the indoor terminal of the ductless heat pump. 


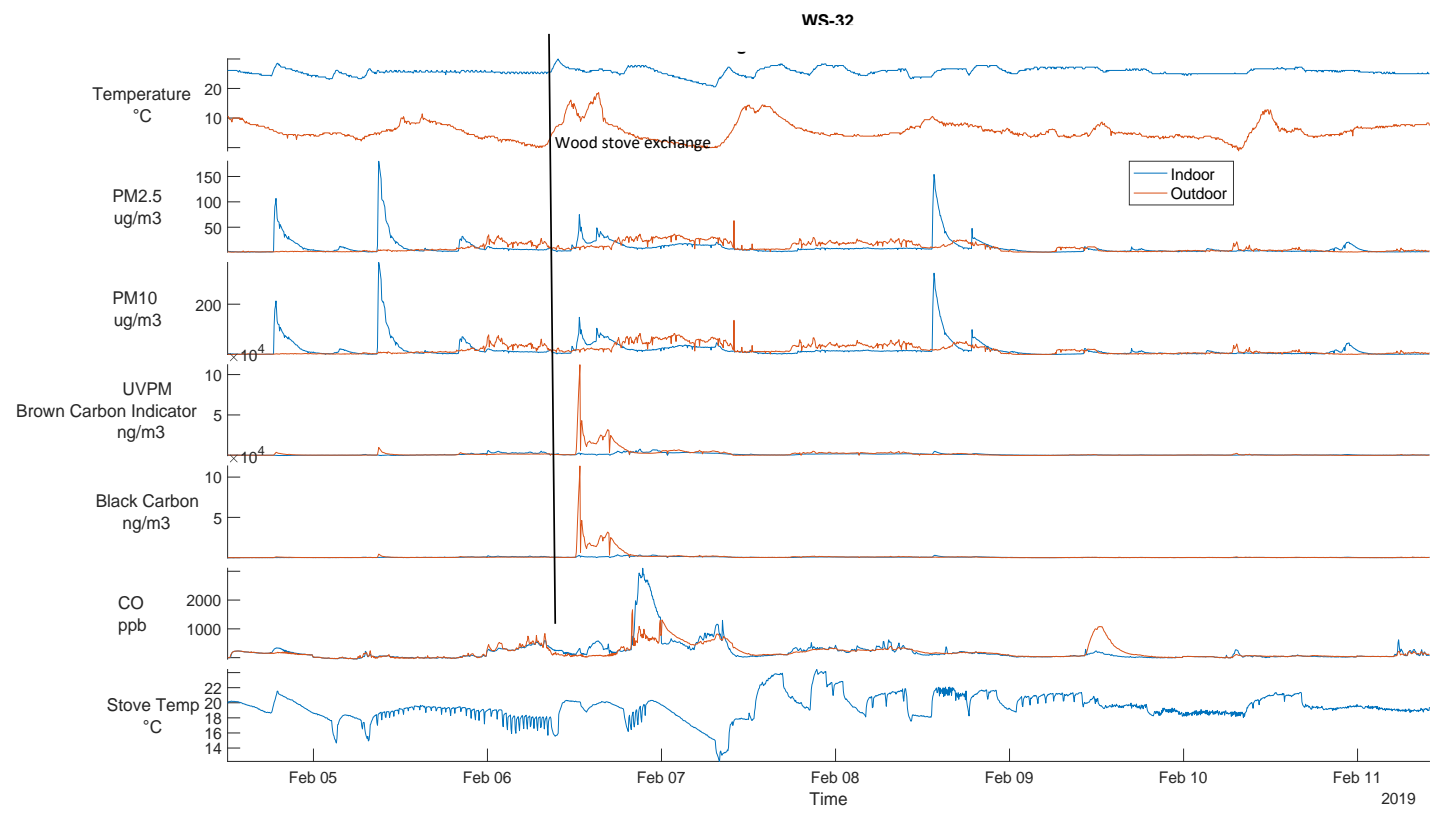

Figure 7. Example of time-series measurements for enhanced monitoring household, E32.

Reported below in Table 12 are the summary results for carbon monoxide for the five households involved in enhanced monitoring. Out of the five houses involved in enhanced monitoring, four had outdoor carbon monoxide levels decrease after the exchange occurred.

Table 12.Magnitudes of measured indoor and outdoor carbon monoxide levels pre and post-exchange.

\begin{tabular}{ccccccc} 
& \multicolumn{3}{c}{ Average Outdoor CO $(\mathbf{p p b})$} & \multicolumn{3}{c}{ Average $\Delta \mathbf{C O}$ (indoors - outdoors) (ppb) } \\
\cline { 2 - 7 } Home & $\begin{array}{c}\text { Pre- } \\
\text { exchange }\end{array}$ & $\begin{array}{c}\text { Post- } \\
\text { exchange }\end{array}$ & $\begin{array}{c}\text { Change } \\
\text { in CO }\end{array}$ & $\begin{array}{c}\text { Pre- } \\
\text { exchange }\end{array}$ & $\begin{array}{c}\text { Post- } \\
\text { exchange }\end{array}$ & $\begin{array}{c}\text { Change in } \\
\Delta \text { CO. }\end{array}$ \\
\hline E-31 & 63.9 & 51.9 & -12.0 & 6.6 & 5.1 & -1.5 \\
E-32 & 172.4 & 107.1 & -65.3 & 116.9 & 27.9 & -89.0 \\
E-33 & 202.8 & 204.0 & 1.1 & -4.6 & 14.2 & 18.8 \\
E-34 & 405.9 & 250.9 & -155 & -149.1 & 1.3 & 150 \\
E-35 & 158.3 & 155.2 & -3.1 & -8.7 & 24.6 & 33.3 \\
\hline Avg. & 200.6 & 153.8 & -46.9 & -7.8 & 14.6 & 22.4 \\
\hline
\end{tabular}


Reported in Table 13 are black carbon summary results for the five households involved in enhanced monitoring. Outdoor black carbon decreased in two of the homes involved in enhanced monitoring. Only one house showed an increase in black carbon. This increase can likely be attributed to the large particulate emission event often observed during the first burn of the new stoves.

Table 13. Magnitudes of measured indoor and outdoor black carbon (BC) levels pre and post-exchange.

\begin{tabular}{ccccccc} 
& \multicolumn{3}{c}{ Average Outdoor BC $\left(\mathbf{n g} / \mathbf{m}^{\mathbf{3}}\right)$} & \multicolumn{3}{c}{ Average $\Delta B C($ indoors - outdoors $)\left(\mathbf{n g} / \mathbf{m}^{3}\right)$} \\
\cline { 2 - 7 } Home & $\begin{array}{c}\text { Pre- } \\
\text { exchange }\end{array}$ & $\begin{array}{c}\text { Post- } \\
\text { exchange }\end{array}$ & $\begin{array}{c}\text { Change } \\
\text { in BC }\end{array}$ & $\begin{array}{c}\text { Pre- } \\
\text { exchange }\end{array}$ & $\begin{array}{c}\text { Post- } \\
\text { exchange }\end{array}$ & $\begin{array}{c}\text { Change } \\
\text { in } \Delta \text { BC. }\end{array}$ \\
\hline E-31 & 328.6 & 158.7 & -170 & -51.2 & 373.8 & 425 \\
E-32 & 3196.3 & 345.9 & -2850 & -2621.6 & -28.3 & 2593 \\
E-33 & 675.2 & 713.4 & 38 & 489.4 & 7.4 & -482 \\
E-34 & 312.6 & 693.7 & 381 & 72.0 & -12.8 & -85 \\
E-35 & 221.2 & 239.2 & 18 & 76.4 & -142.9 & -219 \\
\hline Avg. & 946.8 & 430.1 & -516.6 & -407.0 & 39.4 & 446.5 \\
\hline
\end{tabular}

In Table 14 levels of UVPM are reported for enhanced monitoring households. UVPM is subsequently referred to brown carbon, as UVPM is the optical absorbance at a wavelength associated with products of biomass combustion. Outdoor levels of brown carbon decrease in 4 out of the 5 homes in the enhanced monitoring. One home exhibited no change. Differences between indoor and outdoor levels of brown carbon before and after the wood stove exchange decreased in 3 of the 5 homes. Similar to levels of black carbon it is likely that the increase observed in homes E-31 and E-32 is due to the large particulate emission events observed with the first burn of a new wood stove. 
Table 14. Magnitudes of measured indoor and outdoor brown carbon (BrC, given by UVPM as described in the methods) levels pre and post-exchange.

\begin{tabular}{ccccccc} 
& \multicolumn{2}{c}{ Average Outdoor BrC $\left(\mathbf{n g} / \mathbf{m}^{3}\right)$} & \multicolumn{3}{c}{ Average $\Delta \mathrm{BrC}(\mathbf{i n d o o r s}-$ outdoors) } \\
\cline { 2 - 7 } Home & $\begin{array}{c}\text { Pre- } \\
\text { exchange }\end{array}$ & $\begin{array}{c}\text { Post- } \\
\text { exchange }\end{array}$ & $\begin{array}{c}\text { Change in } \\
\text { Out. BrC. }\end{array}$ & $\begin{array}{c}\text { Pre- } \\
\text { exchange }\end{array}$ & $\begin{array}{c}\text { Post- } \\
\text { exchange }\end{array}$ & $\begin{array}{c}\text { Change } \\
\text { in } \Delta \text { BrC. }\end{array}$ \\
\hline E-31 & 779.4 & 237.4 & -542.0 & -219.3 & 626.3 & 845.7 \\
E-32 & 3611.6 & 736.1 & -2875.5 & -2371.7 & -79.1 & 2292.6 \\
E-33 & 1325.5 & 1325.5 & 0.0 & 373.7 & 152.1 & -221.6 \\
E-34 & 561.7 & 1245.4 & -683.7 & 143.0 & -91.4 & -234.4 \\
E-35 & 397.5 & 382.0 & -15.5 & 686.4 & -162.7 & -849.1 \\
\hline Avg. & 1335.1 & 785.3 & -823.3 & -277.6 & 89.0 & 366.6 \\
\hline
\end{tabular}

\subsection{Bulk Statistical Analysis}

To determine whether differences in $\mathrm{PM}_{2.5}$ pre and post exchange were statistically significant, two tools were used. Standard MATLAB box plots were created to compare pre and post values of $\mathrm{PM}_{2.5}$ and to evaluate normality of distributions. It was determined by the boxplots that the distribution was non-normal. A sign test was then used to determine whether the difference in medians was significant for each nonparametric data set. A statistically significant difference between two medians will result in a p-value less than 0.05. All values in Figure 9 shown below were during periods of stove use. 

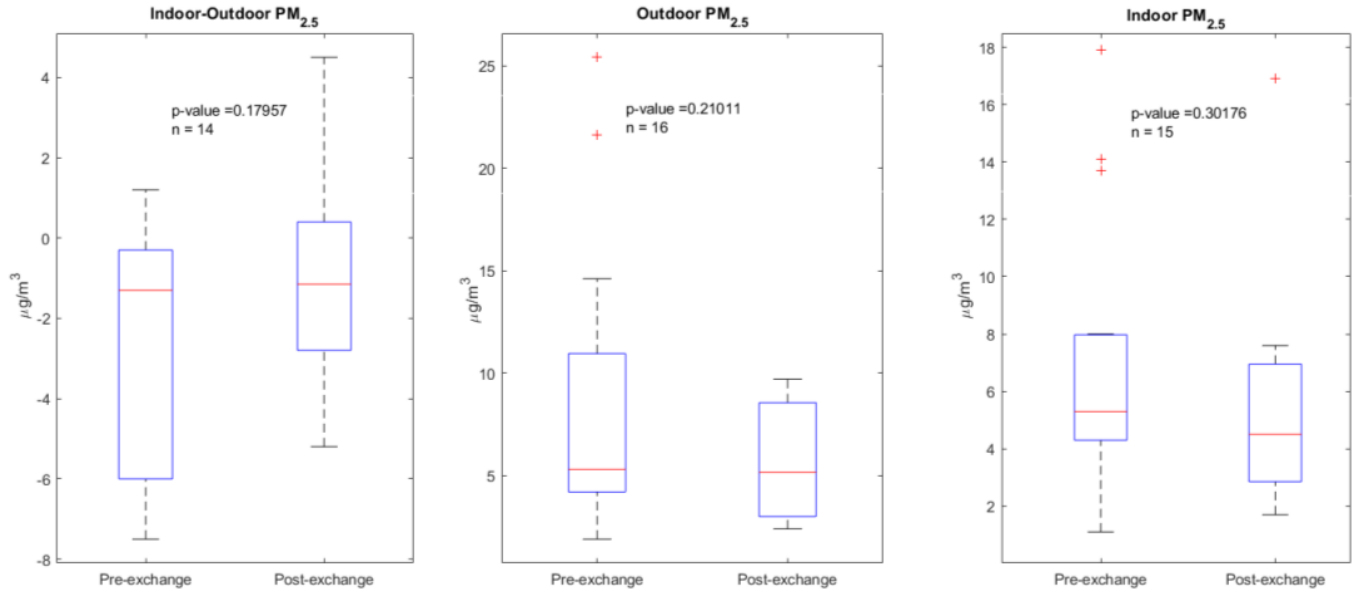

Figure 8. Statistical analysis of PM2.5 medians before and after exchange

In Figure 8, all p-values exceed 0.05 which implies that the difference in median values pre and post exchange, in all comparisons, was not statistically significant. From this it can be deduced that for the homes included in this study, the wood stove exchange program was not an effective means of lowering indoor or local outdoor levels of $\mathrm{PM}_{2.5}$. 


\subsection{Emission Event Source Strength Analysis}

Below is a set of time resolved data for one example home, B-7, during the first burn event there is a very large spike in $\mathrm{PM}_{2.5}$.

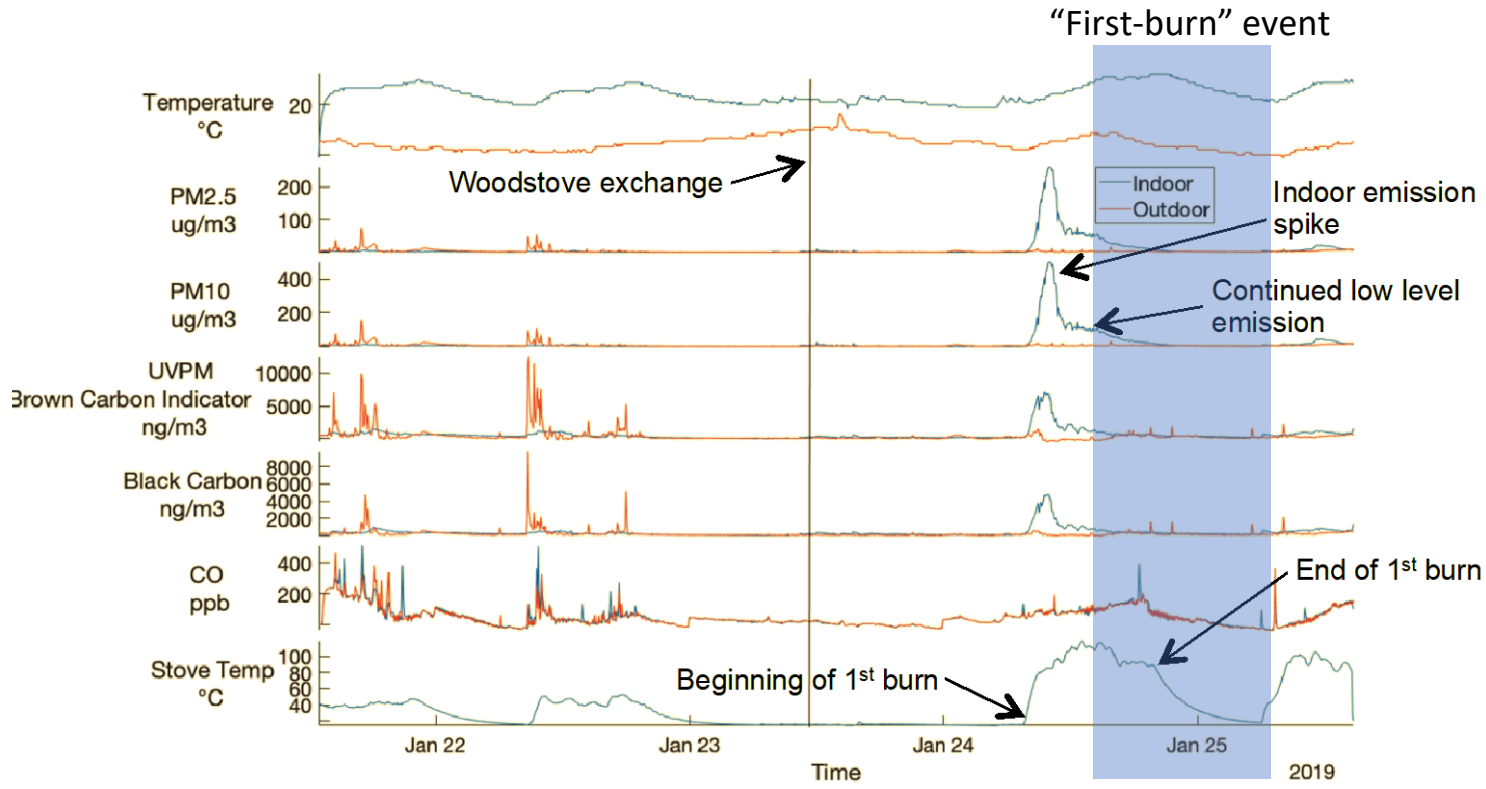

Figure 9. Time resolved data for home B-7. 
Looking closely at the large peak, the non-linear fit, equation 6, was fit to both the injection and the decay period as described in section 3.6.

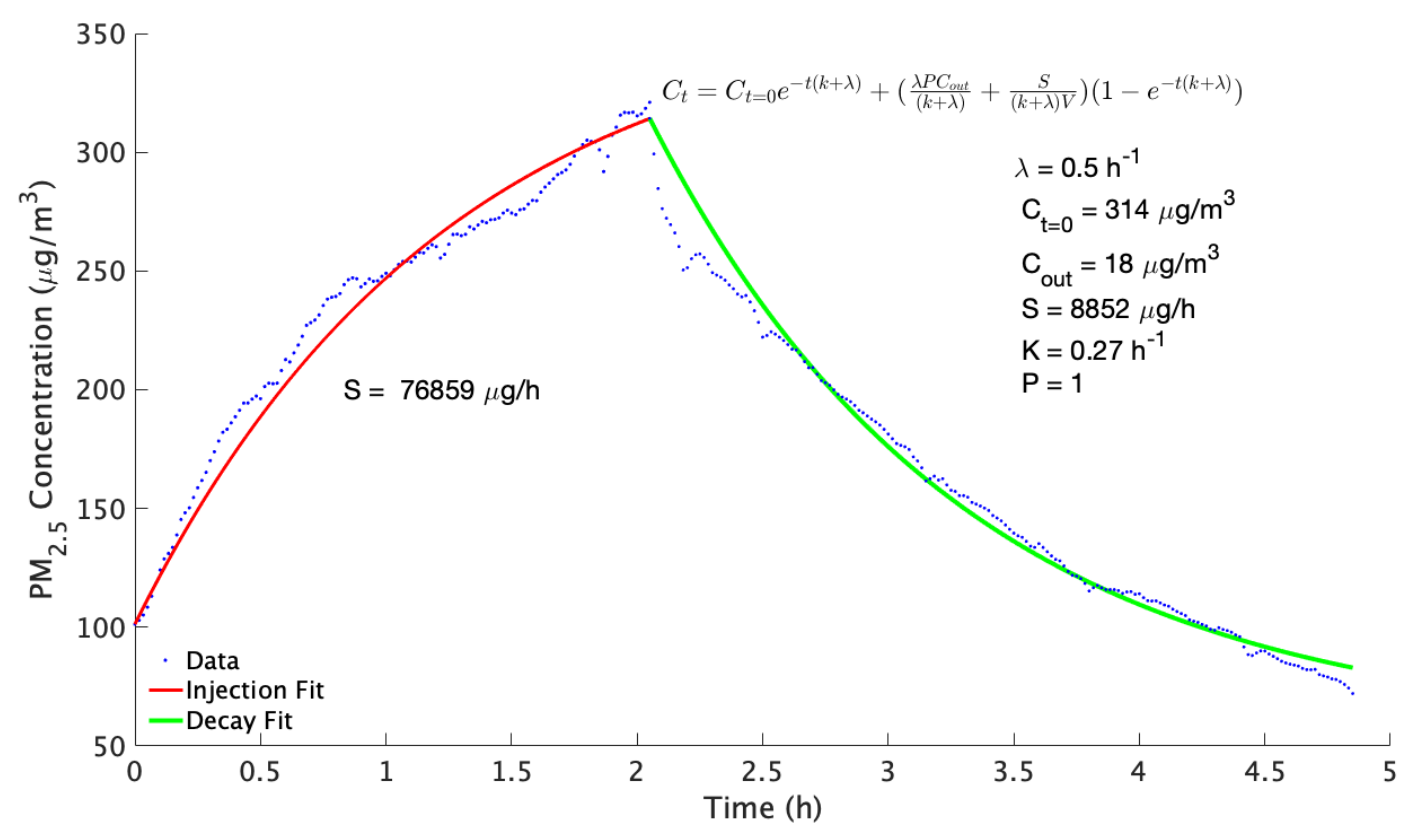

Figure 10. Non-linear curve fit for home B-7.

The value of $S_{2}$, the source during the decay period can solely be attributed to normal stove operation. Figure 9 shows that stove operation continued even after began to decay. This is why it is valid to assume that there is still a source during the decay period.

Even though 13 out of 17 homes with data available showed a large transient peak, only 4 had peaks that were amenable to this type of analysis. Peaks that could not be used had data sets that were too small, or not smooth in their transitions between injection and decay periods. Below are stove source strengths for 4 new woodstoves. The values calculated are considered realistic when compared with literature values of common household activities such as walking, vacuuming and folding laundry ${ }^{42}$. 
Table 15. Fit parameters derived from fitting equation 6 to experimental data.

\begin{tabular}{cccccc} 
Home & $\begin{array}{c}\text { Penetratio } \\
\text { n Factor }\end{array}$ & $\begin{array}{c}\text { Loss } \\
\text { Coefficient K } \\
\left(\mathbf{h r}^{-1}\right)\end{array}$ & $\begin{array}{c}\boldsymbol{\lambda} \\
(\mathbf{h r}\end{array}$ & $\begin{array}{c}\mathbf{S}_{1} \text { Emission Peak Source } \\
\text { Strength (ug/h) }\end{array}$ & $\begin{array}{c}\text { S2 Normal } \\
\text { Operation Source } \\
\text { Strength (ug/h) }\end{array}$ \\
\hline B-6 & 0.23 & 0.27 & 0.5 & 76859 & 10709 \\
B-10 & 0.99 & 0.00 & 0.7 & 20702 & 9432 \\
B-11 & & 1.24 & 0.8 & & 13078 \\
& 0.84 & 1.01 & 0.5 & 71619 & 23304 \\
E-31 & 1.00 & & 3 & 125630 &
\end{tabular}

\subsection{Key Findings}

- $\quad$ Median levels of $\mathrm{PM}_{2.5}$ pre and post-exchange are similar across all homes.

○ Median change in household outdoor $\mathrm{PM}_{2.5}$ was $-0.2 \mu \mathrm{g} / \mathrm{m} 3$ (post minus pre)

○ Median change in indoor $\mathrm{PM}_{2.5}$ was $+0.8 \mu \mathrm{g} / \mathrm{m} 3$ (post minus pre)

○ Median change in indoor $\mathrm{PM}_{2.5}$ was $+0.6 \mu \mathrm{g} / \mathrm{m} 3$ (post minus pre) when excluding peak due to first burn

- For 13 of 17 houses with data available, large transient peaks of $\mathrm{PM}_{2.5}(>100 \mu \mathrm{g} / \mathrm{m} 3$, measured via PurpleAir sensor) were observed following first stove use. Operating the newly installed stove with the home unoccupied for the first burn may be considered.

- Variability in impacts on indoor and household $\mathrm{PM}_{2.5}$ were observed across households.

○ Seven homes experienced reductions in indoor $\mathrm{PM}_{2.5}$ levels post-exchange while ten homes experienced an increase post-exchange $(\Delta: \max +11 \mu \mathrm{g} / \mathrm{m} 3$, min -4 $\mu \mathrm{g} / \mathrm{m} 3)$

- Comparing air quality levels only during periods of woodstove use led to more marked differences when comparing pre and post-exchange impacts. 
- 12 of 17 households had reduced levels of indoor $\mathrm{PM}_{2.5}$ post woodstove exchange when considering only periods of stove use (vs. 7 of 17 when considering all periods)

- The median change in indoor $\mathrm{PM}_{2.5}$ was $-0.72 \mu \mathrm{g} / \mathrm{m} 3$ (post minus pre, stove on only), or $-1.0 \mu \mathrm{g} / \mathrm{m} 3$ when the peak due to first burn is excluded

- Statistical comparison of bulk $\mathrm{PM}_{2.5}$ levels, indoors and outdoors indicates that the wood stove exchange program had negligible impact on the air quality in and around the homes that participated in this study.

- Airtightness is anti-correlated with changes in a proxy of indoor $\mathrm{PM}_{2.5}$ source strength, implying homes with high ventilation removed indoor emissions from the woodstoves. 


\section{Conclusion}

This study aimed to investigate the relationship between woodstove exchange that replaced older, inefficient woodstoves with new heating systems and indoor and household outdoor air quality levels. The investigation primarily focused on particulate matter, with indoor-outdoor $\mathrm{PM}_{2.5}$ measurements made in seventeen out twenty households engaged in the study. Additional measurements include size-resolved particulate matter across the 0.3 - 10 micrometer range, measurements of household airtightness, woodstove temperature as a proxy for stove use, and in select households, optical absorption properties of indoor and outdoor aerosol and indoor and outdoor carbon monoxide levels.

The sample, consisting of twenty households in which measurements were made, constitutes one of the largest studies of indoor and outdoor pre- and post-woodstove exchange air quality measurements conducted to date. Major observations include that the woodstove have a relatively modest impact on absolute magnitudes of household and indoor $\mathrm{PM}_{2.5}$ levels. Median indoor and outdoor levels of $\mathrm{PM}_{2.5}$ pre and post-exchange were similar in magnitude when aggregating across all homes for which data is available. Across all homes, median household outdoor $\mathrm{PM}_{2.5}$ was $0.3 \mu \mathrm{g} / \mathrm{m}^{3}$ lower post-exchange (4.6 vs $4.9 \mu \mathrm{g} / \mathrm{m}^{3}$ ), while indoor $\mathrm{PM}_{2.5}$ levels were $0.3 \mu \mathrm{g} / \mathrm{m}^{3}$ higher post-exchange $(4.3$ vs $\left.4.7 \mu \mathrm{g} / \mathrm{m}^{3}\right)$.

There existed substantial variability and mixed effects in the observations on indoor and household $\mathrm{PM}_{2.5}$ pre and post woodstove exchange observed across the sample of homes. While aggregate differences were small as noted above, seven homes experienced 
reductions in indoor $\mathrm{PM}_{2.5}$ levels post-exchange while ten homes experienced an increase in indoor $\mathrm{PM}_{2.5}$ post-exchange. One household experienced an $11 \mu \mathrm{g} / \mathrm{m}^{3}$ increase in indoor $\mathrm{PM}_{2.5}$ post-exchange (though it should be noted that occupants smoked cigarettes inside this household) while another house experienced a $4 \mu \mathrm{g} / \mathrm{m}^{3}$ decrease. Attribution of these effects solely to the woodstove is difficult, however, since ambient regional background $\mathrm{PM}_{2.5}$ changed over the course of the study and the households and neighborhoods themselves were dynamic and uncontrolled in this observational study.

In an attempt to better isolate the effect of the woodstove, we compared air quality levels only during periods of stove use, as indicated by an installed stove surface temperature monitor. Pre- and post-exchange comparisons of for only periods when the old and new stoves were operating led to more marked differences when comparing pre and post-exchange impacts. For this analysis, 12 of 17 households had reduced levels of indoor $\mathrm{PM}_{2.5}$ post woodstove exchange when considering only periods of stove use (vs. 7 of 17 when considering all periods). The median change in indoor $\mathrm{PM}_{2.5}$ post-exchange was also affected. When only considering periods of stove operation, absolute magnitudes of indoor $\mathrm{PM}_{2.5}$ post-exchange were $0.8 \mu \mathrm{g} / \mathrm{m}^{3}$ lower than pre-exchange, compared with a $0.6 \mu \mathrm{g} / \mathrm{m}^{3}$ increase post-exchange when all time periods are considered.

We observed substantial indoor emission events of particles during the new woodstove's first use. For 13 of 17 houses with data available, large transient peaks of $\mathrm{PM}_{2.5}\left(>100 \mu \mathrm{g} / \mathrm{m}^{3}\right)$ were observed following first stove use. Of the four houses not 
experiencing a peak, two received pellet stoves (which reach lower surface temperatures than wood burning stoves) and one received a ductless heat pump. It is recommended that the installed stove be operated with the home unoccupied for the first burn, if possible. This emission event is generally not observed on subsequent stove use periods, thus we speculate that this first-burn indoor emission event is the result of an emission from heating of the surface finishing on the new woodstove.

Finally, we used measured metrics of airtightness, in this case, the normalized leakage area, determined from data acquired with a depressurization blower door test of each home, to explain variance in indoor-outdoor air pollution relationships. We observed that the normalized leakage areas of homes are strongly anti-correlated $\left(\mathrm{r}^{2}=\right.$ 0.89 ) with measured changes in a proxy of indoor $\mathrm{PM}_{2.5}$ source strength. We speculate that this indicates that high ventilation was protective of indoor emissions from the woodstove, most likely a result of higher ventilation and thus removal of indoor $\mathrm{PM}_{2.5}$ originating from the "first burn" emission event noted previously. We suspect this firstburn emission event is an important driver of this observed relationship since the median values of pre- and post-exchange indoor $\mathrm{PM}_{2.5}$ indicated that the woodstove was not a primary determinant of indoor $\mathrm{PM}_{2.5}$ levels.

Reduction of $\mathrm{PM}_{2.5}$ exposure is a concern in Washington County as the winter-time particulate matter levels often surpasses the threshold of "healthy air" as defined by the Oregon Department of Environmental Quality. Woodstove exchange programs have been shown to be effective in improving regional air quality, but there is less research showing their impact on the specific indoor environments. This study attempted to answer the 
question of what if any impact does a wood stove exchange program have on the indoor air quality. It was found that there was very little reduction in $\mathrm{PM}_{2.5}$ within the homes. In general people with less time averaged exposure have improved health outcomes compared to people with high levels of exposure ${ }^{43}$. This study implies that for significant reduction in $\mathrm{PM}_{2.5}$ within a home, methods other than a wood stove exchange should be used. 


\section{Limitations and Future Work}

\subsection{Limitations}

There are a few factors that made this work challenging. Originally during home recruitment it was expected that we would have more than 20 homes participate in this study. Unfortunately, the 2018-19 heating season was the shortest heating season since the start of the Washington County Wood Stove Exchange season. Colder temperatures did not arrive until November 2018, one month later than expected, and warmer temperatures returned much earlier than typical in years past. This reduced the number of applicants to 104 as compared to 150 from the two previous seasons. Not only did the short heating season reduce overall applicants it made it difficult to collect long sets of data which would have better outlined stove effect and eased comparison between homes.

Additional data was lost due to household disturbances. Sensors would be unplugged or misplaced during data collection periods. Even though the majority of the instruments in the sampling suite were functional, if one was missing it became hard to do comparative measurements, and the depth of analysis in a particular house was diminished.

\subsection{Future Work}

Future analysis is necessary to gain a more quantitative conclusion of stove particulate source strengths. While newer more efficient stoves theoretically result in more complete combustion and less particulate emission, homeowner stove use habits can result in large emission events in the home. Each individual house could have pre and 
post source strength analysis performed to better understand the wood stove exchange impact on air quality on a house by house basis. 


\section{References}

(1) EIA. Residential Energy Consumption Survey (RECS) - Data - U.S. Energy Information Administration (EIA) https://www.eia.gov/consumption/residential/data/2009/ (accessed Jan 15, 2018).

(2) US EPA, O. Burn Wise - Changeout Guide https://www.epa.gov/burnwise/burnwise-changeout-guide (accessed Jan 15, 2018).

(3) Semmens, E. O.; Noonan, C. W.; Allen, R. W.; Weiler, E. C.; Ward, T. J. Indoor Particulate Matter in Rural, Wood Stove Heated Homes. Environ Res 2015, 138, 93-100. https://doi.org/10.1016/j.envres.2015.02.005.

(4) Iii, C. A. P.; Burnett, R. T.; Thun, M. J.; Calle, E. E.; Krewski, D.; Ito, K.; Thurston, G. D. Lung Cancer, Cardiopulmonary Mortality, and Long-Term Exposure to Fine Particulate Air Pollution. JAMA 2002, 287 (9), 1132-1141. https://doi.org/10.1001/jama.287.9.1132.

(5) Anderson, J. O.; Thundiyil, J. G.; Stolbach, A. Clearing the Air: A Review of the Effects of Particulate Matter Air Pollution on Human Health. J. Med. Toxicol. 2012, 8 (2), 166-175. https://doi.org/10.1007/s13181-011-0203-1.

(6) Stölzel, M.; Breitner, S.; Cyrys, J.; Pitz, M.; Wölke, G.; Kreyling, W.; Heinrich, J.; Wichmann, H.-E.; Peters, A. Daily Mortality and Particulate Matter in Different Size Classes in Erfurt, Germany. Journal of Exposure Science \& Environmental Epidemiology 2007, 17 (5), 458-467. https://doi.org/10.1038/sj.jes.7500538.

(7) Utell, M. J.; Frampton, M. W.; Zareba, W.; Devlin, R. B.; Cascio, W. E. Cardiovascular Effects Associated with Air Pollution: Potential Mechanisms and Methods of Testing. Inhalation Toxicology 2002, 14 (12), 1231-1247. https://doi.org/10.1080/08958370290084881.

(8) Klepeis, N. E.; Nelson, W. C.; Ott, W. R.; Robinson, J. P.; Tsang, A. M.; Switzer, P.; Behar, J. V.; Hern, S. C.; Engelmann, W. H. The National Human Activity Pattern Survey (NHAPS): A Resource for Assessing Exposure to Environmental Pollutants. Journal of Exposure Science \& Environmental Epidemiology 2001, 11 (3), 231-252. https://doi.org/10.1038/sj.jea.7500165.

(9) Riley, W. J.; McKone, T. E.; Lai, A. C. K.; Nazaroff, W. W. Indoor Particulate Matter of Outdoor Origin: Importance of Size-Dependent Removal Mechanisms. Environ. Sci. Technol. 2002, 36 (2), 200-207. https://doi.org/10.1021/es010723y.

(10) US EPA, O. Particulate Matter (PM) Pollution https://www.epa.gov/pm-pollution (accessed Feb 4, 2018).

(11) Laumbach, R. J.; Kipen, H. M. Respiratory Health Effects of Air Pollution: Update on Biomass Smoke and Traffic Pollution. Journal of Allergy and Clinical Immunology 2012, 129 (1), 3-11. https://doi.org/10.1016/j.jaci.2011.11.021.

(12) Ward, T.; Noonan, C. Results of a Residential Indoor PM2.5 Sampling Program before and after a Woodstove Changeout. Indoor Air 2008, 18 (5), 408-415. https://doi.org/10.1111/j.1600-0668.2008.00541.x.

(13) Ward, T.; Boulafentis, J.; Simpson, J.; Hester, C.; Moliga, T.; Warden, K.; Noonan, C. Lessons Learned from a Woodstove Changeout on the Nez Perce Reservation. Science of The Total Environment 2011, 409 (4), 664-670. https://doi.org/10.1016/j.scitotenv.2010.11.006. 
(14) Noonan, C. W.; Navidi, W.; Sheppard, L.; Palmer, C. P.; Bergauff, M.; Hooper, K.; Ward, T. J. Residential Indoor PM2.5 in Wood Stove Homes: Follow-up of the Libby Changeout Program. Indoor Air 2012, 22 (6), 492-500. https://doi.org/10.1111/j.1600-0668.2012.00789.x.

(15) Noonan, C. W.; Ward, T. J.; Navidi, W.; Sheppard, L. A Rural Community Intervention Targeting Biomass Combustion Sources: Effects on Air Quality and Reporting of Children's Respiratory Outcomes. Occup Environ Med 2012, 69 (5), 354-360. https://doi.org/10.1136/oemed-2011-100394.

(16) Ward, T. J.; Palmer, C. P.; Houck, J. E.; Navidi, W. C.; Geinitz, S.; Noonan, C. W. Community Woodstove Changeout and Impact on Ambient Concentrations of Polycyclic Aromatic Hydrocarbons and Phenolics. Environ. Sci. Technol. 2009, 43 (14), 5345-5350. https://doi.org/10.1021/es8035253.

(17) Ward, T. J.; Palmer, C. P.; Noonan, C. W. Fine Particulate Matter Source Apportionment Following a Large Woodstove Changeout Program in Libby, Montana. Journal of the Air \& Waste Management Association 2010, 60 (6), 688693. https://doi.org/10.3155/1047-3289.60.6.688.

(18) Bergauff, M. A.; Ward, T. J.; Noonan, C. W.; Palmer, C. P. The Effect of a Woodstove Changeout on Ambient Levels of PM2.5 and Chemical Tracers for Woodsmoke in Libby, Montana. Atmospheric Environment 2009, 43 (18), 29382943. https://doi.org/10.1016/j.atmosenv.2009.02.055.

(19) Ward, T. J.; Palmer, C. P.; Bergauff, M.; Jayanty, R. K. M.; Noonan, C. W. Organic/Elemental Carbon and Woodsmoke Tracer Concentrations Following a Community Wide Woodstove Changeout Program. Atmospheric Environment 2011, 45 (31), 5554-5560. https://doi.org/10.1016/j.atmosenv.2011.05.005.

(20) Ward, T. J.; Palmer, C. P.; Hooper, K.; Bergauff, M.; Noonan, C. W. The Impact of a Community-Wide Woodstove Changeout Intervention on Air Quality within Two Schools. Atmospheric Pollution Research 2013, 4 (2), 238-244. https://doi.org/10.5094/APR.2013.025.

(21) Allen, R. W.; Leckie, S.; Millar, G.; Brauer, M. The Impact of Wood Stove Technology Upgrades on Indoor Residential Air Quality. Atmospheric Environment 2009, 43 (37), 5908-5915. https://doi.org/10.1016/j.atmosenv.2009.08.016.

(22) Ward, T. J.; Semmens, E. O.; Weiler, E.; Harrar, S.; Noonan, C. W. Efficacy of Interventions Targeting Household Air Pollution from Residential Wood Stoves. Journal of Exposure Science and Environmental Epidemiology 2017, 27 (1), 64. https://doi.org/10.1038/jes.2015.73.

(23) Giles Luisa V.; Barn Prabjit; Künzli Nino; Romieu Isabelle; Mittleman Murray A.; van Eeden Stephan; Allen Ryan; Carlsten Chris; Stieb Dave; Noonan Curtis; Smargiassi Audrey; Kaufman Joel D.; Hajat Shakoor; Kosatsky Tom; Brauer Michael. From Good Intentions to Proven Interventions: Effectiveness of Actions to Reduce the Health Impacts of Air Pollution. Environmental Health Perspectives 2011, 119 (1), 29-36. https://doi.org/10.1289/ehp.1002246.

(24) Wheeler, A. J.; Gibson, M. D.; MacNeill, M.; Ward, T. J.; Wallace, L. A.; Kuchta, J.; Seaboyer, M.; Dabek-Zlotorzynska, E.; Guernsey, J. R.; Stieb, D. M. Impacts of Air Cleaners on Indoor Air Quality in Residences Impacted by Wood Smoke. 
Environ. Sci. Technol. 2014, 48 (20), 12157-12163.

https://doi.org/10.1021/es503144h.

(25) Allen, R. W.; Leckie, S.; Millar, G.; Brauer, M. The Impact of Wood Stove Technology Upgrades on Indoor Residential Air Quality. Atmospheric

Environment 2009, 43 (37), 5908-5915. https://doi.org/10.1016/j.atmosenv.2009.08.016.

(26) Singer, B. C.; Delp, W. W. Response of Consumer and Research Grade Indoor Air Quality Monitors to Residential Sources of Fine Particles. Indoor Air 2018, 28 (4), 624-639. https://doi.org/10.1111/ina.12463.

(27) Magi, B. I.; Cupini, C.; Francis, J.; Green, M.; Hauser, C. Evaluation of PM2.5 Measured in an Urban Setting Using a Low-Cost Optical Particle Counter and a Federal Equivalent Method Beta Attenuation Monitor. Aerosol Science and Technology 2019, 0 (ja), 1-14. https://doi.org/10.1080/02786826.2019.1619915.

(28) Ruiz-Mercado, I.; Canuz, E.; Smith, K. R. Temperature Dataloggers as Stove Use Monitors (SUMs): Field Methods and Signal Analysis. Biomass and Bioenergy 2012, 47, 459-468. https://doi.org/10.1016/j.biombioe.2012.09.003.

(29) ASTM. Test Method for Determining Air Leakage Rate by Fan Pressurization; ASTM International, 2003. https://doi.org/10.1520/E0779-19.

(30) Hansen, A. D. A.; Rosen, H.; Novakov, T. The Aethalometer - An Instrument for the Real-Time Measurement of Optical Absorption by Aerosol Particles. Science of The Total Environment 1984, 36, 191-196. https://doi.org/10.1016/00489697(84)90265-1.

(31) Drinovec, L.; Močnik, G.; Zotter, P.; Prévôt, A. S. H.; Ruckstuhl, C.; Coz, E.; Rupakheti, M.; Sciare, J.; Müller, T.; Wiedensohler, A.; Hansen, A. D. A. The "Dual-Spot" Aethalometer: An Improved Measurement of Aerosol Black Carbon with Real-Time Loading Compensation. Atmospheric Measurement Techniques 2015, 8 (5), 1965-1979. https://doi.org/10.5194/amt-8-1965-2015.

(32) Caubel, J.; Cados, T.; Kirchstetter, T.; Caubel, J. J.; Cados, T. E.; Kirchstetter, T. W. A New Black Carbon Sensor for Dense Air Quality Monitoring Networks. Sensors 2018, 18 (3), 738. https://doi.org/10.3390/s18030738.

(33) Wang, Q.; Han, Y.; Ye, J.; Liu, S.; Pongpiachan, S.; Zhang, N.; Han, Y.; Tian, J.; Wu, C.; Long, X.; Zhang, Q.; Zhang, W.; Zhao, Z.; Cao, J. High Contribution of Secondary Brown Carbon to Aerosol Light Absorption in the Southeastern Margin of Tibetan Plateau. Geophysical Research Letters 2019, 46 (9), 4962-4970. https://doi.org/10.1029/2019GL082731.

(34) The Energy Conservatory. Minneapolis Blower Door Operation Manual for Model 3 and Model 4 Systems; 2012.

(35) Sherman, M.; Dickerhoff, D. Air Tightness of U.S. Dwellings $\mid$ Energy Technologies Area; LBL-35700; 1994.

(36) Gall, E. T.; Chueng, T.; Schiavon, S.; Nazaroff, W. W. Real-Time Measurement of Personal Exposures to Carbon Dioxide in Singapore. In Proceedings of Indoor Air 2016; Ghent, Belgium, 2016; p Paper 508.

(37) Nazaroff, W. W.; Cass, G. R. Mathematical modeling of chemically reactive pollutants in indoor air https://pubs.acs.org/doi/pdf/10.1021/es00151a012 (accessed Jun 9, 2020). https://doi.org/10.1021/es00151a012. 
(38) Levy Zamora, M.; Xiong, F.; Gentner, D.; Kerkez, B.; Kohrman-Glaser, J.; Koehler, K. Field and Laboratory Evaluations of the Low-Cost Plantower Particulate Matter Sensor. Environ. Sci. Technol. 2019, 53 (2), 838-849. https://doi.org/10.1021/acs.est.8b05174.

(39) Stephens, B.; Carter, E. M.; Gall, E. T.; Earnest, C. M.; Walsh, E. A.; Hun, D. E.; Jackson, M. C. Home Energy-Efficiency Retrofits. Environ Health Perspect 2011, 119 (7), a283-a284. https://doi.org/10.1289/ehp.1103621.

(40) Building Energy Codes. Buidling Energy Code Resource Guide Air Leakage Guide; PNNL-SA-82900; U.S. Department of Energy, 2011.

(41) Guyot, G.; Sherman, M. H.; Walker, I. S. Smart Ventilation Energy and Indoor Air Quality Performance in Residential Buildings: A Review. Energy and Buildings 2018, 165, 416-430. https://doi.org/10.1016/j.enbuild.2017.12.051.

(42) Ferro, A. R.; Kopperud, R. J.; Hildemann, L. M. Source Strengths for Indoor Human Activities That Resuspend Particulate Matter. Environ. Sci. Technol. 2004, 38 (6), 1759-1764. https://doi.org/10.1021/es0263893.

(43) Kloog, I.; Ridgway, B.; Koutrakis, P.; Coull, B. A.; Schwartz, J. D. Long- and Short-Term Exposure to PM2.5 and Mortality. Epidemiology 2013, 24 (4), 555561. https://doi.org/10.1097/EDE.0b013e318294beaa. 


\section{Appendix A: Quality assurance and quality control, supplemental information.}

\section{Calibration and Data Quality Criteria for Monitoring Devices}

Instruments used in this study followed the calibration criteria shown in Table1 and other relevant quality assurance/quality control information is provided in Tables A-2 and A-3. Low-cost light-scattering instruments (in this acse, PurpleAir PA-II sensors) required assessment and determination of acceptable correlation coefficient, as these instruments do not have an available EPA standard protocol established for use. For the purposes of this study, we assume an acceptable level of specification for calibration is a coefficient of determination of at least 0.80 . Other instruments used in this study followed standard protocols implemented previously by Oregon Department for Environmental Quality or the U.S. EPA.

Table A-1. Calibration Criteria for Monitoring Devices

\begin{tabular}{|c|c|c|c|}
\hline Parameter & Calibration & Frequency & Spec \\
\hline $\begin{array}{c}\text { PM } \\
\text { estimates } \\
\text { via } \\
\text { PurpleAir } \\
\end{array}$ & $\begin{array}{c}\text { Field co-location } \\
\text { and calibration as } \\
\text { described in Section } \\
3.3 \\
\end{array}$ & $\begin{array}{l}\text { Start of project or } \\
\text { every six months }\end{array}$ & Correlation coefficient $>0.80$ \\
\hline Stove Temp & $\begin{array}{r}\text { One-point } \\
\text { temperature } \\
\text { audit } \\
\end{array}$ & annually & $<+2^{\circ} \mathrm{C}$ \\
\hline $\mathrm{CO}$ & Multi-Point Span & $\begin{array}{c}\text { Start of } \\
\text { monitoring } \\
\text { or once per } \\
\text { year. }\end{array}$ & $\begin{array}{c}\text { Span : range } 0.5-5 \mathrm{ppm} \\
<+10.1 \% \text { (percent difference) } \\
\text { Zero: drift }<+0.41 \mathrm{ppm}(24 \mathrm{hr}),<+ \\
0.61 \mathrm{ppm}(>24 \mathrm{hr}-14 \text { day }), \text { Span drift } \\
<+10.1 \\
\%\end{array}$ \\
\hline $\begin{array}{l}\text { Black } \\
\text { Carbon }\end{array}$ & $\begin{array}{l}\text { Multi-point Flow } \\
\text { Verification Optical } \\
\text { calibration by } \\
\text { Vendor }\end{array}$ & $\begin{array}{c}\text { Start of } \\
\text { monitoring } \\
\text { or once per } \\
\text { year. When } \\
\text { new, or } \\
\text { when } \\
\text { needed. }\end{array}$ & $\begin{array}{l}5 \mathrm{lpm} \pm 10 \% \text { design flow } \\
\pm 10 \% \text { design audit flow }\end{array}$ \\
\hline
\end{tabular}


Table A-2. Calibration Criteria for Monitoring Devices

\begin{tabular}{|c|c|c|c|c|c|}
\hline Parameter & $\begin{array}{l}\text { Reporting } \\
\text { Units }\end{array}$ & Zero & Precision & $\underset{*}{\operatorname{Accuracy}}(\mathbf{B i a s})$ & Data Completeness** \\
\hline $\mathrm{CO}$ & $\operatorname{ppm}(\mathrm{V})$ & $\begin{array}{c}<24 \mathrm{hrs}=0.4 \\
1-14 \text { days }=6.1\end{array}$ & $< \pm 10.1 \%$ & $< \pm 10.1 \%$ & $>75 \%$ of minutes for hourly average. \\
\hline $\mathrm{BC}$ & $1 \mathrm{pm}$ & $\begin{array}{c}\text { Lk Check= } \\
1.0\end{array}$ & $< \pm 10.1 \%$ & $< \pm 10.1 \%$ & $>75 \%$ of hours for daily average. \\
\hline $\mathrm{PM}_{2.5}$ est. & $(-)$ & & & & $>85 \%$ of hours per sampling period \\
\hline
\end{tabular}

To comply with PSU Institutional Review Board policies, approval of the deployment of the location of instrumentation was required by the homeowner, including whether the researcher's preferred location was acceptable to the homeowner. While we discussed the need for particular locations for sampling devices with each homeowner, ultimately, a site-specific decision was made in consultation with the homeowner regarding the placement of each sensor.

$\mathrm{PM}_{2.5}$ Continuous Sensors (PurpleAir and Aethalometer)

Outdoor siting criteria When siting a visibility monitor that uses a probe, the probe should be located from 2 to $15 \mathrm{~m}$ above the ground. The probe is to be more than $1 \mathrm{~m}$ vertically and horizontally away from any supporting structure, and at least $2 \mathrm{~m}$ from any nearby small obstructions (poles, pipes, cables, etc.), or other sampler or probe intakes. The distance between the probe and any obstacle that protrudes above the probe must be more than twice the height that the obstruction extends above the probe. The probe should be located a minimum of $20 \mathrm{~m}$ from any shrubs or trees. The probe must have an unrestricted airflow of at least $270^{\circ}$ and this arc shall include the predominant wind directions. There shall be no micro scale sources of any pollutant within $100 \mathrm{~m}$ of the probe. Visibility monitors requiring 
clear lines of sight (telephotometers) should have several targets (mountains or other permanent landmarks) visible from the same vantage point (site) and at varying distances (3 to $50 \mathrm{~km}$ ) from the site. This requires an open field of view in at least one direction. There should be no micro scale sources of any pollutant within $100 \mathrm{~m}$ of the monitor and no sources of any visible pollutant within $100 \mathrm{~m}$ (on either side) of a centerline running from the monitor to the target. Note that the aethalometer was placed inside and a sample line was run through an installed, insulated fenestration in an available window.

Indoor siting criteria

Siting of continuous sensors in indoor environments required relaxation of the guidelines articulated previously for outdoor siting of $\mathrm{PM}_{2.5}$ continuous sensors due to the presence of indoor surfaces, finishings, and occupants. For PurpleAir monitors, we prioritized a location with an unobstructed view of the living room, and installed the PurpleAir sensors with 3M hook mounts to a wall. For the Aethaloemter, we ran a half-inch line of conductive tubing (provided by Magee Scientific) to the center of the living room. Both sensors were installed to collect a sample at approximately breathing height $(\sim 1.5-2 \mathrm{~m})$.

\section{Carbon Monoxide (CO) Sensors}

Outdoor siting criteria

If the site is a city street canyon and the desired measurement scale is micro scale, the probe intake must be located $3 \pm 0.5$ meters $(\mathrm{m})$ above the ground. The probe inlet was at least one meter horizontally or vertically away from any supporting structures. The probe intake shall be at least $2 \mathrm{~m}$ from any small local obstruction such as a pipe or pole, and at least $2 \mathrm{~m}$ from any other sampler probe intake. The major concern with trees and shrubs 
is their ability to alter normal wind flow patterns. In situations where trees or shrubs could be considered an obstruction (this is particularly true of large coniferous trees), the distance between the trees or shrubs shall be either at least 20 meters or twice the height that the tree protrudes above the sampler intake, whichever is greater. The distance between the probe and any large obstruction higher than the probe must be more than twice the height that the obstruction extends above the probe. For micro scale stations, no trees or shrubs should be located between the probe inlet and the road. The sampler must have an unrestricted airflow in at least a $270^{\circ}$ arc around the sampler, unless the probe is in an urban street canyon. The arc must include the predominant wind directions for the season of maximum concentration. If the probe is used in an urban street canyon and is attached to the side of a building, it must have an unrestricted airflow of $180^{\circ}$. For street traffic micro scale monitoring, the probe must be 2 to $10 \mathrm{~m}$ from the roadway and at least $10 \mathrm{~m}$ from an intersection. A mid-block location is preferred. Sites set up to monitor CO from wood-fired residential heating should be classed as neighborhood and sited accordingly. See 40 CFR Part 58, Appendix E, for more detailed siting considerations.

\section{Indoor siting criteria}

Siting of carbon monoxide sensors in indoor environments required relaxation of the guidelines articulated previously for outdoor siting of the sensors due to the presence of indoor surfaces, finishings, and occupants. For the carbon monoxide monitor, we ran a half-inch line of conductive tubing (provided by Magee Scientific) to the center of the living room. Both sensors were installed to collect a sample at approximately breathing height ( 1.5-2 m). 
Gravimetric sampling

When monitoring for indoor gravimetric measurements of $\mathrm{PM}_{2.5}$ with a low volume sampler, it is important to select a site or sites where the collected particulate mass is representative of the monitored area. Optimum placement of the sampling inlet for $\mathrm{PM}_{2.5}$ is at breathing height level. However, practical factors such as prevention of vandalism, security, and safety precautions must also be considered. The sampler location was prioritized to be placed in the living room, away from any furnace or incineration flues. Collocated samplers (i.e. deployed PurpleAir sensors) must be at least $2 \mathrm{~m}$, but not greater than $4 \mathrm{~m}$, away from each other. Samplers should be located at least $20 \mathrm{~m}$ from the dripline of the nearest trees, but must be 10 meters from the dripline when it acts as an obstruction. The sampler must be located away from obstacles such as buildings, so that the distance between the obstacle and the sampler is at least two times the height that the obstacle protrudes above the sampler. There must be unrestricted airflow in an arc of at least $270^{\circ}$ around the sampler. The predominant wind direction for the season or project with the greatest pollutant concentration potential must be included in the $270^{\circ}$ unrestricted arc. These include accessibility under all weather conditions, availability of adequate electricity, and the security of the monitoring personnel and equipment. The sampler must be situated where the operator can reach it safely despite adverse weather conditions. If the sampler is located on a rooftop, care should be taken that the operator's personal safety is not jeopardized by a slippery roof surface. The lack of suitable power source can often result in the loss of many samples because of power interruptions or fluctuations. To ensure that adequate power is available, consult the manufacturer's instruction manual for the sampler's minimum voltage and power requirements. 
Flow rate measurement quality assurance

For instruments that monitor flow, a flow rate audit will be performed a minimum of every quarter. The audit is made by measuring the analyzer's normal operating flow rate using a certified flow rate transfer standard. The flow rate standard used for auditing may not be the same flow rate standard used to calibrate the analyzer. However, both the calibration standard and the audit standard shall be referenced to the same primary flow rate or volume standard. Flowrates will be monitored with a primary flow calibrator (Sensidyne, Gilibrator 2) with calibration certificate performed less than 2 years prior to a given flow rate audit.

\section{Data management}

The following section will identify the processes and procedures that are to be followed to acquire, transmit, transform, reduce, analyze, store, and retrieve data. These processes and procedures will maintain the data integrity and validity through application of the identified data custody protocols.

Much of the data to be collected for this project will be recorded electronically. To accomplish this, the monitoring site will be equipped with a Campbell Scientific CR1000 data logger and controller operating Windows 10. A data logger will be set up to record each monitor's output, perform specific data manipulations, and format the resulting data in preparation for downloading to a database or spreadsheet. Some instruments, such as PurpleAir sensors used in this study, require that on-board data storage be used, as they cannot be easily interfaced with a central data logging and acquisition system. 
Data that require manual entry, such as those obtained from the gravimetric sampler, are recorded onto a laboratory notebook and uploaded to a secure, electronic database.

Note that all data management requires encoding of household identifiers according to an anonymized code to ensure compliance with the IRB protocol approved by Portland State University.

Continuous data will be generated by the monitors and stored at the site on the Campbell Scientific data logger. Prior to the woodstove exchange and after the 


\section{Calibration certificate for carbon monoxide monitor}

\begin{tabular}{|c|c|c|c|}
\hline \multicolumn{2}{|c|}{$\underset{\text { Air Pollution Monitoring Systems }}{\underset{\text { ECOTECH }}{\text { E M E I C A N }}}$} & \multicolumn{2}{|c|}{$\begin{array}{c}\text { Serinus S30 CO Analyzer Calibration } \\
\text { Report }\end{array}$} \\
\hline Customer & & Technician & $A C$ \\
\hline Instrument & Ecotech S30 & Date & $8 / 2 / 2018$ \\
\hline ID No. & $18-14-1158$ & Location & RI \\
\hline
\end{tabular}

\begin{tabular}{|l|c|c|c|c|c|}
\hline \multicolumn{1}{|c|}{ Parameter } & Model & Serial \# & $\begin{array}{c}\text { Certificate } \\
\text { Expiry Date }\end{array}$ & Pressure (psi) & Conc. (ppm) \\
\hline Calibrator & Ecotech Gascal 1100 & $09-1754$ & $01 / 28 / 19$ & - & - \\
\hline Zero Air & Lab Air & - & - & - & - \\
\hline CO Cylinder & High Bottle & ALM028693 & $12 / 23 / 22$ & 300 & 3001 \\
\hline
\end{tabular}

\begin{tabular}{|l|c|c|l|c|c|}
\hline \multicolumn{1}{|c|}{ Displayed Instrument Parameters } \\
\hline \multicolumn{1}{|c|}{ Parameter } & As Found & As Left & \multicolumn{1}{c|}{ Parameter } & As Found & As Left \\
\hline Ambient Pressure (torr) & 764.39 & 757.84 & PGA Gain & 128 & 128 \\
\hline Cell Pressure (torr) & 759.64 & 743.83 & Input Pot & 199 & 203 \\
\hline Gas Flow $(s l p m)$ & 1 & 1 & Measure Zero (Coarse) & 197 & 197 \\
\hline Cell Temp $\left({ }^{\circ} \mathrm{C}\right)$ & 50 & 50 & Measure Zero (Fine) & 19 & 25 \\
\hline Converter Temp. $\left({ }^{\circ} \mathrm{C}\right)$ & 89.99 & 90 & Reference Voltage $(\mathrm{V})$ & 3.96 & 3.89 \\
\hline Chassis Temp $\left({ }^{\circ} \mathrm{C}\right)$ & 31.28 & 34.69 & Source & 227 & 227 \\
\hline Mirror Temp $\left({ }^{\circ} \mathrm{C}\right)$ & 50 & 50 & Cooler Voltage $(\mathrm{V})$ & 1.23 & 1.25 \\
\hline Firmware Version & 3.68 .0009 & 3.73 .0000 & Background & 0.002 & 0.0013 \\
\hline Instrument Gain & 0.9874 & 0.9874 & PTF Correction & 0.9819 & 1.0027 \\
\hline Zero Offset (ppb) & 0 & 0 & Range & $\mathbf{5 0 . 0}$ & ppm \\
\hline
\end{tabular}

\begin{tabular}{|c|c|c|c|c|c|c|}
\hline \multicolumn{7}{|c|}{ Precision Check } \\
\hline Point & $\begin{array}{c}\text { Expected CO } \\
(\mathbf{p p m})\end{array}$ & Air Flow (ccm) & Gas Flow (ccm) & $\begin{array}{c}\text { Calculated CO } \\
(\mathbf{p p m})\end{array}$ & $\begin{array}{c}\text { Measured CO } \\
(\mathbf{p p m})\end{array}$ & Error \\
\hline Zero & $\mathbf{0 . 0}$ & 5000 & 0.0 & 0.0 & 0.0 & -0.04 \\
\hline $\mathbf{8 0} \%$ & $\mathbf{4 0 . 0}$ & 3285 & 44.6 & $\mathbf{4 0 . 2}$ & 40.2 & $-0.1 \%$ \\
\hline
\end{tabular}

Precision values must be within $10 \%$ of expected values. 


\begin{tabular}{|c|c|c|c|c|c|c|}
\hline \multicolumn{7}{|c|}{ Multipoint Linearity Check } \\
\hline Point & $\begin{array}{c}\text { Expected CO } \\
(\mathrm{ppm})\end{array}$ & Air Flow $\quad(\mathrm{ccm})$ & Gas Flow $(\mathrm{ccm})$ & $\begin{array}{c}\text { Calculated CO } \\
(\mathrm{ppm})\end{array}$ & $\begin{array}{c}\text { Measured CO } \\
(p p m)\end{array}$ & Error \\
\hline Zero & 0.0 & 5000 & 0.0 & 0.0 & 0.0 & 0.0 \\
\hline $80 \%$ & 40.0 & 3286 & 44.6 & 40.2 & 40.3 & $0.31 \%$ \\
\hline $60 \%$ & 30.0 & 3297 & 33.4 & 30.1 & 30.0 & $-0.35 \%$ \\
\hline $40 \%$ & 20.0 & 3313 & 22.3 & 20.0 & 19.8 & $-1.05 \%$ \\
\hline $20 \%$ & 10.0 & 3319 & 11.1 & 10.0 & 9.9 & $-0.99 \%$ \\
\hline $10 \%$ & 5.0 & 3323 & 5.5 & 4.9 & 4.9 & $-0.90 \%$ \\
\hline Zero & 0.0 & 5000 & 0.0 & 0.0 & -0.1 & -0.1 \\
\hline
\end{tabular}

All values must be within $2 \%$ of range

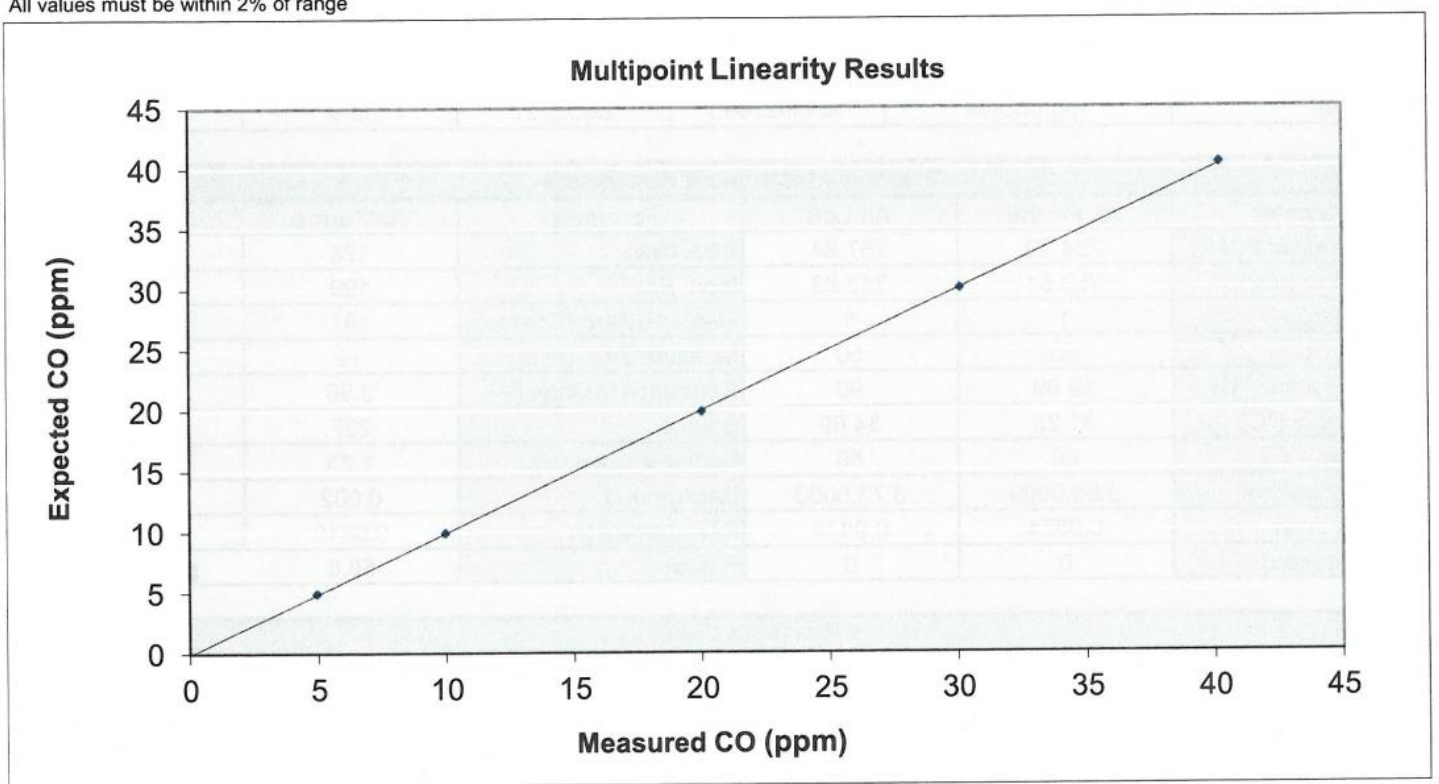

\begin{tabular}{|l|c|}
\hline Slope & 1.0023 \\
\hline Intercept & -0.1011 \\
\hline R-Square value & 1.0000 \\
\hline Standard error about $y=x$ (\% FS) & $0.21 \%$ \\
\hline Uncertainty due to non-linearity, at 95\% confidence (\% FS) & $0.52 \%$ \\
\hline
\end{tabular}

Standard Error must be below $2 \%$.

\begin{tabular}{|l|l|}
\hline Internal Zero $(\mathrm{ppm})$ & 0.01 \\
\hline External Zero $(\mathrm{ppm})$ & 0.01 \\
\hline Difference $(\mathrm{ppm})$ & $\mathbf{0 . 0 0}$ \\
\hline
\end{tabular}


Co-location of Magee Aethalometer with Neutral Density Filter corrected Aethalometer on August 22, 2018
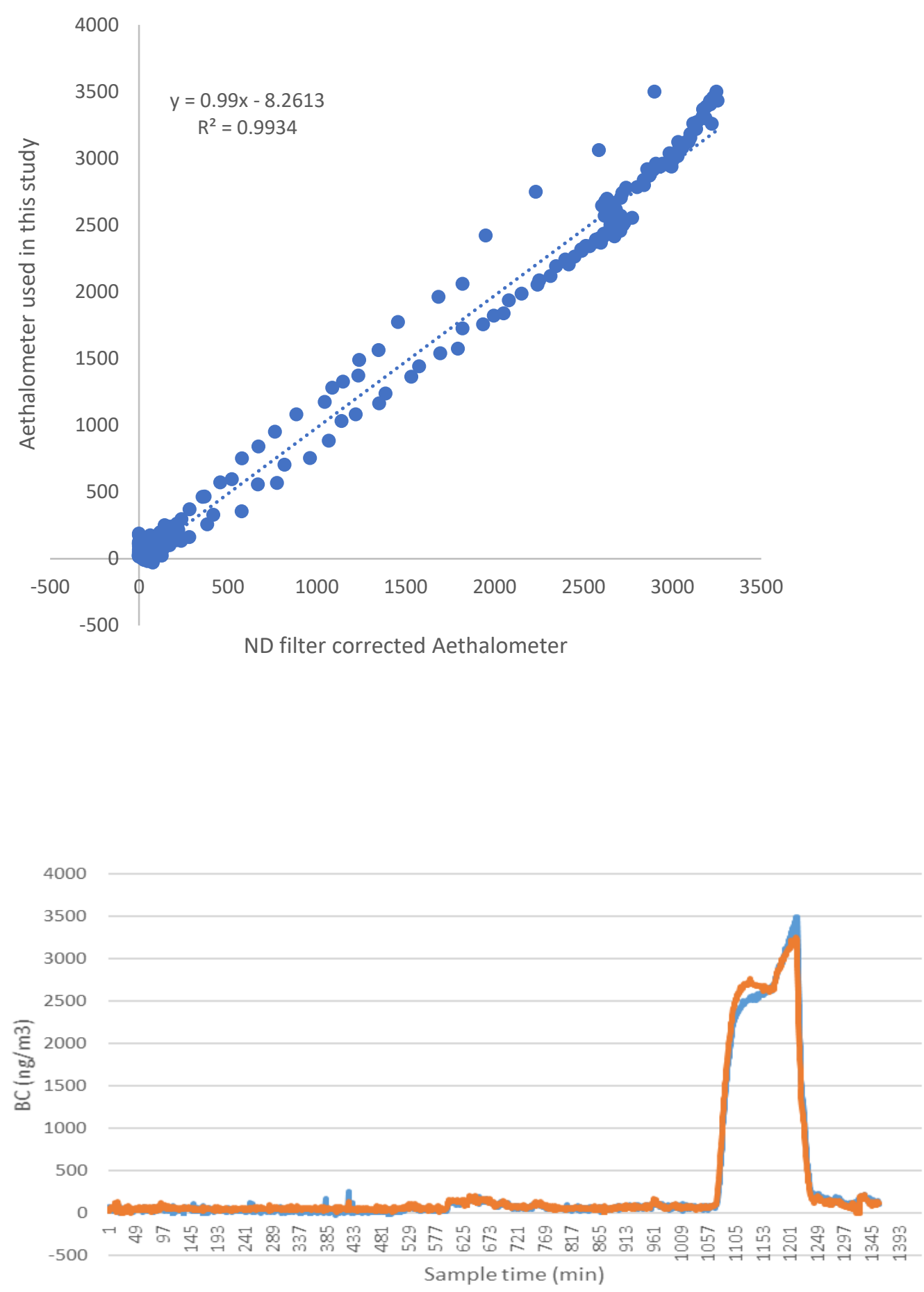

Aethelometer used in this study ND filter corrected aethalometer 
Table A-4. Low volume gravimetric sampler located for indoor co-location with PurpleAir sensors with PM2.5 inlet.

\begin{tabular}{|c|c|c|}
\hline Sample A-1 & Sample A-2 & Sample A-3 \\
\hline FILENAME: & FILENAME: 6041100K.CSV & FILENAME: 6041100N.CSV (A3)* \\
\hline 6041098V.CSV & & SERIAL: 16041 \\
\hline SERIAL: 16041 & SERIAL: 16041 & SAMPLE: 58140 \\
\hline SAMPLE: 58130 & SAMPLE: 58136 & MODE: ON \\
\hline MODE: PROGRAM & MODE: PROGRAM & START: $10 / A P R / 19$ at $13: 30$ \\
\hline START: 08/APR/19 at & START: 09/APR/19 at $10: 27$ & SAMPLE DURATION: $24: 11: 56$ \\
\hline $21: 00$ & PROG DURATION: 26:54:00 & SAMPLE VOLUME: 24.240 \\
\hline PROG DURATION: & SAMPLE DURATION: & STANDARD VOLUME: 24.051 \\
\hline $12: 00: 00$ & $26: 54: 00$ & AVERAGE FLOW: 16.69 \\
\hline SAMPLE DURATION: & SAMPLE VOLUME: 2.915 & AVERAGE TEMP: 24.2 \\
\hline 12:00:00 & STANDARD VOLUME: & AVERAGE PRESS: 752 \\
\hline SAMPLE VOLUME: & 2.901 & AVERAGE PM $_{2.5}: 0.146$ \\
\hline 12.022 & AVERAGE FLOW: 16.70 & AVERAGE PM10: 0.146 \\
\hline STANDARD VOLUME: & AVERAGE TEMP: 25.0 & SET FLOW: 16.7 \\
\hline 11.905 & AVERAGE PRESS: 756 & START VDC: 23.0 \\
\hline AVERAGE FLOW: 16.70 & AVERAGE PM $_{2.5}: 0.191$ & END VDC: 23.0 \\
\hline AVERAGE TEMP: 23.5 & AVERAGE PM10: 0.191 & \\
\hline AVERAGE PRESS: 749 & SET FLOW: 16.7 & \\
\hline AVERAGE PM $2.5: 0.211$ & START VDC: 23.0 & \\
\hline AVERAGE PM10: 0.548 & END VDC: 23.0 & \\
\hline SET FLOW: 16.7 & & \\
\hline START VDC: 23.0 & & \\
\hline END VDC: 23.0 & & \\
\hline
\end{tabular}

Table A-5. Gravimetric measurements made by Oregon Dept. of Environmental Quality for Portland State University.

FILTER NAME
$\begin{array}{lllllllll}\text { ENTERED } & \text { TARE WEIGHT } & \text { LOADED WEIGHT } & \text { TARE DATE ENTERED } & \text { L } \\ \text { F58130 } & 365.129 & 365.157 & \text { 01-Apr-19 } & \text { 09-May-19 } & \text { CGOOVAE } & \text { CGOOVAE } & \text { A1 } \\ \text { F58131 } & 369.329 & 369.398 & \text { 01-Apr-19 } & \text { 09-May-19 } & \text { CGOOVAE } & \text { CGOOVAE } & \text { B1 } \\ \text { F58132 } & 370.944 & 371.594 & \text { 01-Apr-19 } & \text { 09-May-19 } & \text { CGOOVAE } & \text { CGOOVAE } & \text { B2 } \\ \text { F58133 } & 372.761 & 373.748 & \text { 01-Apr-19 } & \text { 09-May-19 } & \text { CGOOVAE } & \text { CGOOVAE } & \text { B3 } \\ \text { F58136 } & 370.3 & 370.657 & \text { 01-Apr-19 } & \text { 09-May-19 } & \text { CGOOVAE } & \text { CGOOVAE } & \text { A2 } \\ \text { F58140 } & 368.034 & 368.726 & \text { 01-Apr-19 } & \text { 09-May-19 } & \text { CGOOVAE } & \text { CGOOVAE } & \text { A3 }\end{array}$


Appendix B: Time series data for each household.

Figure B-1. Example time-series data from wood stove exchange participant B-1.
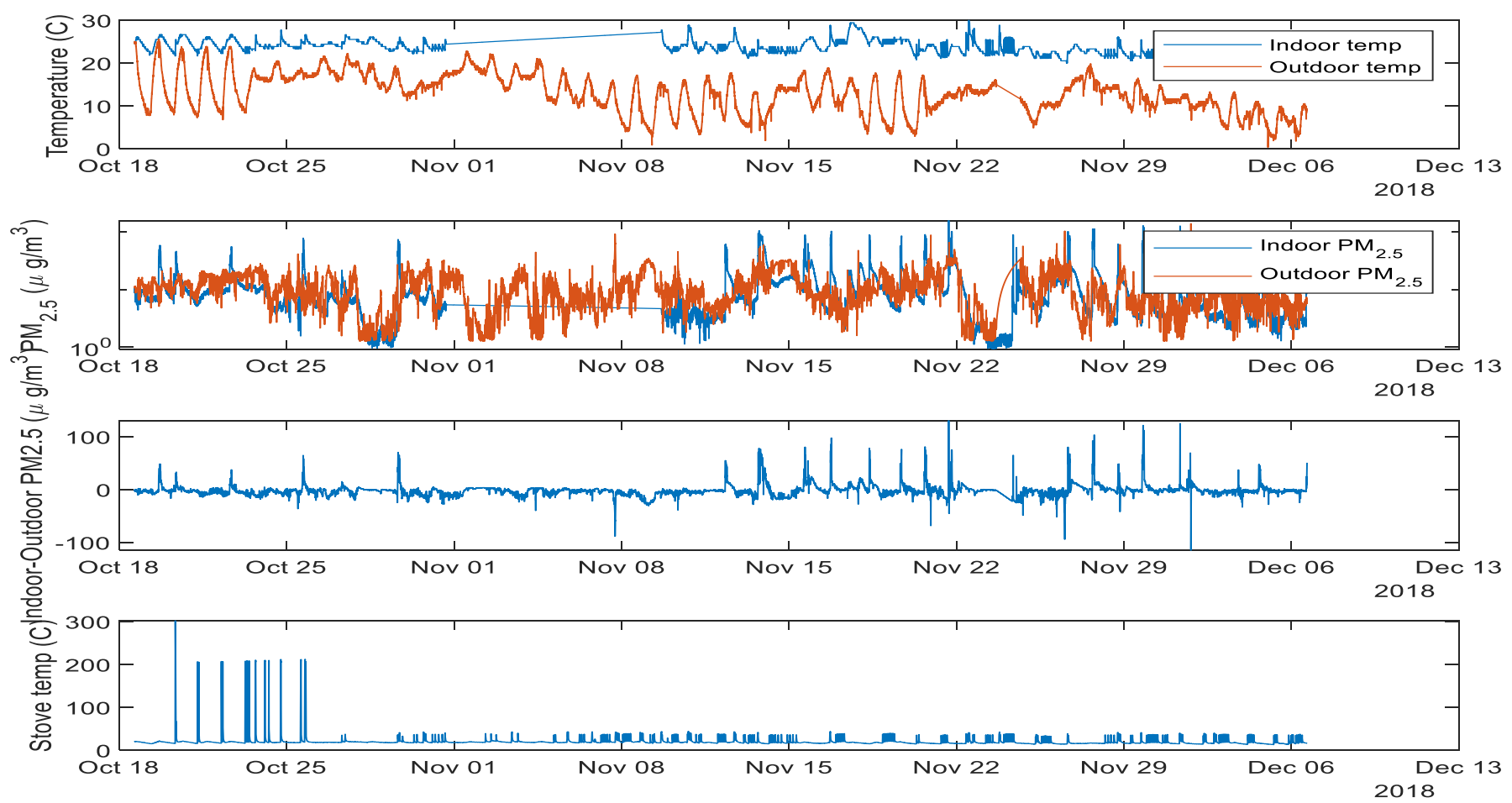

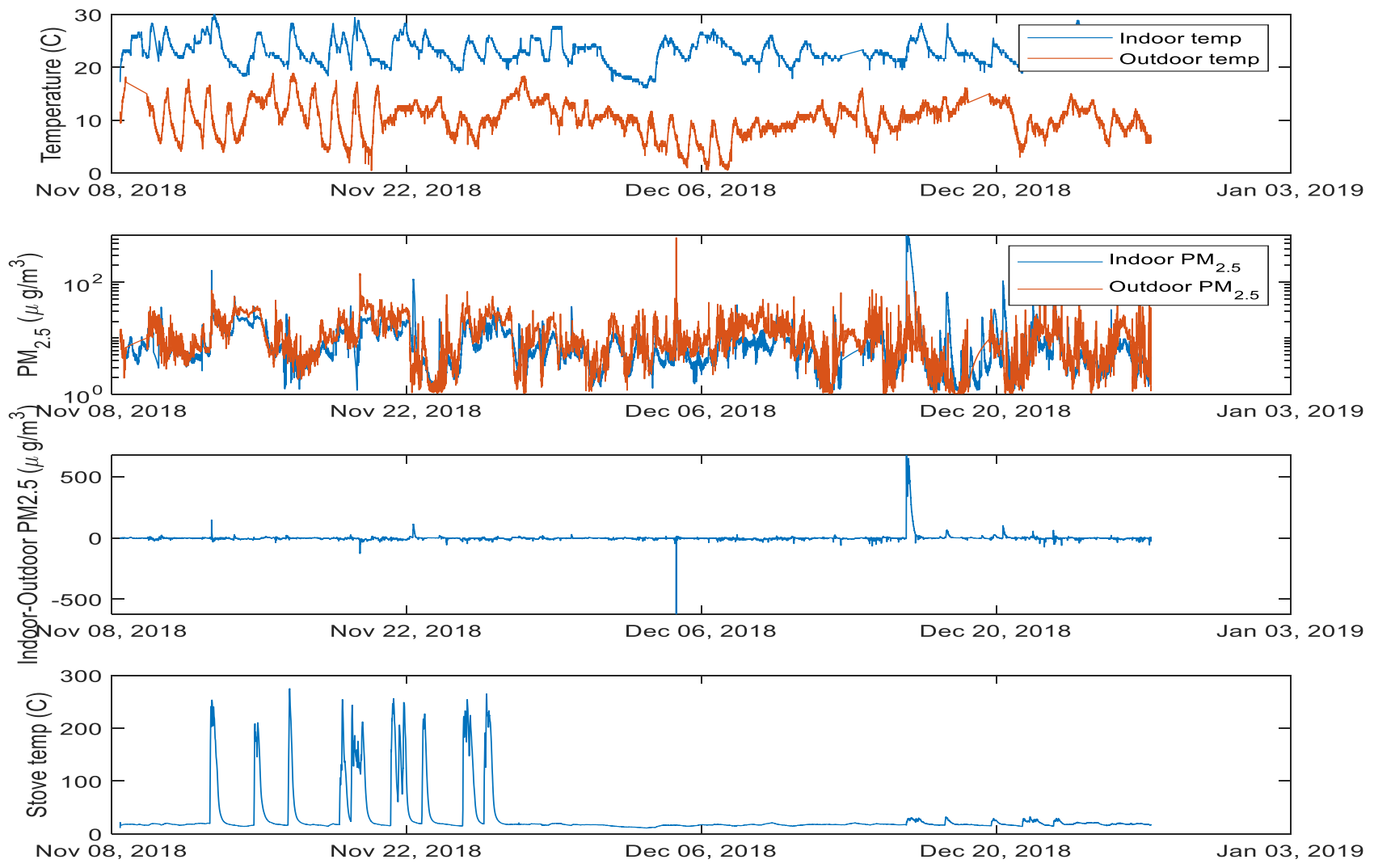

Figure B-2. Example time-series data from wood stove exchange participant B-2. 

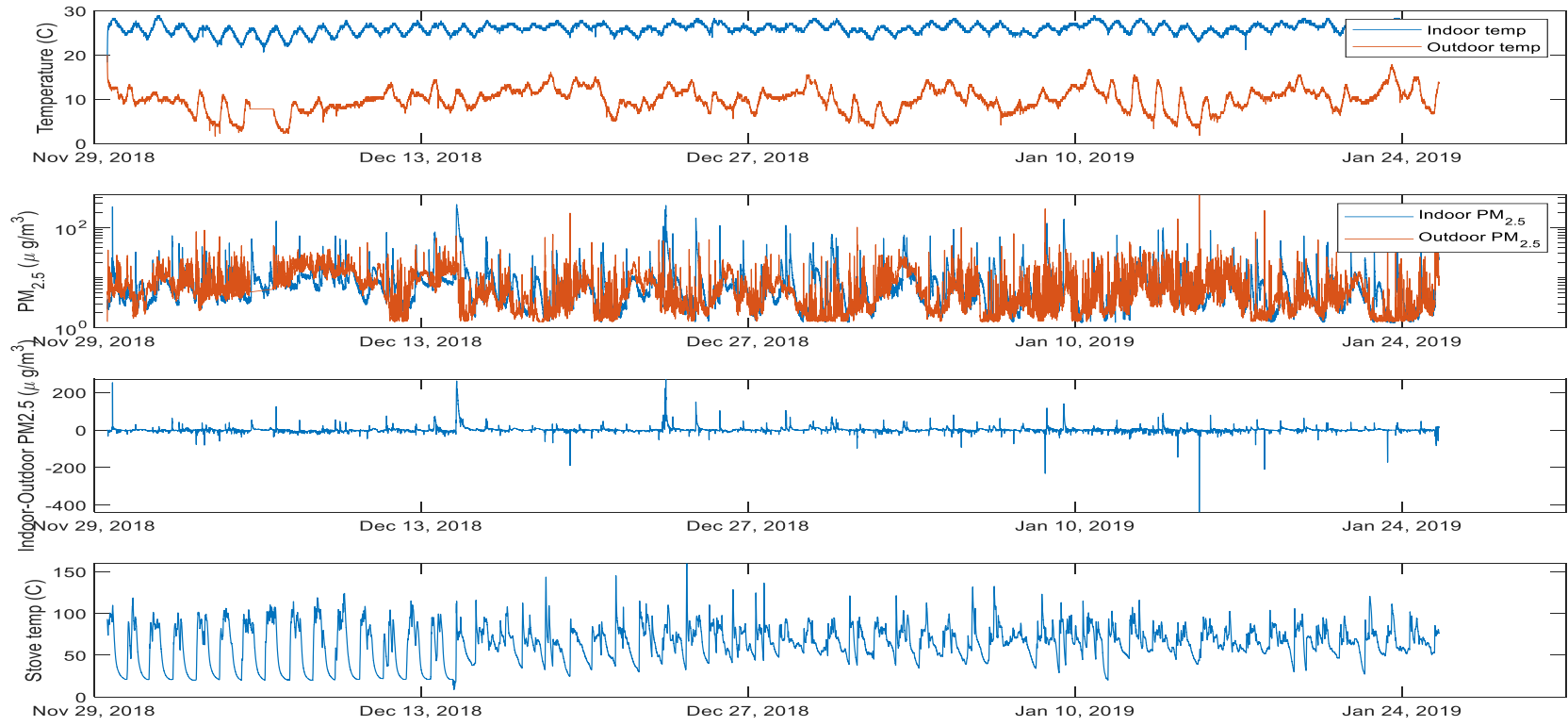

Figure B-3. Example time-series data from wood stove exchange participant B-3. 


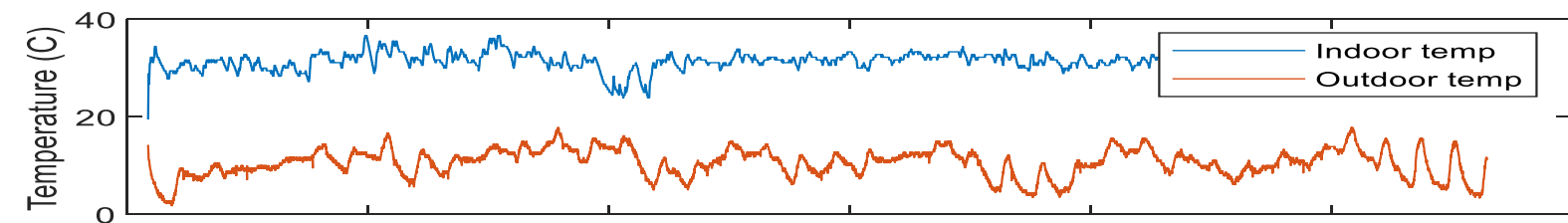

Dec 06, 2018 Dec 13, 2018 Dec 20, 2018 Dec 27, 2018 Jan 03, 2019 Jan 10, 2019 Jan 17, 2019

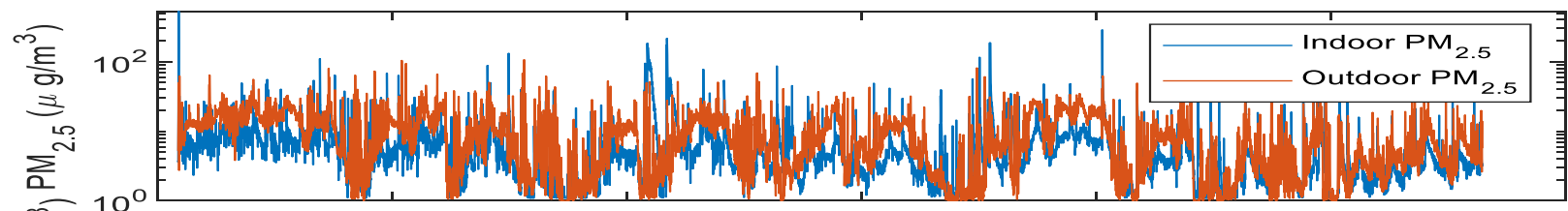

昌ec 06, 2018 Dec 13, 2018 Dec 20, 2018 Dec 27, 2018 Jan 03, 2019 Jan 10, 2019 Jan 17, 2019 量

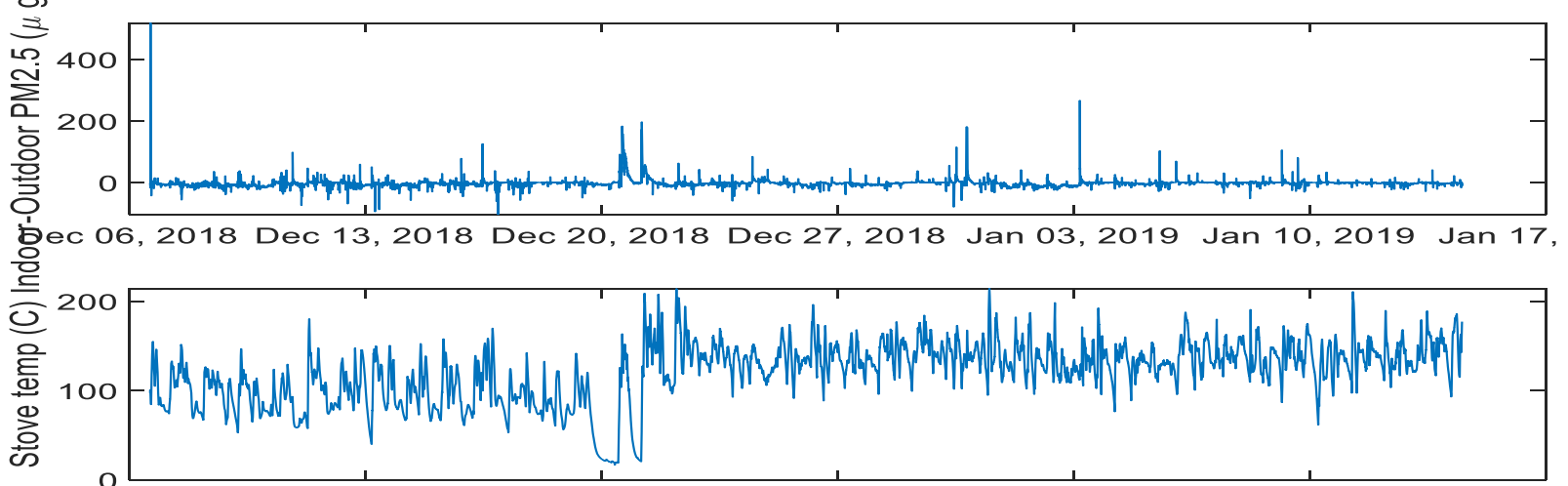

Dec 06, 2018 Dec 13, 2018 Dec 20, 2018 Dec 27, 2018 Jan 03, 2019 Jan 10, 2019 Jan 17, 2019

Figure B-4. Example time-series data from wood stove exchange participant B-4. 

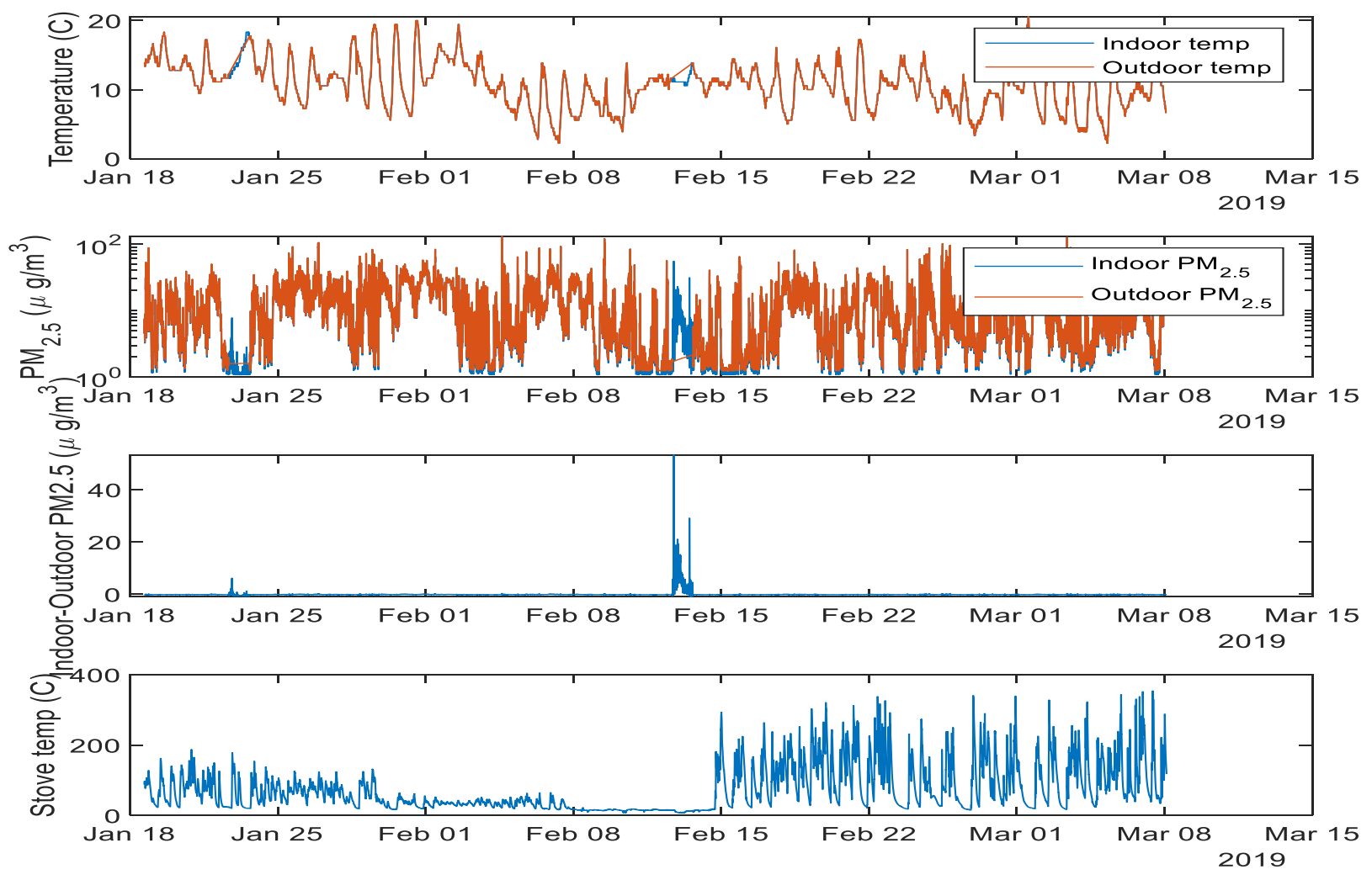

Figure B-5. Example time-series data from wood stove exchange participant B-5. 

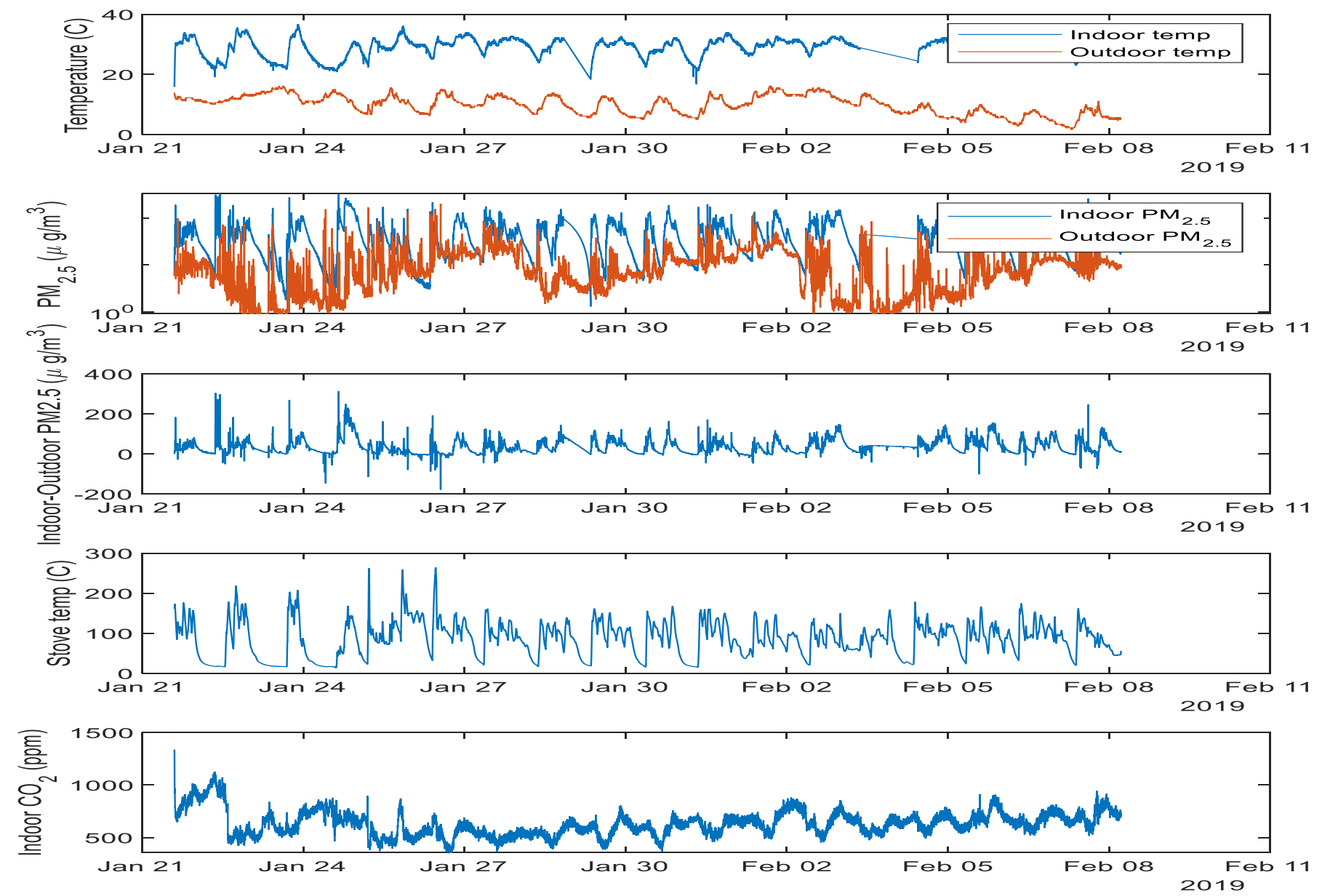

Figure B-6. Example time-series data from wood stove exchange participant B-6. 

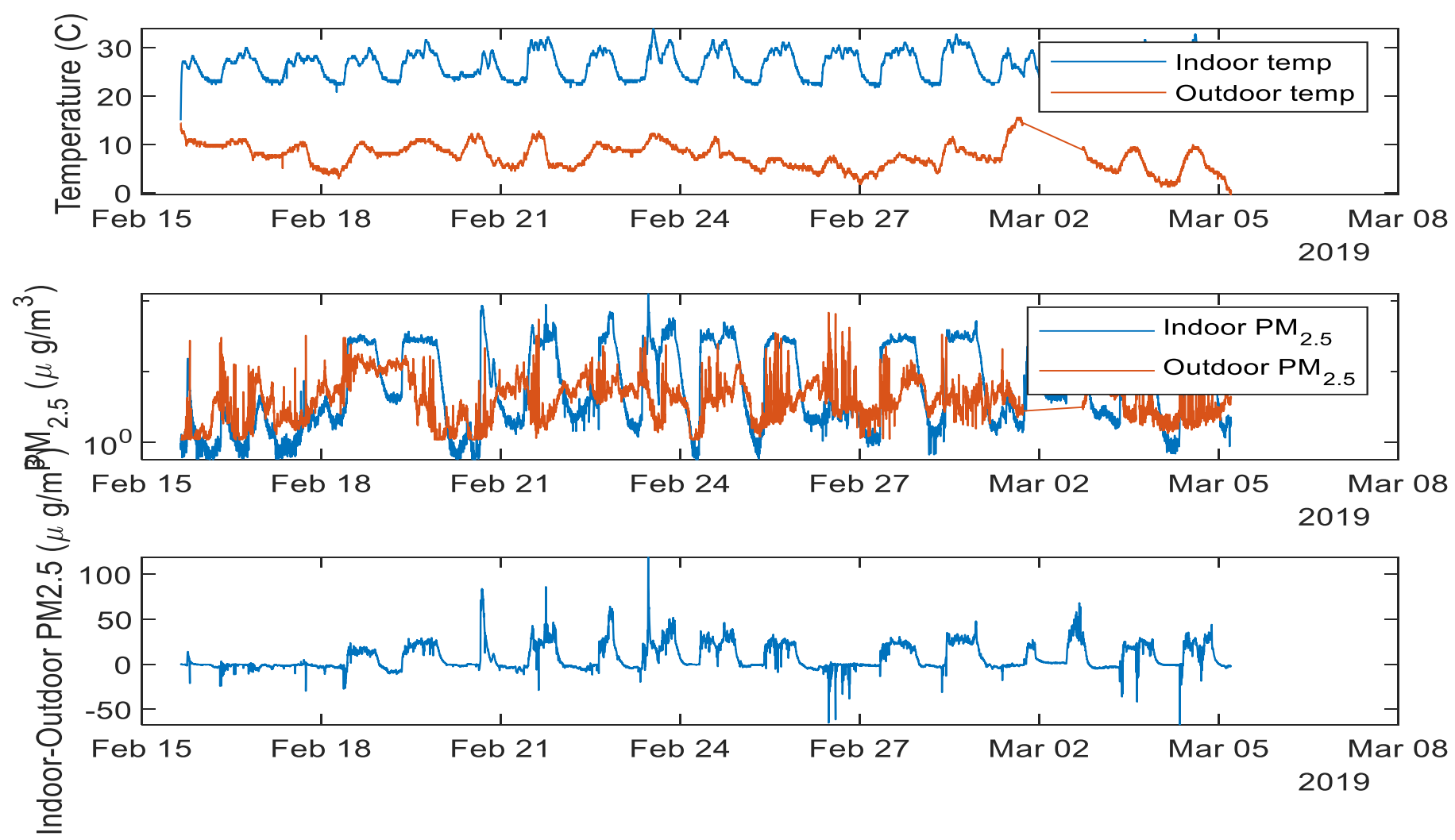

Figure B-7. Example time-series data from wood stove exchange participant B-7. 

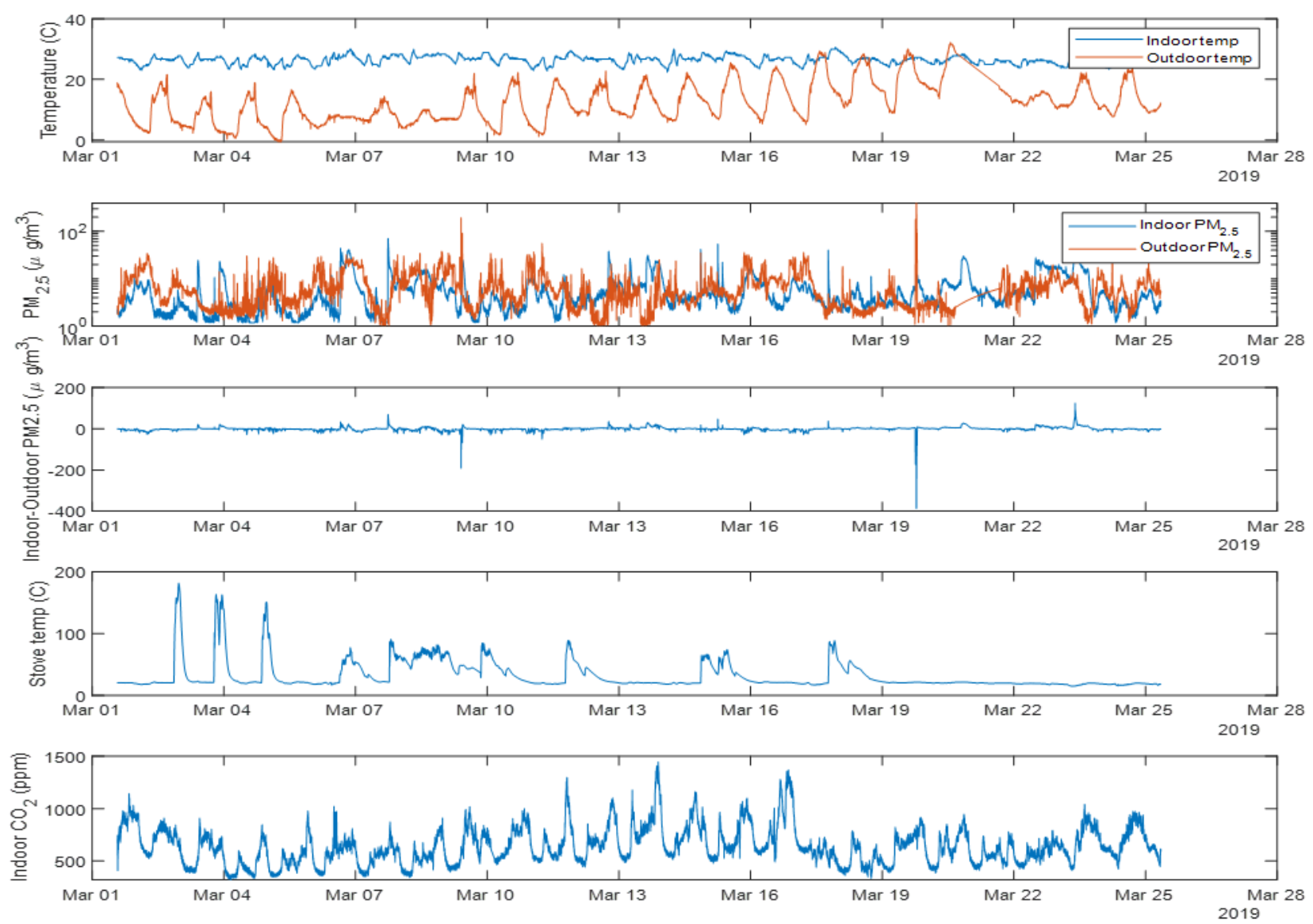

Figure B-8. Example time-series data from wood stove exchange participant B-8. 

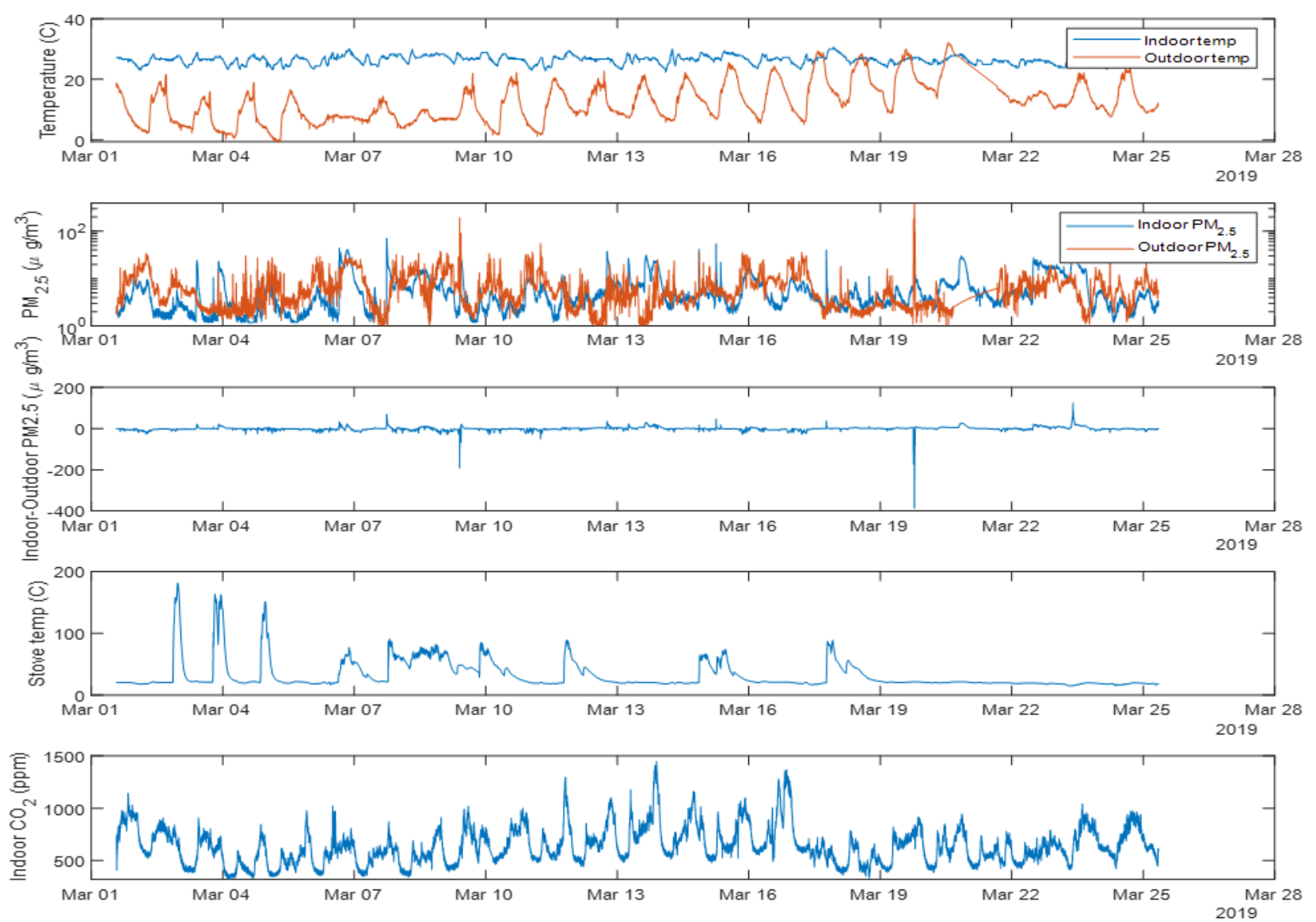

Figure B-9. Example time-series data from wood stove exchange participant B-9. 

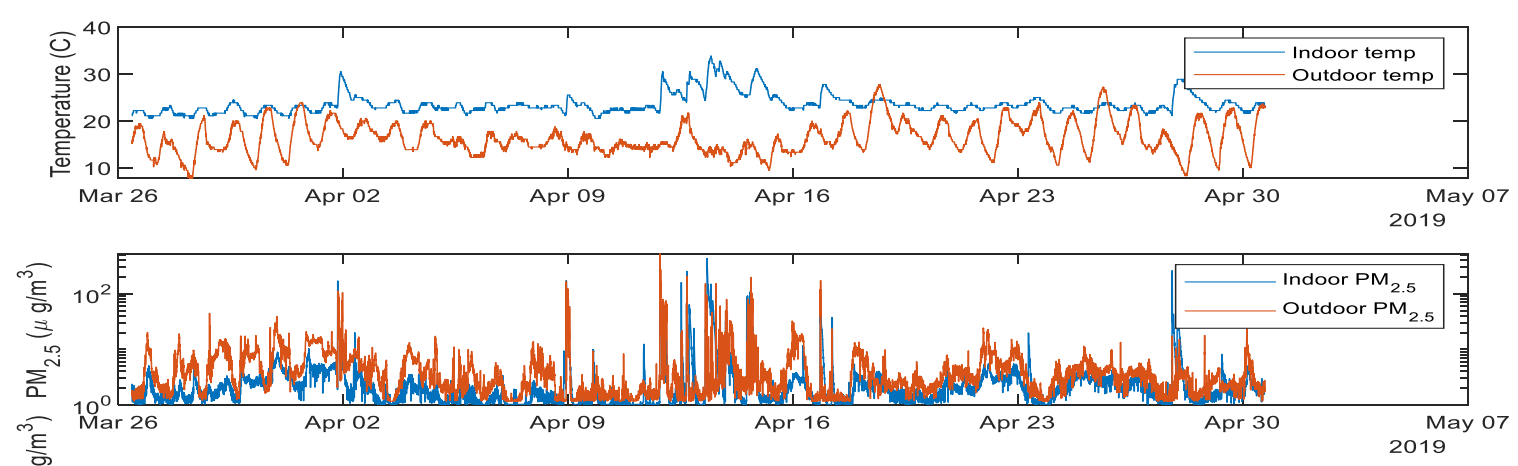

$\infty$
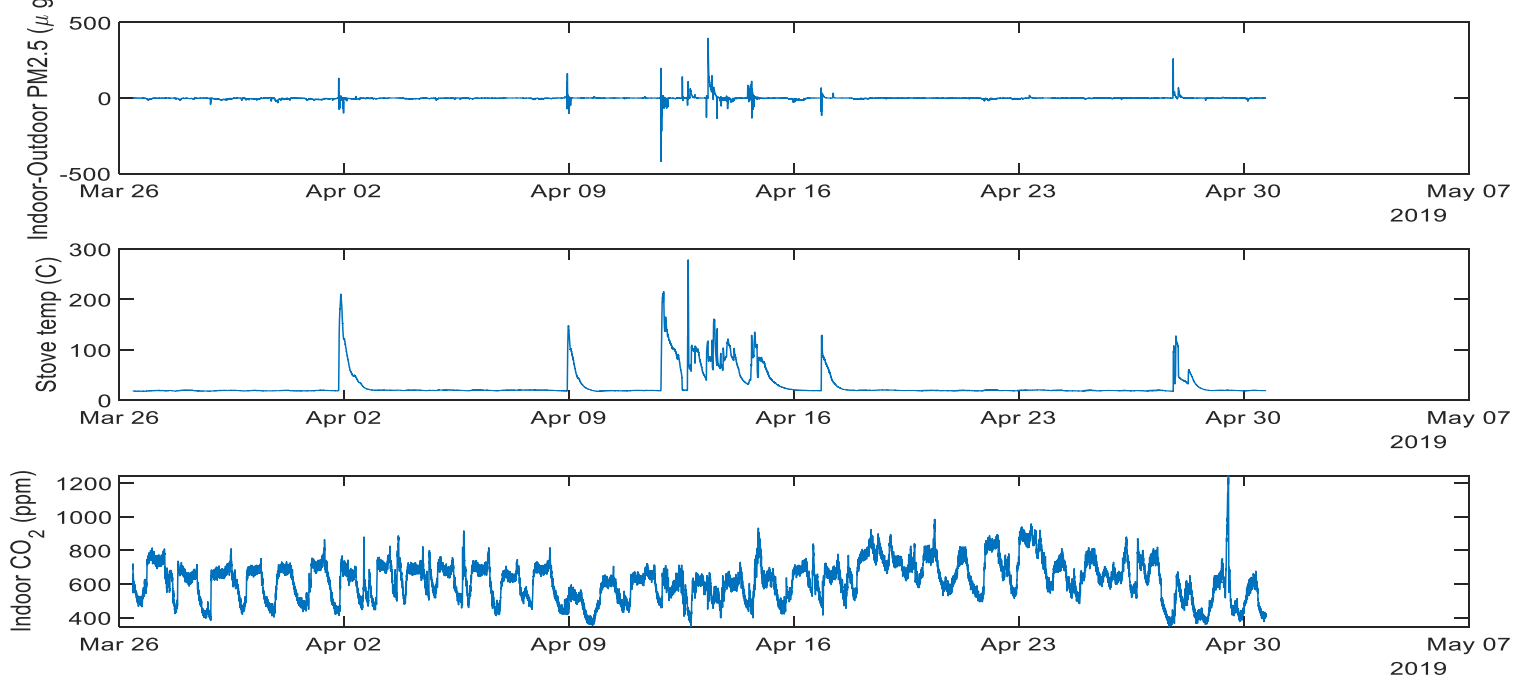

Figure B-10. Example time-series data from wood stove exchange participant B-10. 

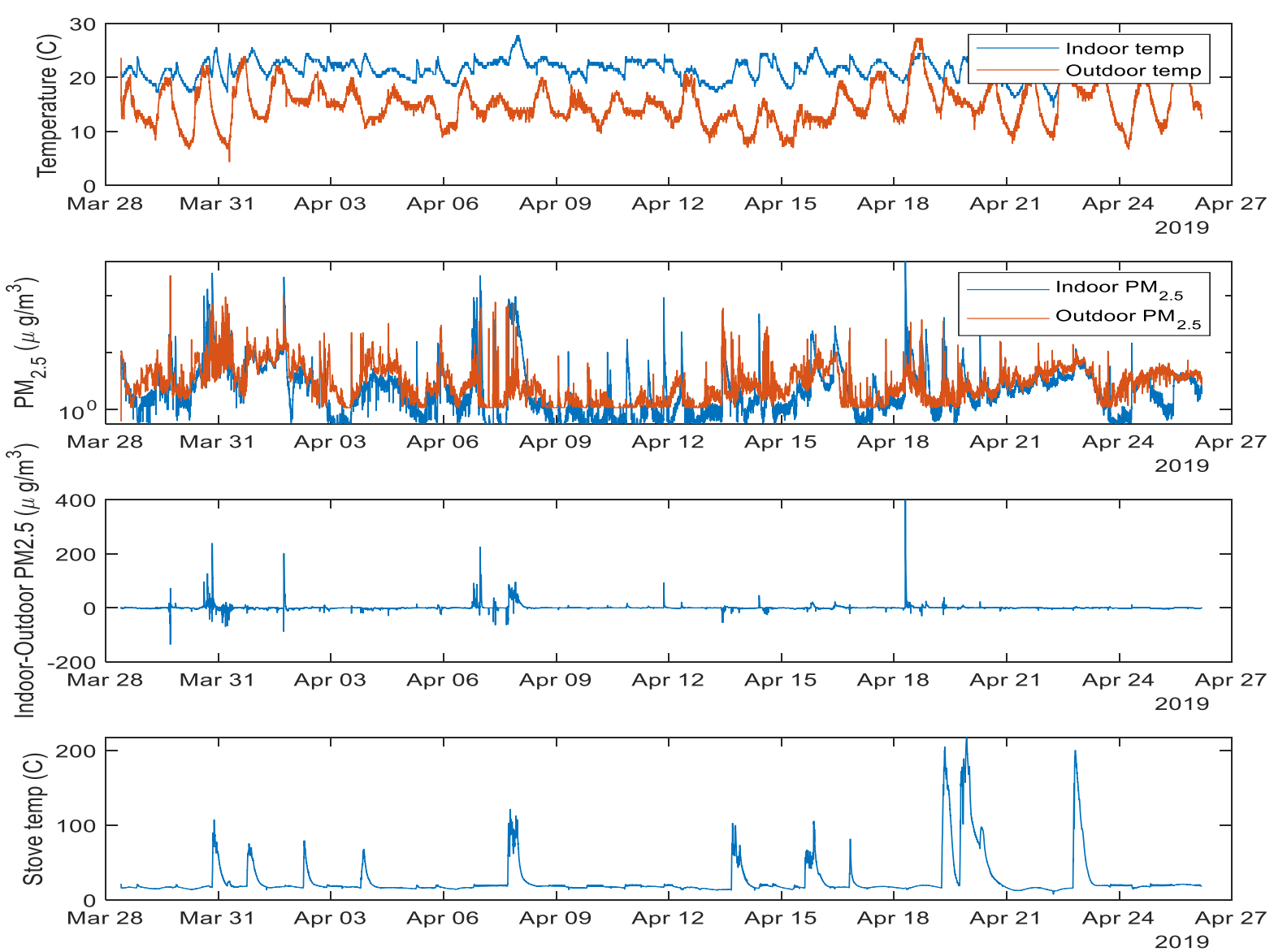

Figure B-11. Example time-series data from wood stove exchange participant B-11. 